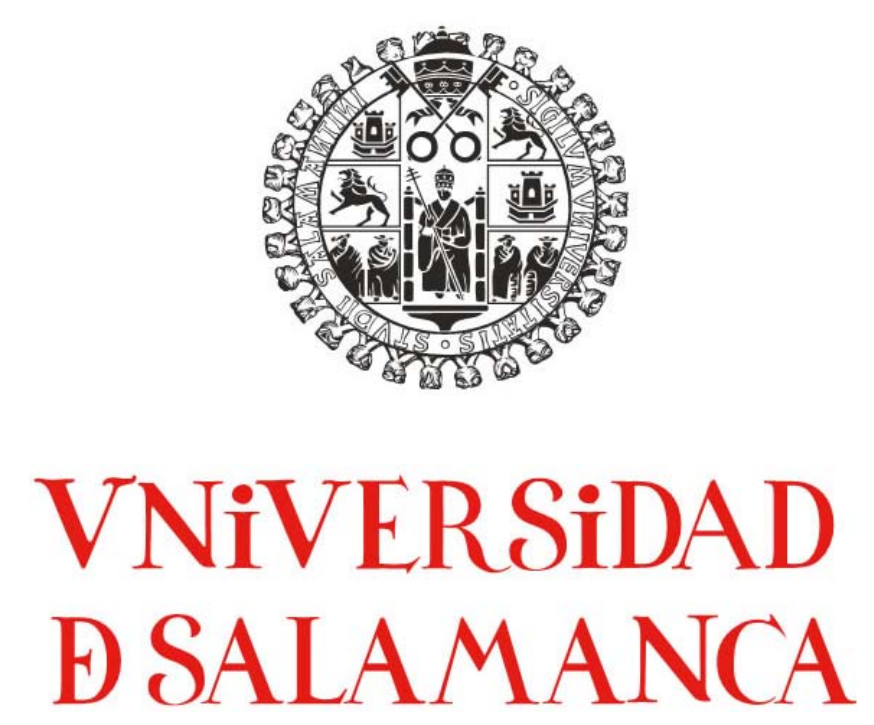

ESTUDIO DEL SISTEMA ZINCÉRGICO EN EL BULBO OLFATORIO DEL RATÓN

-TESIS DOCTORAL-

CARMEN AIRADO CERRATO

Salamanca, Junio 2010 



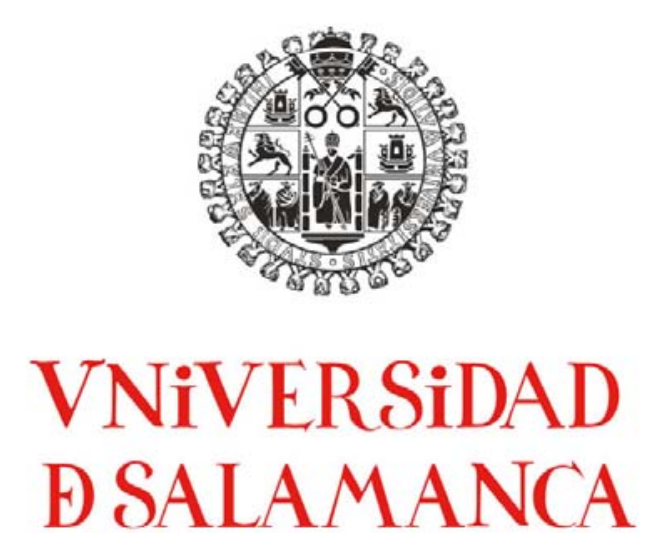

departamento de Biología Celvlar y Patelogía

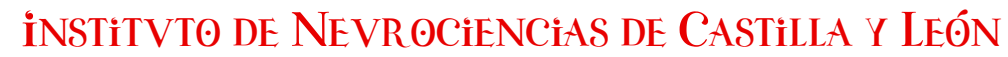

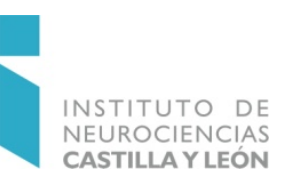

\section{ESTUDIO DEL SISTEMA ZINCÉRGICO EN EL BULBO OLFATORIO DEL RATÓN}

Memoria presentada por Carmen Airado Cerrato para optar al grado de Doctor por la Universidad de Salamanca Directores:

Prof. Dr. D. José Ramón Alonso Peña

Dra. Da . Carmela Gómez Rodríguez

Junio 2010 

José Ramón Alonso Peña, Catedrático de Biología Celular, y Carmela Gómez

Rodriguez, Profesor Ayudante Doctor de Biología Celular

HACEN CONSTAR:

QUE el presente trabajo titulado "Estudio del sistema zincérgico en el bulbo olfatorio del ratón", ha sido realizado por la licenciada en Biología Da. Carmen Airado Cerrato en el departamento de Biología Celular y Patología de la Universidad de Salamanca y en el Instituto de Neurociencias de Castilla y León.

QUE ha sido desarrollado bajo nuestra dirección y dentro del programa de doctorado Neurociencias de nuestra universidad.

QUE, en nuestra opinión, reúne todos los requisitos científicos y formales para ser defendido como Tesis Doctoral y así optar al grado de Doctor por la Universidad de Salamanca.

Para que así conste, lo firmamos en Salamanca, a dieciséis de Junio de dos mil diez.

El director

La directora

Fdo.: José Ramón Alonso Peña

Fdo.: Carmela Gómez

Rodríguez 

Gracias a mis directores, el Prof. Dr. D. José Ramón Alonso Peña y la Prof. Dra. Dña. Carmela Gómez Rodríguez. Por su dedicación y paciencia conmigo. Gracias por haber hecho posible que este Trabajo salga adelante.

Al Prof. Dr. D. Gorm Danscher, del Instituto de Anatomía de la Universidad de Aarhus, Dinamarca, y a todo su equipo. Por dedicar su tiempo a enseñarme pacientemente todo lo que sé sobre los métodos de marcaje de zinc. Sin su ayuda este Trabajo no hubiera sido posible.

Al Prof. Dr. D. Richard Palmiter, del Instituto Médico Howard Hughes, (Universidad de Washington), por proporcionarme amablemente el anticuerpo anti ZnT3.

A la Prof. Dra. Dña Concepción Lillo, por su impagable colaboración en el análisis ultraestructural del marcaje zincérgico.

A todo el equipo de profesores, técnicos, becarios y amigos del Departamento de Biología Celular y Patología de la Universidad de Salamanca. Por echarme una mano (unas cuantas...) siempre que lo he necesitado. Bien sabéis que este Trabajo es tan vuestro como mío. Quiero añadir un gran GRACIAS a Carmelilla, por aguantarme con tanto arte y por sacar adelante este Trabajo a pesar de todo.

Gracias a mis amigos (de Burgos, de la resi, de la facultad, del coro, de Alemania), por aguantar mis “yo no puedo, la próxima vez...”. Gracias por vuestro apoyo incondicional durante todos estos años.

A mi familia, sobre todo a mis padres y mi hermana. Por estar conmigo en todas las decisiones, por recogerme en los peores momentos y por tener fe en mí. Gracias por vuestra paciencia, cariño y comprensión.

A Ale, el último en llegar, por darme un importante motivo para estar aquí.

GRACIAS a todos, de corazón, por haberme acompañado a lo largo de este camino.

Este trabajo de Tesis Doctoral ha sido financiado por la Junta de Castilla y León, el Centro en Red de Medicina Regenerativa y Terapia Celular de Castilla y León, la Federación de Cajas de Ahorros de Castilla y León, el Ministerio de Educación y Ciencia (SAF 2006-05705), el Ministerio de Salud y Consumo (PNSD SA002A07) y la Fundación de Investigación Médica Mutua Madrileña Automovilística. 



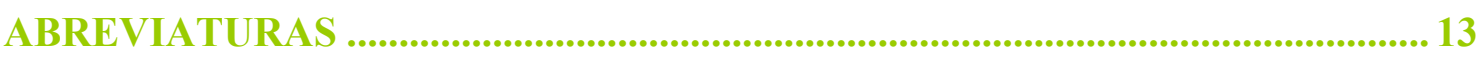

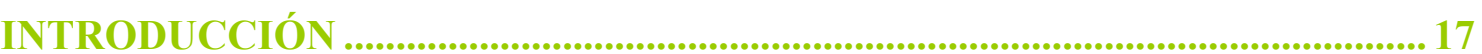

1. El zinc en el sistema nervioso .................................................................... 19

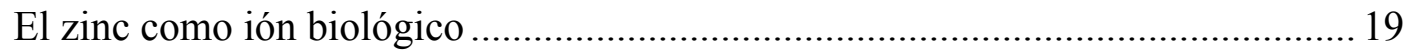

Distribución de zinc vesicular en el sistema nervioso .......................................... 21

Homeostasis del zinc en el sistema nervioso ..................................................... 22

Disminución de zinc citosólico ......................................................................... 23

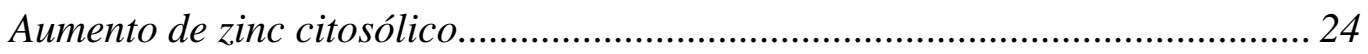

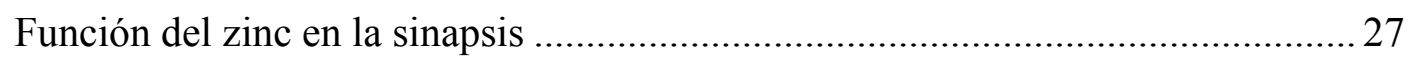

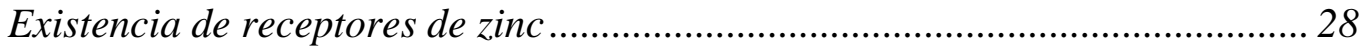

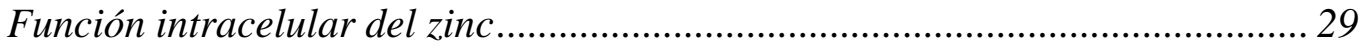

Métodos de detección del zinc............................................................................ 31

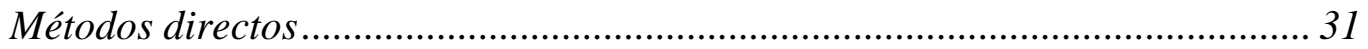

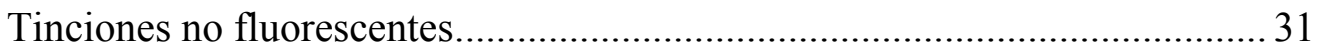

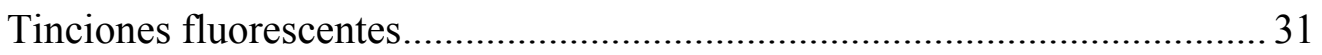

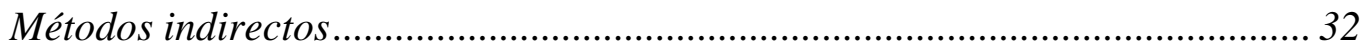

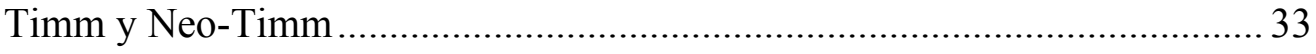

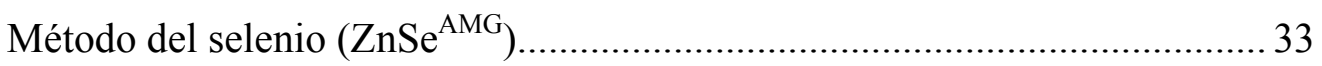

2. El sistema olfatorio de los roedores ..............................................................34

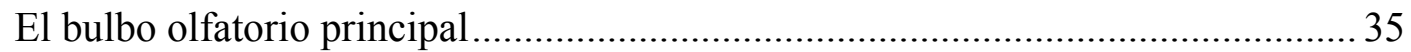

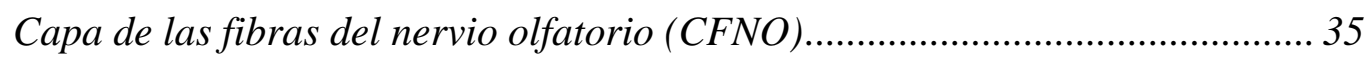

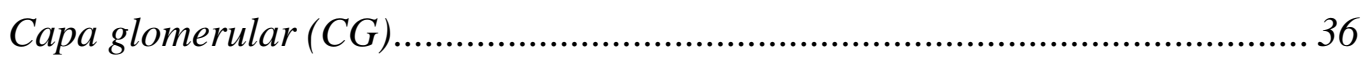

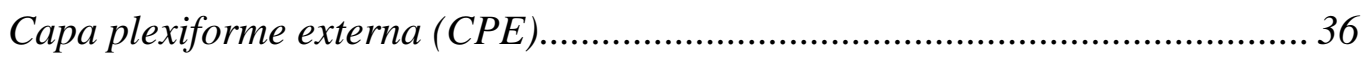

Capa de las células mitrales (CCM).............................................................. 37

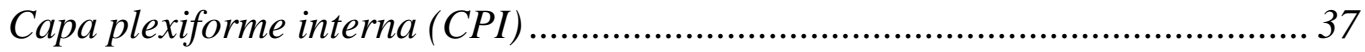

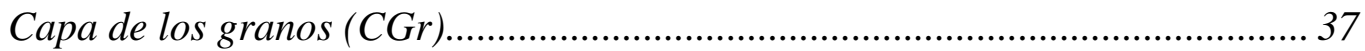

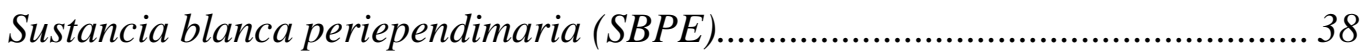

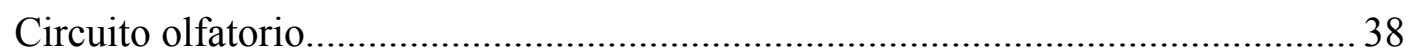

Modulación centrífuga de la transmisión olfatoria .......................................... 39

3. El zinc en el sistema olfatorio...........................................................................40 
4. Plasticidad en el sistema olfatorio .......................................................................... 42

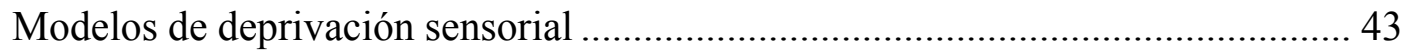

Deprivación sensorial olfatoria........................................................................ 43

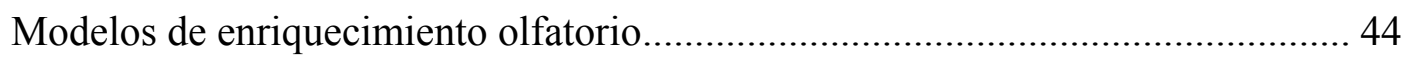

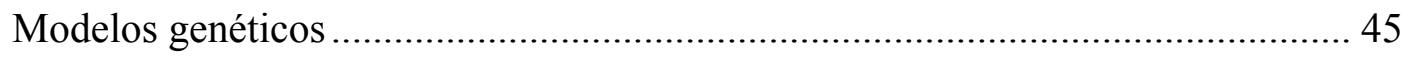

El ratón knock-out para NOSn ......................................................................... 45

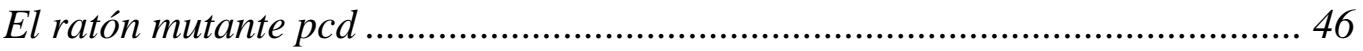

5. Justificación y Objetivos ............................................................................................. 48

1. Animales de experimentación.............................................................................53

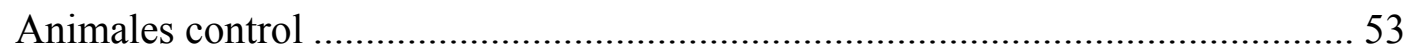

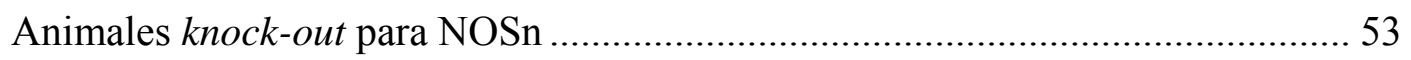

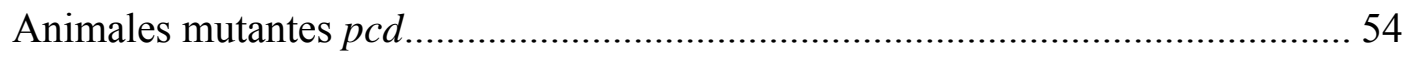

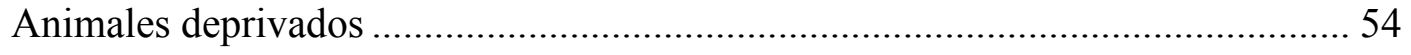

Animales sometidos a enriquecimiento olfatorio ............................................... 54

2. Procedimientos previos al sacrificio...........................................................56

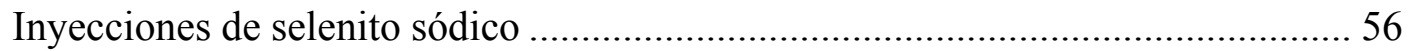

Marcaje de terminales ZEN.............................................................................. 56

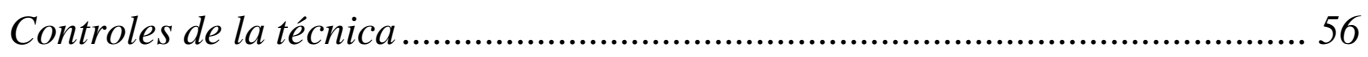

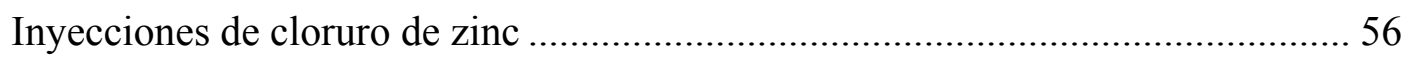

3. Obtención y preparación del tejido para técnicas morfológicas ...................... 57

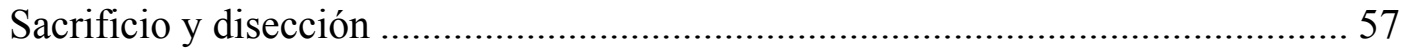

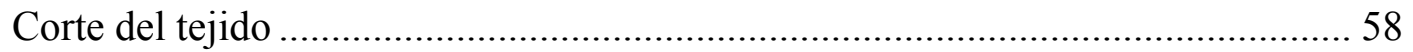

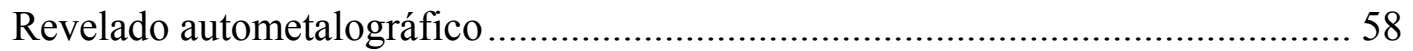

Procesado final de las muestras para microscopía electrónica .............................. 59

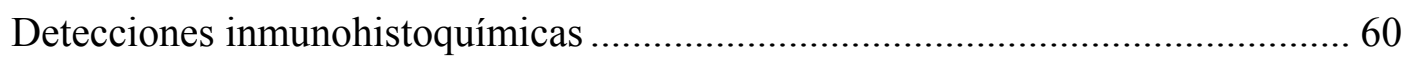

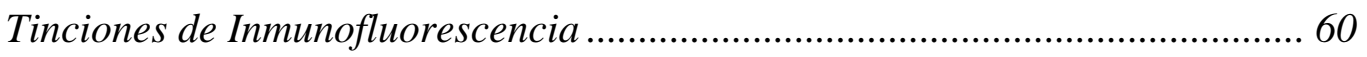

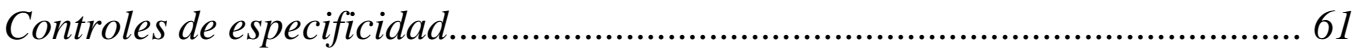

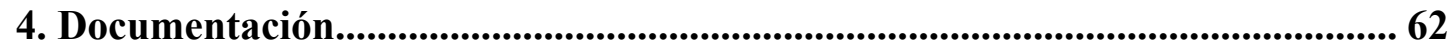

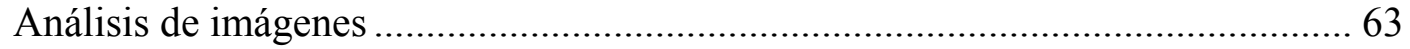

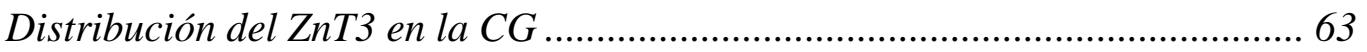

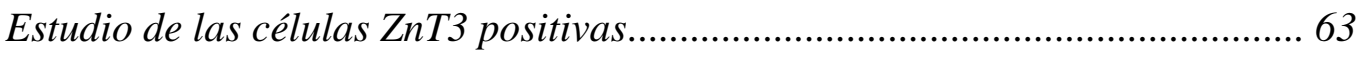

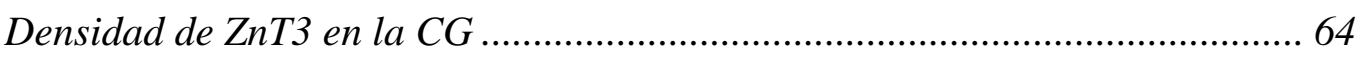

5. Técnicas de Biología Molecular..................................................................... 64

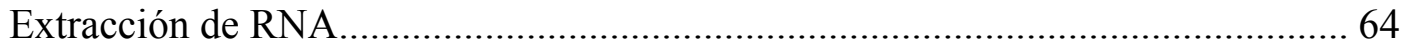




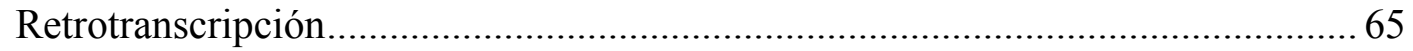

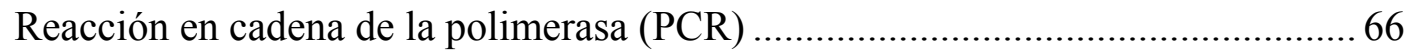

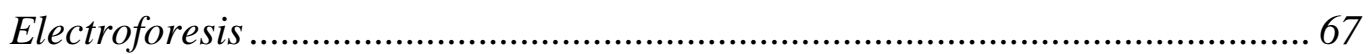

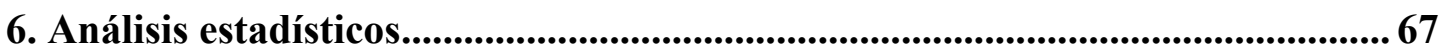

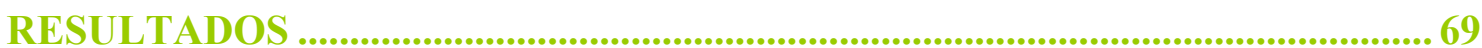

1. Consideraciones técnicas ................................................................................... 71

2. Modulación zincérgica en el BO ...................................................................... 72

Caracterización de terminales ZEN en el BO .................................................... 72

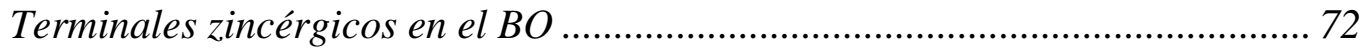

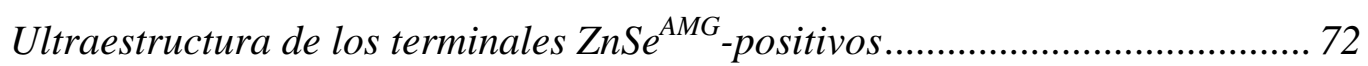

Terminales zincérgicos en el BO de animales sobre-expuestos a zinc.................. 74

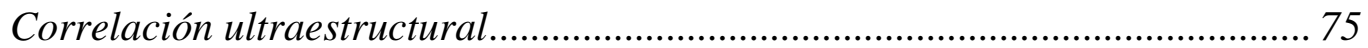

3. Estudio del transportador ZnT3 en la CG .......................................................76

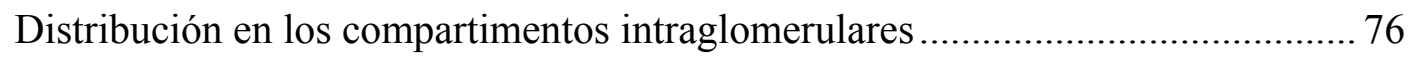

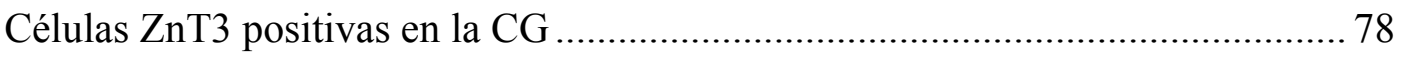

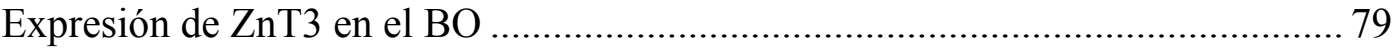

Caracterización neuroquímica de las células ZnT3 .......................................... 82

4. Plasticidad de las proyecciones zincérgicas ......................................................... 84

Modificaciones en la entrada de la información olfatoria ................................... 85

Proyección zincérgica en animales enriquecidos.............................................. 85

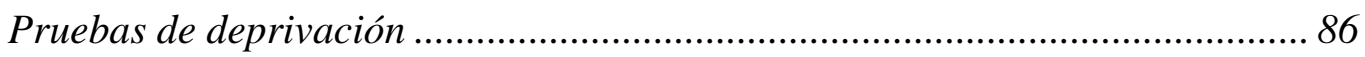

Sistema zincérgico en el BO del ratón KO para NOSn ......................................... 87

Sistema zincérgico en el BO del ratón mutante $p c d$.............................................. 90

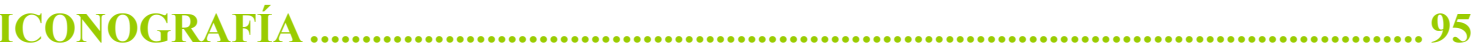

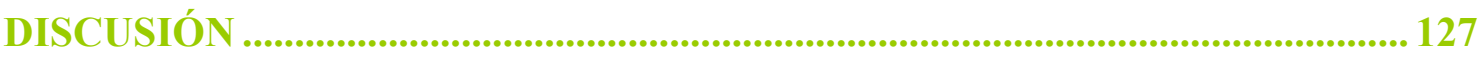

1. Aspectos de la modulación zincérgica en el BO de animales silvestres........... 129

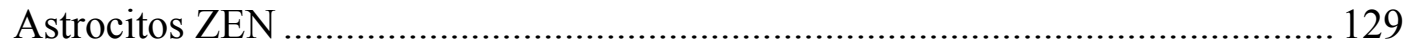

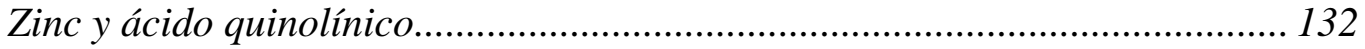

Diferencia entre el marcaje inmunohistoquímico y $\mathrm{ZnSe}^{\mathrm{AMG}}$ en la CG ............... 134

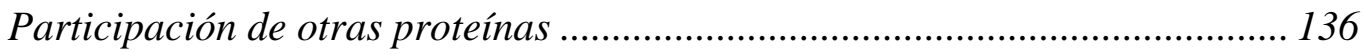

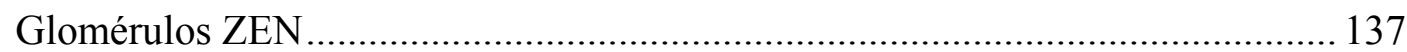


2. Comprobación de la desaparición de marcaje $\mathrm{ZnSe}^{\mathrm{AMG}}$ por transporte retrógrado.

3. Animales sobre-expuestos a zinc: verificación de la sensibilidad del método139

4. Estudio de la proteína ZnT3 ............................................................................. 140

Localización de ZnT3 en la CG y heterogeneidad glomerular........................... 140

¿Posee el BO su propio sistema zincérgico intrínseco? ...................................... 142

Zinc y autoinhibición en las PGs ZnT3-positivas ............................................. 144

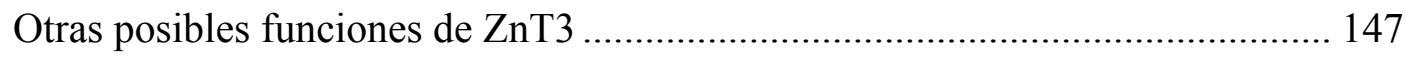

5. Animales enriquecidos y deprivados: la actividad olfatoria............................ 148

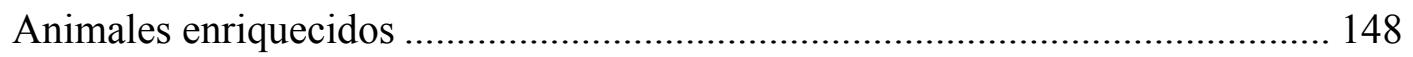

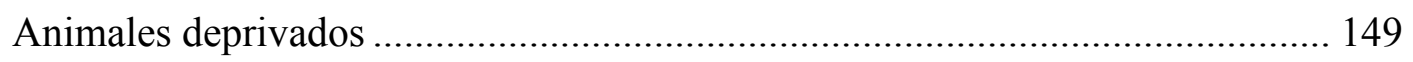

6. Animales KO para NOSn: implicación del ON .................................................. 150

7. Animales mutantes pcd: papel de las células mitrales en la inervación

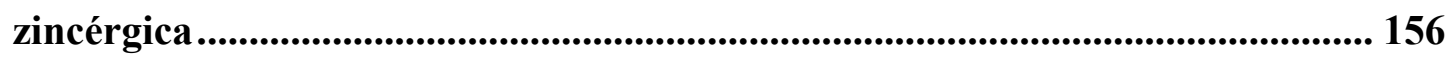

Conclusiones.................................................................................................... 161 
ABREVIATURAS 



\section{Abreviaturas}

ABC: complejo avidina-biotina-peroxidasa

ADN: ácido desoxirribonucléico

ADNc: ADN copia

AG: aparato de Golgi

AMG: autometalografía

AMPA: ácido $\alpha$-amino-3-hidroxi-5-metil-4-isoxazolepropiónico

ARN: ácido ribonucléico

ARNm: ARN mensajero

BO: bulbo olfatorio principal

BOA: bulbo olfatorio accesorio

CB: calbindina D-28K

CCM: capa de células mitrales

CDF: facilitador de la difusión catiónica

CFNO: capa de fibras del nervio olfatorio

CG: capa glomerular

CGr: capa de los granos

CPE: capa plexiforme externa

CPI: capa plexiforme interna

CR: calretinina

DAB: 3,3'-diaminobenzidina

DEDTC: dietil ditiocarbamato

DEPC: dietil pirocarbonato

EDTA: ácido etilenodiaminotetraacético

EEM: error estándar de la media

GABA: ácido $\gamma$-aminobutírico

GAD: ácido glutámico descarboxilasa

GFAP: proteína ácida fibrilar glial

3HAO: enzima ácido 3-hidroxiantranílico oxigenasa

KO: knock-out

MAP2: proteína asociada a microtúbulos 2

MT: metalotioneína

NAD: nicotinamida adenina dinucleótido

NMDA: N-metil-D-aspartato

NO: nervio olfatorio

NOA: núcleo olfatorio anterior

NOAe: pars externa del NOA

NOAd: pars dorsalis del NOA

NOAI: pars lateralis del NOA

NOAm: pars medialis del NOA

NOAv: pars ventralis del NOA

NOS: óxido nítrico sintasa

NOSe: NOS endotelial

NOSi: NOS inducible

NOSn: NOS neuronal

NRO: neurona receptora olfatoria

OMP: proteína marcadora olfatoria

ON: óxido nítrico 
PCD: del inglés, Purkinje Cell Degeneration

PG: periglomerular

PIXE: emisión de rayos $\mathrm{X}$ inducidos por partículas

PKC: proteína kinasa $\mathrm{C}$

QPRT: enzima ácido quinolínico fosforribosil transferasa

QUIN: ácido quinolínico

RPLP0: proteína ribosomal grande P0

SBPE: sustancia blanca periependimaria

SNC: sistema nervioso central

TFS: tampón fosfato salino

TH: tirosina hidroxilasa

TOL: tracto olfatorio lateral

Trp: triptófano

TS: tampón Sørensen

TSQ: N-(6-metoxi-8-quinolil)-p-toluenosulfonamida

TT: taenia tecta

ZEN: del inglés, zinc-enriched

ZIP: del inglés, Zrt, Irt-like Protein

$\mathbf{Z n S e}^{\mathbf{A M G}}$ : método del selenio

ZnT: transportador de zinc 
INTRODUCCIÓN 



\section{Introducción}

\section{El zinc en el sistema nervioso}

\section{El zinc como ión biológico}

El zinc es un elemento esencial, y como tal, se encuentra en todas las células, y es necesario para la vida (Prasad y cols., 1963; Colvin y cols., 2003; Maret, 2009). Es el segundo metal traza más abundante en los primates después del hierro (Takeda, 2000). El zinc desempeña un papel crucial en la función de numerosas proteínas. Entre el 4 y el 10\% del genoma de todos los organismos codifica para proteínas que contienen zinc (Alberts y cols., 1998; Auld, 2001; Andreini y cols., 2006a). De hecho, existen más de 20.000 tipos de enzimas que contienen zinc, donde éste funciona como cofactor necesario para su actividad catalítica (Frederickson, 1989). En humanos, aproximadamente 3000 proteínas contienen zinc, siendo las más importantes la superóxido dismutasa y la anhidrasa carbónica (Andreini y cols., 2006b). En algunas proteínas, como en ciertos factores de transcripción, los iones zinc desempeñan una función estructural en lugar de catalítica, estabilizando los dominios proteicos denominados "dedos de zinc".

Como componente de un gran número de factores de transcripción, el zinc está relacionado con procesos de replicación y transcripción del ADN y ejerce su influencia sobre los procesos de división y diferenciación celular (Coleman, 1992). Por ello, el zinc resulta especialmente necesario en aquellas partes del cuerpo donde existe un recambio celular rápido, como por ejemplo, en la médula ósea (Shankar y Prasad, 1998; Nakashima y Dyck, 2009). Además de la función estructural y catalítica en las proteínas, el zinc puede actuar como segundo mensajero, modificando el estado de determinadas proteínas, como la proteína kinasa $\mathrm{C}$ (PKC; Korichneva y cols., 2002). Hoy también sabemos que el ión $\mathrm{Zn}^{2+}$ participa en la modulación de la neurotransmisión (Hosie y cols., 2003; Takeda y cols., 2003, 2004; Ruiz y cols., 2004) regulando la actividad de gran variedad de áreas cerebrales, como las que gobiernan el gusto y el olfato (Emsley, 2001). Asimismo, recientemente se ha conocido su acción como regulador de la neurogénesis adulta en el hipocampo de ratas y ratones (Corniola y cols., 2008; Suh y cols., 2009). 
El zinc se distribuye por todo el cuerpo, encontrándose las mayores concentraciones de este ión en el músculo y en el hueso (Nakashima y Dyck, 2009). La absorción de zinc ocurre en el sistema digestivo. El 98\% del zinc que es absorbido se transporta por el organismo unido a proteínas séricas (Harris y Keen, 1989), sobre todo a la albúmina, que contiene dos sitios de unión de alta afinidad para este ión (Simons, 1993). El resto se transporta bien unido a aminoácidos libres, como la histidina y la cisteína (Harris y Keen, 1989), o bien como ión libre. Tras su absorción, el zinc es transportado a diferentes órganos, incluso atraviesa la barrera hematoencefálica para llegar al sistema nervioso (Pullen y cols., 1990; Franklin y cols., 1992). Una vez en las células diana, el zinc puede localizarse en 4 reservorios (fig. 1):

1. Puede unirse a proteínas citosólicas, como las metalotioneínas (MTs, en torno al 80\% del zinc total)

2. Una pequeña proporción queda libre, diluida en el citosol

3. Se puede almacenar en compartimentos citoplasmáticos, es decir, puede pasar al interior de determinados orgánulos celulares (lisosomas, endosomas, mitocondrias, etc.)

4. Por último, y sólo en el caso de algunas neuronas, principalmente glutamatérgicas, el zinc se puede incluir en vesículas presinápticas junto con el neurotransmisor. Este reservorio de iones zinc es especialmente importante, puesto que es el responsable de la modulación de algunas sinapsis. Las neuronas que poseen $\mathrm{Zn}^{2+}$ dentro de sus vesículas presinápticas, se denominan neuronas zincérgicas (zincergic neurons) o neuronas ZEN, (zinc-enriched neurons; Frederickson, 1989; Frederickson y Danscher, 1990) y son el objeto de nuestro estudio. 


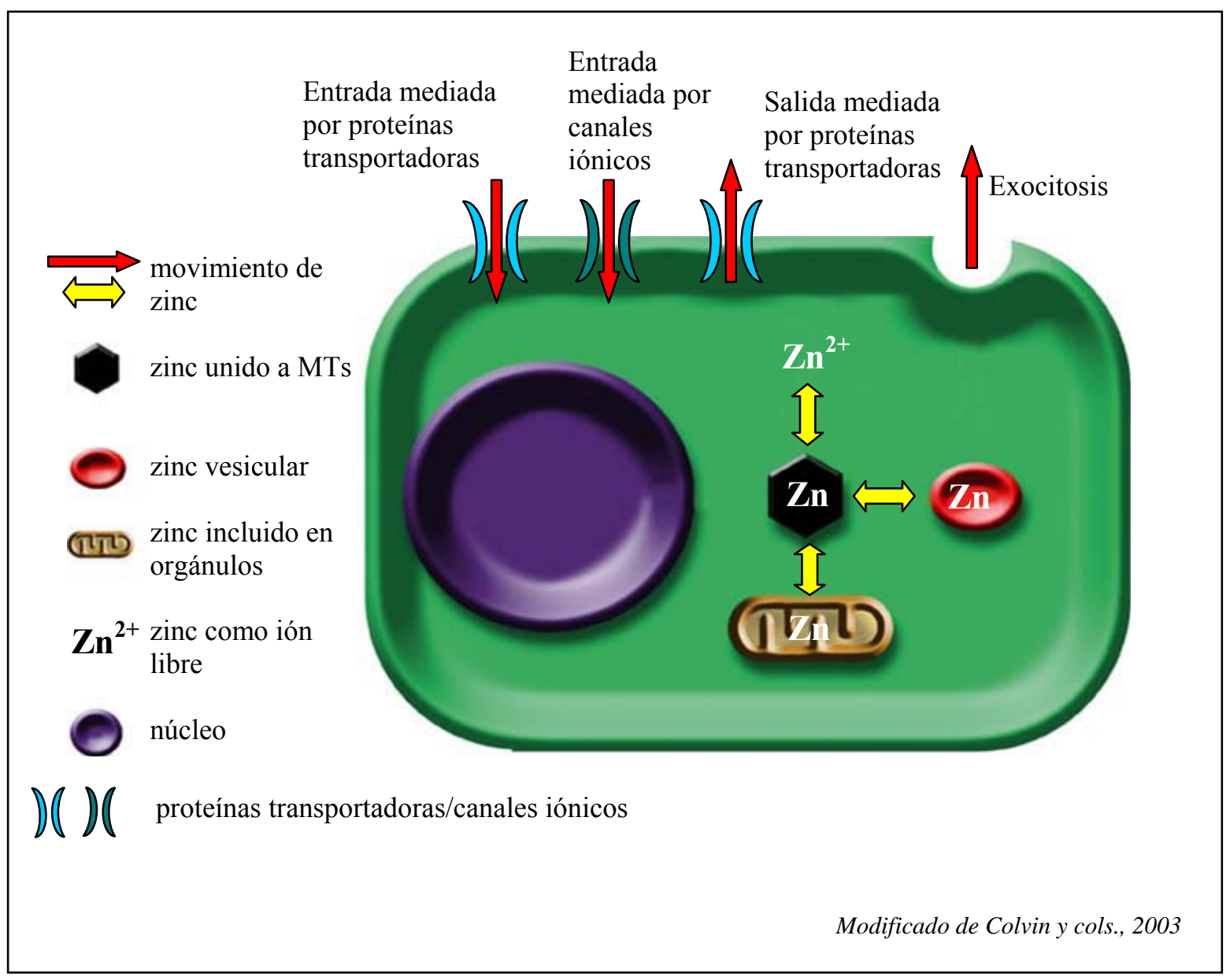

Figura 1. Representación de los cuatro posibles reservorios generales de iones zinc en el interior celular: los iones zinc libres, el zinc unido a metalotioneínas, el zinc incluído en vesículas presinápticas y los iones zinc que se encuentran almacenados dentro de ciertos orgánulos celulares.

\section{Distribución de zinc vesicular en el sistema nervioso}

La existencia de neuronas con altas concentraciones de zinc en sus vesículas sinápticas en el encéfalo de mamíferos se conoce desde hace aproximadamente 50 años (Maske, 1955). El ejemplo más conocido de fibras nerviosas ricas en zinc son los terminales de las fibras musgosas que proyectan desde el giro dentado hasta las neuronas piramidales de la capa CA3 del hipocampo (Slomianka, 1992). Sin embargo, la mayoría de los somas de las neuronas ZEN aparecen en la amígdala y el córtex cerebral, incluyendo el alocórtex (Pérez-Clausell y cols., 1989; CasanovasAguilar y cols., 1998; Christensen y Frederickson, 1998; Slomianka y cols., 1990). Las fibras eferentes de las neuronas ZEN de estas regiones proyectan al córtex cerebral, el núcleo estriado y algunas dianas del sistema límbico como la amígdala, el 
septo, los núcleos de la banda diagonal de Broca y el hipotálamo medial (PérezClausell y cols., 1989; Christensen y Frederickson, 1998). Además de estas vías descritas inicialmente, con el tiempo se han ido describiendo proyecciones ZEN hacia otros lugares: el bulbo olfatorio principal (BO), donde ya se había descrito la abundancia de proyecciones positivas para marcaje de zinc (Friedman y Price, 1984), confirmándose posteriormente la existencia de un sistema zincérgico en esta estructura (Pérez-Clausell y Danscher, 1985; Jo y cols., 2000; Airado y cols., 2008), el núcleo coclear dorsal, el cerebelo, el tálamo (Mengual y cols., 2001), el tronco del encéfalo, la médula espinal y la retina (como revisiones, ver Frederickson y cols., 2000; Brown y Dyck, 2004).

A pesar de la gran diversidad en la distribución de terminales zincérgicos, un rasgo característico común, que se deduce del trazado de proyecciones de las neuronas ZEN, es que se trata de sistemas de neuronas de asociación más que de neuronas de proyección (Frederickson y cols., 2000). Estas neuronas, con axones más cortos y somas más pequeños, son generalmente más tardías en el desarrollo y más plásticas en las conexiones con sus dianas. Por ello, se ha propuesto que el zinc de las vesículas esté implicado, al menos en parte, en la plasticidad de las conexiones sinápticas que poseen estas neuronas de asociación (Jacobson, 1990; Frederickson y cols., 2000; Nakashima y Dyck, 2009).

\section{Homeostasis del zinc en el sistema nervioso}

Todas las células, incluyendo las neuronas, disponen de mecanismos de transporte y almacenamiento de zinc que les permiten mantener la concentración intracelular de este ión fuertemente regulada, puesto que alteraciones tanto por encima como por debajo de los requerimientos fisiológicos resultan fatales para la supervivencia celular (Colvin, 2002).

Los dispositivos que permiten a las neuronas el mantenimiento de la homeostasis de zinc pasan por controlar cómo llega el ión a las neuronas, dónde se almacena en el citosol y las funciones que lleva a cabo dentro de las neuronas. La cantidad de zinc libre intracelular en el citoplasma neuronal se estima en órdenes inferiores a 1nM, mientras que en las vesículas de los terminales de las fibras musgosas del hipocampo se han medido concentraciones superiores a $1 \mathrm{mM}$ (Frederickson y cols., 1983; Canzoniero y cols., 1997; Thompson y cols., 2002). Por tanto, las células necesitan regular los niveles de zinc libre mediante el control del 
flujo de entrada y salida del ión al exterior o a los compartimentos intracelulares, así como a través de la neutralización del mismo uniéndolo a proteínas.

\section{Disminución de zinc citosólico}

Las estrategias con las que cuentan las células para disminuir la concentración de zinc libre intracelular son dos: unir el zinc a proteínas o transportarlo bien fuera de la célula, bien a compartimentos intracelulares, acción que realizan los transportadores de zinc ( $\mathrm{ZnT})$.

Una vez dentro de las neuronas, aproximadamente el $80 \%$ del zinc total se une a proteínas. De entre ellas, la proteína S-100 o la tubulina pueden ocasionalmente unir iones zinc; sin embargo, son las metalotioneínas (MTs) las proteínas encargadas específicamente de llevar a cabo esta función. Las MTs se unen con gran afinidad al zinc, pudiendo incorporar hasta 7 átomos de este ión por cada unidad proteica, y funcionan secuestrando zinc inmediatamente después de que éste haya sido introducido en el citoplasma celular, para prevenir la toxicidad (Palmiter, 1998). En mamíferos se han identificado 4 isoformas diferentes de MTs (MT-I-MTIV, Hidalgo y cols., 2001). Las MTs por un lado disminuyen la concentración intracelular de zinc libre, que queda en torno a 0,05-0,5 nM (Cheng y Reynolds, 1998) y por otro, facilitan la translocación del ión a las vesículas sinápticas, donde es secuestrado por los transportadores ZnT (Palmiter y cols., 1996a,b).

Los transportadores ZnT pertenecen a la familia CDF, acrónimo de cation diffusion facilitator (Palmiter y Findley, 1995) e incluyen una subfamilia que contiene desde el ZnT1 al ZnT10 (fig. 2). Estas proteínas (ZnT1-10), se encargan del transporte de zinc al exterior celular así como de la inclusión del ión en diferentes orgánulos celulares. De todos los transportadores de zinc, el más relevante para nosotros, debido a su función en el sistema nervioso central (SNC), es el ZnT3. Este transportador es el encargado de incluir los iones zinc en las vesículas presinápticas neuronales (Palmiter y cols., 1996a). Así, se ha observado que el contenido en zinc vesicular de ratones knock-out para el transportador ZnT3 es muy inferior al de los animales silvestres para el alelo ZnT3 (Cole y cols., 1999). Además, los marcajes obtenidos por hibridación in situ e inmunohistoquímica para el transportador ZnT3 en hipocampo son coincidentes con el marcaje para zinc vesicular observado con el método de Timm y con el marcador fluorescente TSQ (Palmiter y cols., 1996a). Este transportador, ZnT3, se expresa casi exclusivamente en el sistema nervioso y en los 
testículos, donde el zinc juega un papel importante en el desarrollo y la función del esperma (Delgado y cols., 1984; Andrews y cols., 1994; Palmiter y cols., 1996a). En cuanto a la regulación de su expresión génica, aunque en el caso de ZnT1, ZnT2, ZnT4, ZnT5 y ZnT7 sí se ha comprobado que el zinc ejerce un efecto modulador sobre la expresión de dichos transportadores (McMahon y Cousins, 1998; Kelleher y Lönnerdal, 2002; Pfaffl y Windisch, 2003; Devergnas y cols., 2004), no se ha demostrado una relación directa entre la regulación de la expresión génica del transportador ZnT3 y la concentración de zinc. No obstante, es posible que aún nos

queden aspectos por descubrir sobre el funcionamiento y regulación del transportador ZnT3 puesto que las novedades sobre esta proteína están a la orden del día. Por ejemplo, las últimas investigaciones en cultivos celulares indican que tanto su capacidad para transportar iones dentro de las vesículas, como su propia localización vesicular, dependen de la dimerización de unidades ZnT3 mediante puentes de tirosina, siendo menos eficaz en su función cuando se encuentra como monómero (Salazar y cols., 2009).

\section{Aumento de zinc citosólico}

El incremento de zinc en el citoplasma celular puede ocurrir por diferentes causas. Cuando la célula se encuentra en una situación de déficit de zinc, moviliza sus reservorios intracelulares de zinc, bien liberando los iones unidos a las MTs, bien transportando zinc desde los compartimentos citoplasmáticos al citoplasma.

Aunque no se conocen con exactitud las vías de señalización, el óxido nítrico (ON) es un potente liberador de zinc cuando contacta con las MTs (Zangger y cols., 2001). Los primeros trabajos que relacionaron el zinc con el ON demostraron que tras realizar infusiones de $\mathrm{ON}$ en el cerebro, se producía un cambio significativo en la localización del zinc vesicular en el hipocampo (Cuajungco y Lees, 1998). Así, el marcaje zincérgico (obtenido por el método de Timm), se encontraba no sólo en los terminales axónicos sino también en los somas de las neuronas. Estudios posteriores demostraron que bajo condiciones de estrés nitrosilativo, se producía una disrupción de los enlaces zinc-sulfuro en las metaloproteínas, dando lugar a la liberación de zinc al citoplasma celular (Aravindakumar y cols., 1999). Además de estos efectos, también se ha descrito la liberación de zinc desde los terminales presinápticos como consecuencia de la acción del ON (Frederickson y cols., 2002). El cruce de vías entre la señalización por ON y la homeostasis del zinc quedó confirmado en 2003 por 
Spahl y cols., cuando observaron que células endoteliales a las que se había inducido la producción de ON liberaban zinc desde las MTs. Este zinc se translocaba al núcleo celular, donde posteriormente provocaba el aumento en la expresión génica de los ARNm para las mismas MTs. Recientemente, hemos conocido una aproximación a lo que podría ser la función del zinc liberado tras los episodios de estrés oxidativo que producen un incremento de $\mathrm{ON}$ en células endoteliales. El zinc libre ejercería un papel protector frente al estrés oxidativo, pues es imprescindible para mantener los niveles de glutatión, la molécula implicada en la eliminación de $\mathrm{H}_{2} \mathrm{O}_{2}$ en la célula (Cortese-Krott y cols., 2009).

A pesar del creciente interés en la materia, la liberación de zinc como consecuencia del aumento en $\mathrm{ON}$ es aún un campo abierto al estudio, pues debido a la gran cantidad de condiciones diferentes en las que se produce esta molécula y a su difícil seguimiento, el estudio de los efectos conjuntos de ambos neuromoduladores resulta complejo.

Además de la liberación de zinc desde las MTs mediada por el ON, existen otros mecanismos de incremento de zinc citosólico. Si en el exterior celular la concentración de zinc es elevada, los iones pueden pasar al interior celular mediante dos posibles vías de entrada: mediante proteínas transportadoras o mediante canales iónicos (Colvin y cols., 2003).

Los transportadores son proteínas saturables y de aparente baja afinidad por el ión (Howell y cols., 1984; Wensink y cols., 1988; Colvin y cols., 2000). La naturaleza molecular del proceso de transporte al citosol no se conoce con detalle. Se sabe que el transporte es inhibido por protones $\left(\mathrm{H}^{+}\right)$en la cara extracelular y facilitado por $\mathrm{H}^{+}$en la cara intracelular (Smart y cols., 2004), lo que hace pensar en un mecanismo de transporte antiporte $z i n c-\mathrm{H}^{+}$(Colvin, 2002). Los candidatos para realizar esta función son los miembros de la familia de proteínas ZIP (Gaither y Eide, 2001). Estas proteínas se encuentran, bien en la membrana plasmática o bien en la membrana de algunos orgánulos intracelulares. Hasta la fecha, se han identificado 14 proteínas ZIP en mamíferos (fig. 2, Huang y cols., 2005; Lichten y Cousins, 2009).

En el transporte del zinc al citosol neuronal mediado por canales iónicos pueden participar los receptores NMDA y AMPA de glutamato, canales de calcio o los intercambiadores de $\mathrm{Na}^{+} / \mathrm{Ca}^{2+}$ (Weiss y cols, 1993; Koh y Choi, 1994; Weiss y Sensi, 2000; Jia y cols., 2002). En algunas circunstancias, el acceso del zinc al 
interior celular, a través de estos canales iónicos, puede estar asociado a fenómenos de neurotoxicidad (Weiss y cols., 2000).

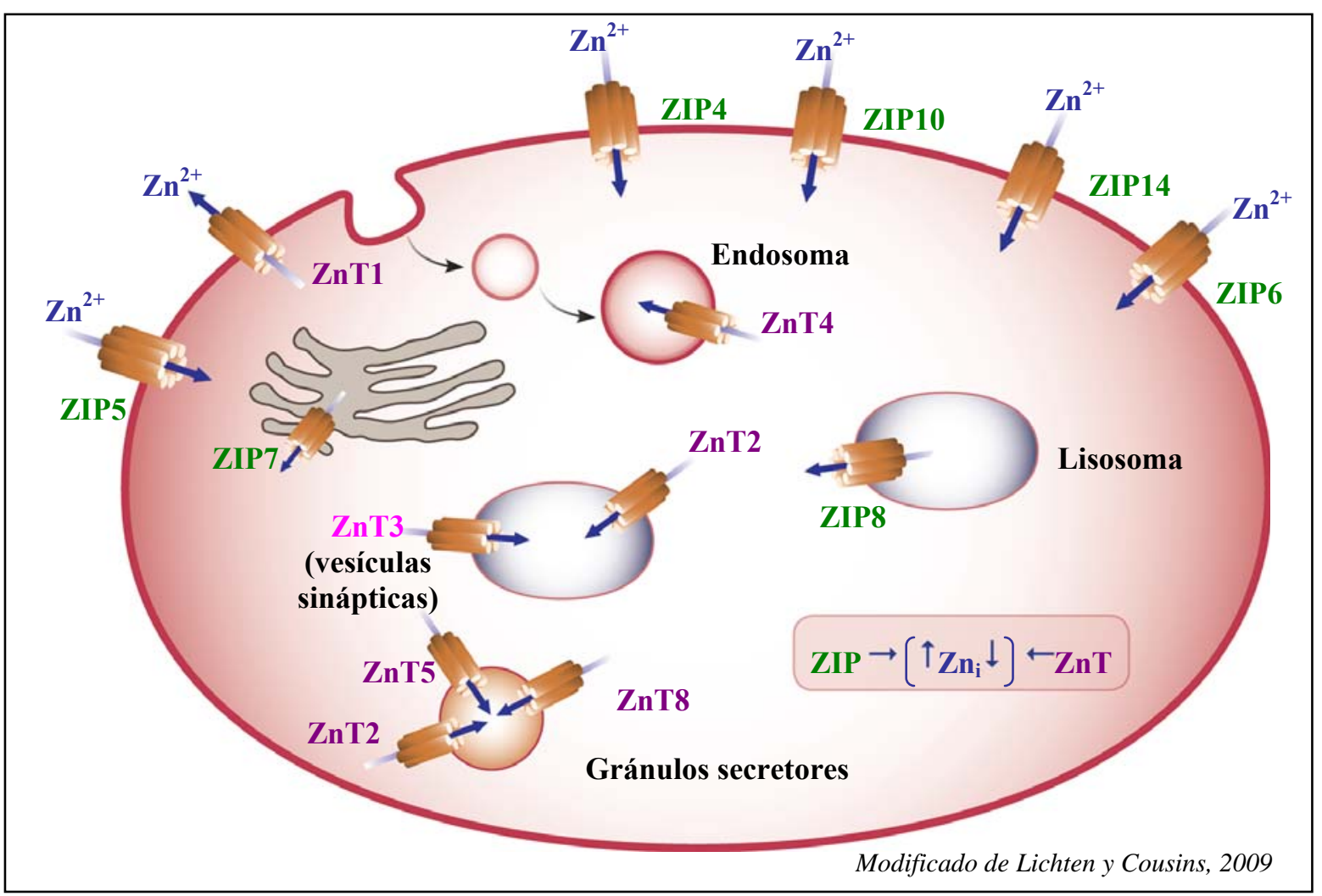

Figura 2. Localización celular de algunas de las proteínas ZIP y ZnT implicadas en la homeostasis de zinc. Mientras las primeras actúan incrementando la concentración intracelular de zinc, de la actividad de las segundas resulta el efecto opuesto. ZnT3 está resaltado en la membrana de vesículas sinápticas. Gran parte de los transportadores ZIP se encuentran en la membrana plasmática, aunque en ocasiones, su localización puede variar entre la membrana de orgánulos celulares y la membrana plasmática, en función de los requerimientos zincérgicos de la célula en cada instante (Lichten y Cousins, 2009).

\section{Toxicidad celular por zinc y enfermedades relacionadas}

El mantenimiento de la homeostasis del zinc es una cuestión vital para las células, de forma que incrementos excesivos en la concentración de zinc pueden tener consecuencias fatales. Cuando las concentraciones intracelulares suben por encima de 400-600 nM, el zinc ejerce un potente efecto neurotóxico que conlleva la inhibición de la respiración celular, la pérdida del potencial de membrana en la mitocondria, la producción de superóxidos mitocondriales (Sensi y cols., 1999; Weiss y cols., 2000; Bossy-Wetzel y cols., 2004), la generación de especies reactivas de oxígeno extra-mitocondriales y la disrupción de la actividad de enzimas metabólicas, dando lugar en último término a la activación de procesos apoptóticos y/o necróticos (Sensi y Jeng, 2004). 
Por otro lado, un déficit en la concentración de zinc también puede tener graves consecuencias. La carencia de zinc en la dieta influye en el desarrollo físico y neurológico (Kasarskis, 1984; Hambidge, 2000). De hecho, conlleva disfunciones cerebrales en aspectos tales como alteraciones del comportamiento, en el aprendizaje, en la expresión de las emociones, en las operaciones cognitivas y en el aumento de la susceptibilidad a convulsiones epilépticas (Hesse, 1979; Frederickson y Danscher, 1990; Frederickson y cols., 2000; Sandstead, 2000; Sandstead y cols., 2000).

Concentraciones intracelulares de zinc anormales se han relacionado con el desarrollo de ciertas enfermedades neurodegenerativas, como el Parkinson y el Alzheimer (Bush y cols., 1994; Bush, 2003a y b; Lee y cols., 2002; Friedlich y cols., 2004). En los enfermos de Parkinson ocurre una pérdida de la homeostasis de zinc en la sustancia negra, donde los niveles de zinc se encuentran aumentados (Squitti y cols., 2007; Barnham y Bush; 2008). Las placas del péptido $\beta$-amiloide, características de la enfermedad de Alzheimer, también contienen altas concentraciones de zinc (Stoltenberg y cols., 2005; Miller y cols., 2006). Los iones zinc liberados durante la neurotransmisión glutamatérgica parecen jugar un papel crítico en la formación de estas placas. En ratones transgénicos APP2596, que expresan la patología cerebral asociada a la deposición de placas de $\beta$-amiloide, la falta de expresión del gen ZnT3 (proteína implicada en la inclusión de zinc en las vesículas sinápticas), inhibe marcadamente la formación de estas placas (Lee y cols., 2002; Friedlich y cols., 2004). No en vano, se están desarrollando ensayos con agentes quelantes de zinc, para inhibir la formación de las placas de $\beta$-amiloide, con resultados cada vez más prometedores (Bush, 2002; Cherny y cols., 2001; Ritchie y cols., 2003; Lee y cols., 2004; Lannfelt y cols., 2008; Adlard y cols., 2008).

\section{Función del zinc en la sinapsis}

El zinc acumulado en las vesículas presinápticas de las neuronas ZEN se libera al espacio extracelular durante el proceso normal de neurotransmisión (Assaf y Chung, 1984; Qian y Noebels, 2005). Una vez allí, bien ejerce efectos de inhibición/potenciación en los receptores o canales iónicos de la membrana postsináptica, o bien puede ser captado por la propia neurona postsináptica (fig. 3, Takeda y cols., 2004; Suh, 2009). Aunque los efectos del zinc se estudiaron inicialmente en la sinapsis glutamatérgica, sobre los receptores de tipo NMDA, 
AMPA y de kainato, hoy sabemos que el incremento de zinc en el fluido extracelular altera también la actividad de gran variedad de receptores y canales: receptores nicotínicos, serotonérgicos, catecolaminérgicos, glicinérgicos y GABAérgicos (Xie y Smart, 1991; Schetz y cols., 1999; Hubbard y Lummis, 2000; Hsiao y cols., 2001; Miller y cols., 2005).

El efecto más conocido del zinc es el observado sobre los receptores NMDA (N-metil-D-aspartato). En neuronas hipocampales y neocorticales, el zinc ejerce un potente bloqueo sobre la activación de los receptores NMDA por glutamato (Peters y cols., 1987; Westbrook y Mayer, 1987). Los receptores NMDA poseen un sitio de unión específico para el ión zinc (Subunidad NR2; Reynolds y Miller, 1988). La incorporación del zinc a este lugar de unión bloquea la activación del receptor (Williams, 1996; Chen y cols., 1997; Paoletti y cols., 1997; Rachline y cols., 2005).

La localización de zinc vesicular en neuronas GABAérgicas en la médula espinal y el cerebelo ha generado mucho interés (Danscher y cols., 2001; Wang y cols., 2002a). El zinc atenúa la activación tanto de los canales iónicos dependientes de ligando GABA y GABA $_{C}$ (Qian y cols., 1996; Ruiz y cols., 2004), como de los receptores metabotrópicos $\mathrm{GABA}_{\mathrm{B}}$ (Xie y Smart, 1991).

\section{Existencia de receptores de zinc}

Además de los efectos moduladores del zinc sobre los receptores de los neurotransmisores, existen evidencias que sugieren que existe un receptor cuyo ligando es el propio ión zinc. Se trata de la proteína GPR39, un receptor acoplado a proteína $\mathrm{G}$ perteneciente a la familia de los receptores de grelina (péptido secretado en el estómago), relacionados con la regulación del apetito (McKee y cols., 1997). El análisis por hibridación in situ ha demostrado que se localiza principalmente en la amígdala, el hipocampo y la corteza auditiva (Jackson y cols., 2006). Mientras que la obestatina, el ligando común para los receptores de esta familia, es inocua para GPR39, el zinc parece ser un potente ligando para este receptor (Holst y cols., 2007; Yasuda y cols., 2007). Aún se desconoce si el zinc es su único ligando, pero sí se sabe que la activación de GPR39 depende de la concentración de zinc y que el receptor actúa como un sensor para la señalización extracelular de las concentraciones de este ión (Holst y cols., 2007). La unión de iones zinc a un receptor metabotrópico, (probablemente el GPR39) en el hipocampo, provoca la activación de la vía de señalización del inositol trifosfato (IP3) con el consiguiente 
incremento de calcio intracelular (Besser y cols., 2009). Si este dato se confirma, el papel que el zinc juega en el SNC sería más importante que el de un modulador de la neurotransmisión ya que, además, se encargaría de enviar información per se a las células que presentasen receptores GPR39 en su membrana.

\section{Función intracelular del zinc}

Además de las funciones desempeñadas por los iones zinc sobre los receptores de las neuronas postsinápticas, los iones zinc pueden entrar en la propia neurona postsináptica (fig. 3, Suh, 2009). Este hecho se relacionó en un principio con estados patológicos que conllevaban la muerte celular; sin embargo, varios estudios han mostrado que, bajo condiciones fisiológicas normales, el zinc puede entrar en las neuronas y ejercer distintos efectos, como por ejemplo, actuar como un segundo mensajero (Li y cols., 2001a; Suh, 2009). La PKC contiene lugares específicos de unión para el zinc y su translocación desde la membrana al citosol se ve incrementada por este ión (Baba y cols., 1991; Korichneva y cols., 2002; Aras y cols., 2009). Además, la autofosforilación de la proteína kinasa dependiente de calcio/calmodulina está relacionada con la concentración de zinc intracelular (Lengyel y cols., 2000). El zinc además interviene en la regulación de la reparación del ADN mediante la estabilización de las interacciones entre el ADN genómico y la proteína p53 (Mocchegiani y cols., 2005). La señalización mediada por zinc provoca una serie de efectos en la célula que han relacionado al ión zinc con procesos de plasticidad y potenciación a largo plazo en el hipocampo (Li y cols., 2001b, Nakashima y Dyck, 2009), así como durante la etapa de envejecimiento, cuando comienza a fallar el proceso de reparación del ADN (Mocchegiani y cols., 2005). 


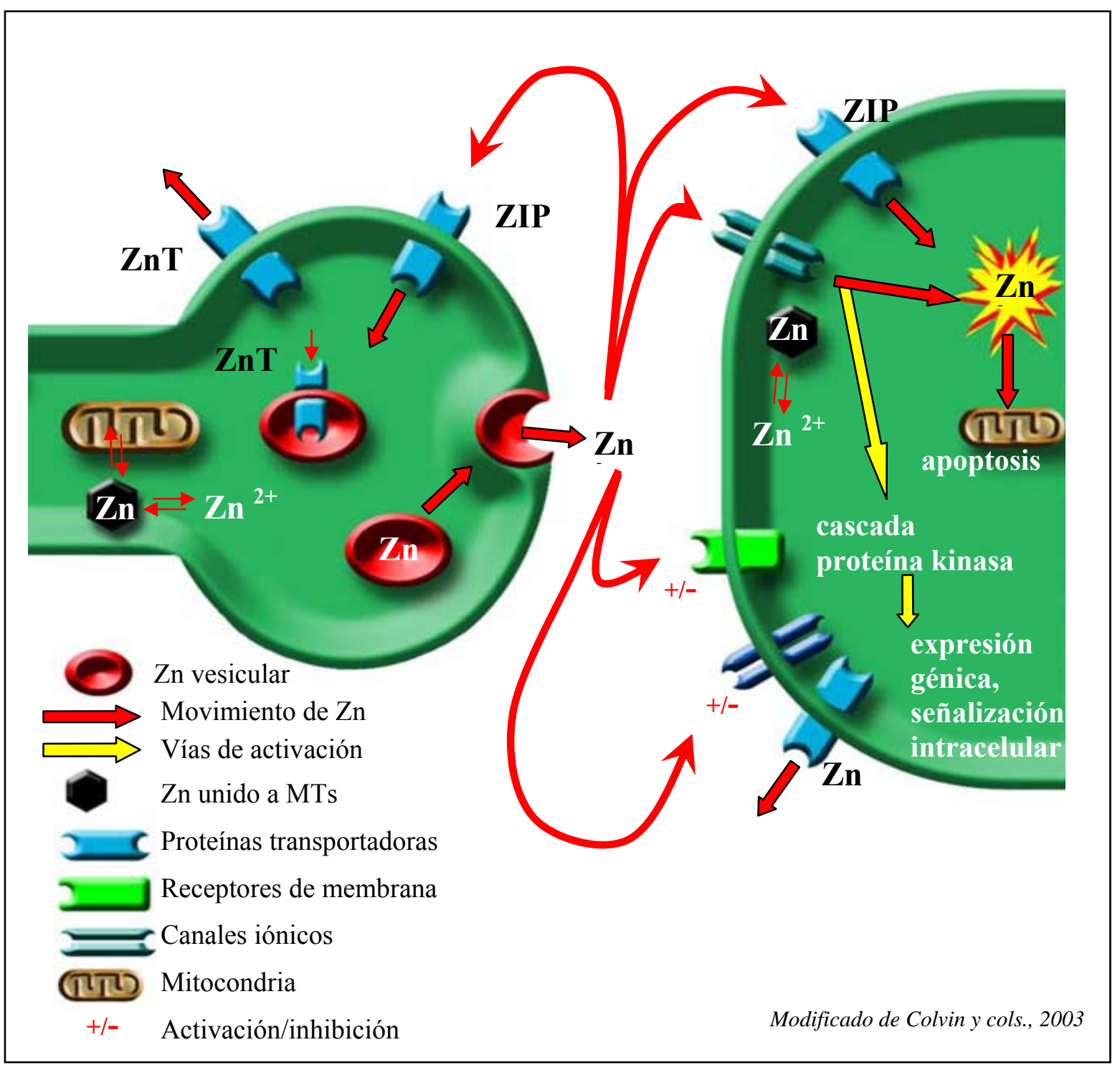

Figura 3. Funciones del zinc en la sinapsis. Liberado al espacio extracelular, el zinc puede modular diferentes receptores de membrana y canales iónicos en la neurona postsináptica, como los NMDA o los receptores GABAérgicos. También puede entrar en la neurona postsináptica a través de canales iónicos o de proteínas ZIP. El zinc restante de la hendidura sináptica puede ser recaptado por la neurona presináptica. Dentro de la neurona postsináptica, el zinc puede actuar como segundo mensajero, aunque si las concentraciones de zinc son demasiado elevadas las consecuencias pueden ser fatales para la célula. 


\section{Métodos de detección del zinc}

La necesidad de caracterización de los circuitos neuronales implicados en la liberación sináptica de zinc ha llevado al desarrollo de diferentes métodos de detección de este ión. Tradicionalmente los distintos métodos para detectar el zinc vesicular se han clasificado en dos tipos: métodos directos y métodos indirectos. Los primeros suelen ser utilizados in vivo para propósitos cuantitativos y microanalíticos, ya que normalmente no permiten una buena preservación histológica. En cambio, los métodos indirectos, a diferencia de los anteriores, no resultan muy adecuados para cuantificar, pero son mucho más sensibles y perfectamente compatibles con estudios microscópicos (López-García y cols., 2002).

\section{Métodos directos}

Implican el uso de sustancias que poseen un color brillante o emiten fluorescencia cuando entran en contacto con los iones metálicos divalentes. Dentro de los métodos directos se incluyen tanto aquellos que emplean colorantes como los que utilizan sustancias fluorescentes.

\section{Tinciones no fluorescentes}

Ejemplos de estos marcajes son los que utilizan la ditizona o el zincon. La ditizona (difeniltiocarbamato) fue el primer método desarrollado para la histoquímica del zinc, es un agente quelante de metales pesados ampliamente empleado en química analítica (Okamoto y Hashimoto, 1944). El zincon es otro compuesto coloreado, más estable que la ditizona, que se une específicamente al zinc en un rango de pH 8.5-10 (Hasan, 1977).

\section{Tinciones fluorescentes}

Existen compuestos que tras interactuar con algunos iones metálicos emiten fluorescencia. Presentan la ventaja de ser en su mayoría liposolubles, pueden atravesar las membranas e interactuar con los iones metálicos bajo condiciones fisiológicas normales de $\mathrm{pH}$ y temperatura. De este modo pueden ser usados in vivo, resultando además adecuados para estudios cuantitativos. Uno de los compuestos de este tipo más empleado en la detección del zinc iónico en el tejido nervioso ha sido la N-(6-metoxi-8-quinolil)-p-toluenosulfonamida (TSQ; Frederickson y cols., 1987). 


\section{Métodos indirectos}

Los métodos indirectos incluyen todos aquellos que implican la fijación y precipitación de los iones metálicos como sales insolubles y su posterior visualización mediante revelado por autometalografía (AMG). Estos métodos se emplean tradicionalmente para marcar el zinc vesicular. En esta clase de métodos se incluyen los métodos de Timm, Neo-Timm y el método del selenio ( $\left.\mathrm{ZnSe}^{\mathrm{AMG}}\right)$.

Podría también considerarse un método indirecto la técnica inmunohistoquímica para marcar la proteína $\mathrm{ZnT3}$, el transportador localizado en la membrana de las vesículas de zinc que se encarga de transportar los iones zinc desde el citosol al interior de las mismas. Utilizando un anticuerpo específico contra dicha proteína podemos estudiar la distribución de las vesículas donde se encuentra el transportador y que, por tanto, deben contener iones zinc en su interior (Palmiter y cols., 1996b, Cole y cols., 1999). Se ha comprobado que el $80 \%$ del marcaje histoquímico (con el método de Neo-Timm) del zinc vesicular desaparece en los ratones knock-out para la proteína ZnT3 (Cole y cols., 1999). Este hecho, unido a la coincidencia de resultados con las otras técnicas empleadas para analizar la distribución del marcaje zincérgico, hace que la inmunohistoquímica para la proteína ZnT3 también sea hoy en día un método generalmente aceptado para el estudio de la distribución del zinc vesicular.

El revelado mediante $\mathrm{AMG}$ es un denominador común para todos los métodos indirectos de marcaje del zinc (salvo en el caso de la inmunohistoquímica para ZnT3), por lo que detallaremos brevemente la base química de este proceso. Las técnicas de AMG representan una transferencia de metodología desde el mundo de la fotografía a la histología. La AMG con plata ofrece la oportunidad de revelar partículas de sales metálicas muy pequeñas, de sulfuro de zinc o selenito de zinc, que catalizan la reducción de iones de plata a plata metálica en presencia de un agente reductor (Liesegang, 1911). Los iones de plata $\left(\mathrm{Ag}^{+}\right)$se adhieren a la superficie de estas sales y algunos iones zinc (o probablemente todos), son reemplazados entonces por iones plata, de modo que los cristales nanométricos de sulfuro/selenito de zinc se transforman en cristales de sulfuro/selenito de plata (Dinsdale, 1984; Danscher, 1996). Posteriormente el proceso se amplifica hasta que los cristales se hacen visibles tanto a microscopía óptica como electrónica. 


\section{Timm y Neo- Timm}

Ambos métodos se basan en el uso de iones sulfuro para formar cristales de sulfuro de zinc que posibiliten la detección del ión zinc. El uso de iones sulfuro con fines histoquímicos data de 1850, cuando Mayer los utilizó para intentar poner de manifiesto la presencia de hierro en los tejidos. Cien años después, este método, basado en la misma transformación de metales a sulfuros metálicos empleando sulfuro de plata, fue desarrollado por Timm (1958) para la detección histoquímica de zinc y otros metales pesados. Observó que al ponerse en contacto iones de plata con la superficie de sulfuros metálicos, en presencia de un revelador adecuado, ocurría la reducción de los iones de plata a plata metálica; hecho que podía ser empleado para visualizar algunos metales que se encuentran en los tejidos.

El exceso de fijación con vapores $\mathrm{SH}_{2}$ inducía un exceso de grupos $\mathrm{SH}$ en las proteínas que unían iones de plata del revelador y actuaban como centros catalíticos para la AMG, condiciones bajo las que solían ocurrir falsos positivos. En 1981 Danscher revisó y mejoró el protocolo inicial de Timm en lo que se conoce ahora como método de Neo-Timm. Este método no presenta el problema de los falsos positivos y además permite estudios de microscopía electrónica (López-García y Martínez Guijarro, 1988) y su combinación con técnicas inmunocitoquímicas (López-García y cols., 1983; Martínez-Guijarro y cols., 1987; de Biasi y Bendotti, 1998).

\section{Método del selenio (ZnSe ${ }^{\mathrm{AMG}}$ )}

En este método se emplean iones de selenio en lugar de iones sulfuro para precipitar los cationes metálicos en el tejido. La inyección intraperitoneal (i.p.) o intracerebral (i.c.) de compuestos de selenio (normalmente selenito o seleniuro sódico) en animales vivos, seguido por un periodo de supervivencia variable previo al sacrificio del animal, resultan en la precipitación de los cationes metálicos (Danscher, 1982). Las sales metálicas de selenio precipitadas se ponen de manifiesto mediante el mismo revelado autometalográfico empleado en el método de NeoTimm. Se acepta, de forma general, que el zinc revelado por el método de selenio es el mismo que se marca con el método de Neo-Timm (Danscher, 1982), por lo que las técnicas pueden considerarse equivalentes.

Una de las ventajas del $\mathrm{ZnSe}^{\mathrm{AMG}}$ frente al método de Neo-Timm es que las sales metálicas de selenio precipitadas son más estables que las que se forman con 
sulfuro. No obstante, puesto que los compuestos de selenio muestran una toxicidad diferencial en los animales experimentales, es necesario ajustar la dosis correcta y el tiempo óptimo de supervivencia previo al sacrificio.

Se conoce la existencia de transporte axonal retrógrado de vesículas desde los terminales presinápticos a los somas de las neuronas ZEN (Takeda, 2000). El zinc acumulado en las vesículas presinápticas interviene de forma pasiva en este proceso, de modo que es transportado también hasta el cuerpo neuronal, donde se acumula dentro de lisosomas. Los nanocristales de selenito de zinc son resistentes a ácidos débiles (Danscher, 1981, 1996; Stoltenberg y Danscher, 2000; Danscher y cols., 2004). Esta relativa estabilidad de los nanocristales de selenio frente a las variaciones de $\mathrm{pH}$ es la cualidad que hace posible la observación de vesículas conteniendo zinc también en los somas de las neuronas ZEN, cuando dejamos un periodo suficiente de supervivencia tras la inyección (12-48 horas, Airado, 2005; Airado y cols., 2008).

\section{El sistema olfatorio de los roedores}

Todos los organismos vivos, desde los unicelulares más sencillos hasta los pluricelulares más evolucionados, poseen la habilidad de adquirir información del medio externo detectando las señales químicas que éste le ofrece; fenómeno que ha alcanzado su máximo grado de desarrollo en los animales vertebrados (Macrides y Davis, 1983; Shipley y Ennis, 1996). En vertebrados, el sistema olfatorio está implicado en funciones esenciales para la supervivencia del animal. Así, interviene en la reproducción, en la regulación neuroendocrina, en el marcaje del territorio, en el reconocimiento de congéneres, en la identificación de clanes (Finger y Silver, 1987), en la interacción predador-presa y en la búsqueda y selección del alimento (Davenport, 1955; Ache, 1987).

En 1953, Allison clasificó a los mamíferos en tres grupos en función del tamaño relativo de las estructuras encefálicas relacionadas con el olfato, volumen que refleja la importancia de este sentido. El grupo más numeroso, animales macrosmáticos (como los roedores o los carnívoros) incluye a mamíferos con centros olfatorios bien desarrollados; los mamíferos microsmáticos (como los primates), poseen centros olfatorios relativamente pequeños y una predominancia funcional de otros sentidos como la vista o el oído; finalmente los mamíferos anosmáticos (como 
los cetáceos odontocetos), lo forman animales cuyas estructuras olfatorias son vestigiales o han desaparecido completamente (Allison, 1953).

La función olfatoria en los roedores está mediada por dos sistemas distintos (Shipley y Ennis, 1996). El sistema olfatorio principal, encargado de la transducción de un amplio rango de señales odorantes, y el sistema olfatorio accesorio, especializado en la comunicación química intraespecífica mediante la captación de feromonas (Halàsz, 1990; Eisthen, 1997). Ambos sistemas olfatorios contienen neuronas receptoras olfatorias (NROs), pero difieren en la localización de estas células receptoras, en el estado físico de las moléculas odorantes que captan y en la estructura encefálica a la que transmiten la información. Mientras que las neuronas receptoras del sistema olfatorio principal, situadas en la mucosa olfatoria, son estimuladas por odorantes volátiles y proyectan sus axones sobre el BO, las neuronas receptoras del sistema olfatorio accesorio, localizadas en el órgano vomeronasal, captan odorantes no-volátiles por mecanismos de bombeo y sus axones proyectan exclusivamente al bulbo olfatorio accesorio (BOA; Shipley y Ennis, 1996).

\section{El bulbo olfatorio principal}

El BO es una estructura par e intracraneal que en los roedores se localiza en el extremo más rostral del encéfalo. En esta estructura se encuentran las primeras neuronas de relevo de la vía olfatoria principal y es donde tiene lugar el primer procesado y modulación de la sensación olfatoria (Macrides y Davis, 1983). Presenta la organización laminar característica de una alocorteza y una estructura general común para todos los vertebrados (Golgi, 1875; Blanes, 1898; Ramón y Cajal, 1911).

En el $\mathrm{BO}$ de roedores adultos podemos distinguir siete capas concéntricas que describimos a continuación de la más externa a la más interna.

\section{Capa de las fibras del nervio olfatorio (CFNO)}

Es el estrato más superficial del BO. Está formado por los axones de las NROs y por un tipo especial de glía que los rodea, la glía envolvente. Los axones de las NROs, delgados y amielínicos (Ramón y Cajal, 1911; Pinching y Powell, 1971a), llegan al BO en haces que discurren por su superficie y que no se ramifican hasta penetrar en la siguiente capa del BO, la capa glomerular (Kratskin y Belluzi, 2003). 


\section{Capa glomerular (CG)}

Se compone de estructuras esféricas, denominadas glomérulos, ricas en neuropilo y rodeadas por neuronas y células gliales (Allison y Warwick, 1949; Royet y cols., 1988; Kratskin y Belluzzi, 2003). Los glomérulos constituyen unidades funcionales individuales en el procesamiento y modulación de la información olfatoria (Kosaka y cols., 1998). Aunque a cada glomérulo llegan cientos de axones distintos, cada axón olfatorio inerva un sólo glomérulo, y una vez dentro de éste, se divide en ramas cada vez de menor diámetro (Halàsz y Greer, 1993; Klenoff y Greer, 1998). El neuropilo glomerular lo constituyen las terminaciones axónicas de las NROs, las dendritas apicales de las neuronas de proyección, terminaciones de diferentes tipos de interneuronas y axones de procedencia centrífuga (Kosaka y cols., 1997; Kasowski y cols., 1999). En función del origen de las proyecciones que forman el neuropilo glomerular, Kosaka y cols. (1995, 1997, 1998), establecieron que cada glomérulo puede dividirse en dos regiones: la zona NO (zona-del-nervioolfatorio) y la zona no-NO (zona-no-del-nervio-olfatorio). La primera de ellas está constituida por los terminales de axones de las NROs, que realizan sinapsis con dendritas de interneuronas y de neuronas de proyección; en cambio, la zona no-NO está formada por procesos dendríticos de interneuronas y de las neuronas de proyección que realizan sinapsis dendrodendríticas entre ellas, así como por fibras centrífugas (Kosaka y cols., 1995, 1997). Las neuronas que se encuentran rodeando a los glomérulos se denominan, en conjunto, células yuxtaglomerulares y pertenecen a tres subpoblaciones morfológica y funcionalmente diferentes: células periglomerulares (PGs), células superficiales de axón corto y células empenachadas externas (Pinching y Powell, 1971b).

\section{Capa plexiforme externa (CPE)}

Se caracteriza por una densidad de somas relativamente baja y un neuropilo muy denso, donde se encuentran las dendritas laterales de las células mitrales y de las células empenachadas medias e internas (Shepherd, 1972), las dendritas apicales de los granos (interneuronas en la región más profunda del BO; Price y Powell, 1970b), los axones de células empenachadas mayoritariamente externas (Schoenfeld y cols., 1985) y fibras centrífugas. En esta capa se localizan, además, los somas de células empenachadas medias e internas (neuronas de proyección del BO) y los somas de un conjunto de interneuronas inhibitorias de morfología variada (Kosaka y cols., 1994). 


\section{Capa de las células mitrales (CCM)}

En esta capa se encuentran alineados los somas de las principales neuronas de proyección del BO, las células mitrales, formando una monocapa (Allison, 1953). Estas células son las neuronas más grandes del $\mathrm{BO}$, con somas triangulares de un diámetro máximo de 20-33 $\mu \mathrm{m}$ en función de la especie (Ramón y Cajal, 1911). Cada célula mitral tiene una gran dendrita apical que atraviesa la CPE y termina ramificándose dentro de un glomérulo olfatorio (Andres, 1970; Price y Powell, 1970a). Poseen también dendritas basales que se orientan paralelamente a la laminación bulbar y se ramifican en la CPE estableciendo contactos sinápticos con los granos, con las interneuronas de la CPE y con fibras centrífugas (Price y Powell, 1970a; Jackowski y cols., 1978; Macrides y Davis, 1983). Los axones de las células mitrales forman colaterales recurrentes que se distribuyen en la capa subyacente antes de proyectar fuera del BO. Estos axones se sitúan posterolateralmente integrándose en el tracto olfatorio lateral (TOL) que manda numerosas colaterales a lo largo de todo el córtex olfatorio comenzando por el núcleo olfatorio anterior (NOA), la segunda estación de relevo de la información olfatoria (Shipley y cols., 1995).

\section{Capa plexiforme interna (CPI)}

Es una capa estrecha, de baja densidad celular. Constituida mayoritariamente por los axones de células mitrales y empenachadas, las dendritas de los granos, fibras centrífugas procedentes de otras regiones encefálicas y colaterales axónicas de células empenachadas externas que viajan hacia el lado opuesto del bulbo ipsilateral (Schoenfeld y cols., 1985).

\section{Capa de los granos (CGr)}

Es la capa de mayor espesor y densidad celular del BO. Las neuronas que la ocupan mayoritariamente, denominadas granos, son las más numerosas del BO (Meisami y Safari, 1981). Sus pequeños somas ovalados o fusiformes, están muy juntos formando agregados de 3-5 células cada uno. Los cuerpos celulares de estos agregados están acoplados mediante uniones gap (Reyher y cols., 1991). Los granos carecen de axón y poseen dendritas apicales que se ramifican en la CPE y cortas dendritas basales que lo hacen en la misma capa de los granos (Price y Powell, 1970b). Aparte de los granos, otras interneuronas, denominadas células profundas de 
axón corto, aparecen en esta capa además de en la CPI y en la CCM (Ramón y Cajal, 1911; Price y Powell, 1970a; Pinching y Powell 1971b; Schneider y Macrides 1978; Kosaka y cols., 1994).

\section{Sustancia blanca periependimaria (SBPE)}

Es la capa más profunda del BO. Está formada fundamentalmente por axones mielinizados y células ependimarias que bordean el ventrículo vestigial. Muchas de las células del BO derivan de esta zona durante el desarrollo, un proceso que se mantiene durante toda la vida adulta (Altman 1969; Kishi, 1987; Luskin, 1993; Lois y cols., 1996). En esta capa encontramos también gran parte de las fibras aferentes y eferentes del BO. Éstas, constituyen el TOL en la zona más caudal del BO.

\section{Circuito olfatorio}

Las sustancias odorantes estimulan las NROs del epitelio olfatorio al interaccionar con las proteínas receptoras localizadas en sus cilios. El proceso de transducción quimiosensorial ocurre en la membrana plasmática de la dendrita apical de las NROs (Getchell, 1986; Labarca y Bacigalupo, 1988; Lowe y Gold, 1993). Los axones amielínicos de las NROs se agrupan para llegar al BO ipsilateral, donde se ramifican en el interior de los glomérulos olfatorios (Macrides y Davis, 1983). Allí establecen sinapsis excitatorias glutamatérgicas con las dendritas apicales de las células mitrales, empenachadas y yuxtaglomerulares (Berkowicz y cols., 1994; Ennis y cols., 1996; Murphy y cols., 2004).

Tradicionalmente, los glomérulos han sido considerados como unidades funcionales, de modo que en cada uno de ellos convergería la información de las NROs sensibles a un único odorante (Ramón y Cajal, 1911; Clark y Warwick, 1946; Allison y Warwick 1949; Clark, 1951, 1957). Estudios posteriores han demostrado que cada glomérulo es activado por diferentes odorantes y, a su vez, cada odorante activa diferentes estirpes de NROs, en diferente grado según su afinidad por el receptor, lo que se traduce en la activación posterior de varios glomérulos (Guthrie y Gall, 1995; Johnson y cols., 1998, 1999; Kashiwadani y cols., 1999; Nagao y cols., 2000; Rubin y Katz, 2001). Así, la información, distribuida ampliamente en el epitelio olfatorio, se traduce en el interior del BO en un mapa olfatorio altamente organizado (Buck, 1996). 
Una vez ha entrado la información por las dendritas de las células mitrales y empenachadas, los axones de las neuronas de proyección emiten colaterales dentro del bulbo en la CPI y CGr y comienzan a agregarse en la CGr para formar fascículos (Mori y cols., 1983). La unión de estos fascículos constituirá el TOL, que aparece a la altura rostrocaudal del BOA y discurre caudalmente a lo largo de la superficie ventrolateral del encéfalo hasta la corteza entorrinal. A lo largo de toda su extensión, los axones que viajan por el TOL van emitiendo colaterales axónicas a los distintos centros superiores inervados por la vía olfatoria (Brunjes y Frazier, 1986).

Las regiones cerebrales que reciben proyecciones directamente del $\mathrm{BO}$ se incluyeron tradicionalmente bajo el término de corteza olfatoria primaria (de Olmos y cols., 1978; Price, 1973, 1987; Halàsz, 1990; Shipley y cols., 1995; Haberly, 2001). Puesto que el BO es, en sí mismo, una estructura cortical, para evitar ambigüedades hoy se emplea el término de estructuras olfatorias secundarias (Cleland y Linster, 2003). Las estructuras olfatorias secundarias comprenden el NOA, la taenia tecta (TT), el tubérculo olfatorio, el indusium griseum, la CP, la corteza periamigdaloide, el núcleo cortical amigdaloide y el área entorrinal ventrolateral (Allison, 1953; Powell y cols., 1965; Dennis y Kerr, 1968; Price y Powell, 1971; Scott y cols., 1980).

\section{Modulación centrífuga de la transmisión olfatoria}

Dentro de los centros sensoriales primarios, el BO destaca por recibir una gran densidad de axones centrífugos, de múltiples procedencias, que juegan un papel importante en la regulación de su fisiología (Ramón y Cajal, 1911; Macrides y Davis, 1983; Kratskin y Gershuni, 1987; Halàsz, 1990; Shipley y Ennis, 1996; Matsutani y Yamamoto, 2008). Estas fibras centrífugas se dividen en dos grupos (Shipley y cols., 1995):

1. Aferencias que proceden de estructuras subcorticales no exclusivamente olfatorias. Conocidas también como aferencias moduladoras, y que poseen extensas proyecciones que regulan el funcionamiento integrado del SNC. Dentro de éstas, encontramos la banda diagonal de Broca (Zaborsky y cols., 1986), los núcleos dorsal y medial del rafe (McLean y Shipley, 1987a, b) y el locus coeruleus (McLean y Shipley, 1991; Woo y cols., 1996). La primera de estas estructuras constituye la principal fuente de inervación colinérgica que recibe el BO. Los núcleos dorsal y medial del rafe son los responsables de la inervación serotonérgica (Descarries y cols., 1982; Gómez y cols., 2005). Por 
su parte, el locus coeruleus es el origen de una fuerte inervación noradrenérgica al BO (McLean y cols., 1989; Gómez y cols., 2006).

2. Aferencias que proceden de estructuras exclusivamente olfatorias. Median específicamente en la función olfatoria. Incluyen las procedentes de todas las estructuras olfatorias secundarias descritas en el apartado anterior, salvo el tubérculo olfatorio, el indusium griseum y la corteza periamigdaloide.

De todas las estructuras olfatorias secundarias que proyectan al $\mathrm{BO}$, son aquellas más rostrales (el NOA y la $\mathrm{CP}$ ) las que envían un mayor número de proyecciones a esta estructura (Shipley y Adamek, 1984). De hecho, la mayor fuente de fibras centrífugas que proyectan al BO procede del NOA (Carson, 1984). Todas las subdivisiones del NOA de cada hemisferio proyectan a ambos BOs. Las subdivisiones medial, dorsal, lateral y ventral proyectan mayoritariamente al hemisferio ipsilateral. El NOAe, en cambio, proyecta mayoritariamente al BO contralateral a través de la comisura anterior (CA; Davis y Macrides, 1981; Haberly y Price, 1978). A pesar de que la mayor densidad de inervación en el BO, la presenta la CGr, el resto de capas también son diana de estas proyecciones centrífugas (Cleland y Linster, 2003, Brunjes y cols., 2005). Las sinapsis entre los terminales procedentes del NOA y las neuronas del $\mathrm{BO}$ se han identificado ultraestructuralmente como sinapsis de tipo asimétrico y, por lo tanto, excitatorias (Brunjes y cols., 2005). De hecho, aunque los neurotransmisores empleados en los terminales presinápticos de las fibras centrífugas procedentes de las estructuras olfatorias secundarias no han sido definitivamente establecidos, la mayor parte de las evidencias de las que disponemos, indican que el glutamato es el principal neurotransmisor excitatorio liberado por estas fibras (Carnes y cols., 1990; Fuller y Price, 1988; Jung y cols., 1990; Ray y cols., 1992; Hoffman y Haberly, 1993; Balu y cols., 2007). Además, la principal diana de estas proyecciones es la CGr (Haberly y Price, 1978), por lo que la activación sobre las interneuronas inhibitorias resultaría en un efecto global de inhibición de la actividad bulbar.

\section{El zinc en el sistema olfatorio}

El BO está fuertemente regulado por zinc, de hecho la asociación entre alteraciones de zinc y disfunciones olfatorias es conocida desde hace 20 años (Mackay-Sim y Dreosti, 1989; Alpers, 1994). La deprivación de zinc en la dieta 
durante 42 días a ratones adultos supone una inducción de anosmia altamente significativa, que nada tiene que ver con alteraciones en el epitelio olfatorio, pues esta estructura se mantiene intacta (Mackay-Sim y Dreosti, 1989).

Gracias al desarrollo de los métodos de marcaje de zinc, hemos podido conocer la distribución de los terminales ZEN y del transportador ZnT3 en el BO del ratón (Jo y cols., 2000; Airado, 2005; Airado y cols., 2008). Hoy sabemos que los terminales ZEN en el BO se distribuyen mayoritariamente en la CG y en la CGr (Jo y cols., 2000; Airado, 2005; Airado y cols., 2008). En la CGr, los terminales ZEN se localizan alrededor de los grupos de granos, mientras que en la CG hay menos terminales ZEN, localizados principalmente en la parte externa de cada glomérulo, en el área yuxtaglomerular. Al observar el marcaje glomerular se hace patente un desfase entre el marcaje presentado por el $\mathrm{ZnSe}^{\mathrm{AMG}}$ y la inmunohistoquímica para el transportador ZnT3: mientras que los gránulos de plata precipitada aparecen en la región yuxtaglomerular, el precipitado de DAB para el transportador ZnT3 se presenta rellenando todo el neuropilo glomerular (Jo y cols., 2000; Airado, 2005; Airado y cols., 2008). Por ello, continuando el trabajo comenzado en 2005, el desfase entre las técnicas será uno de los interrogantes a resolver en el presente trabajo de Tesis Doctoral.

La situación de los terminales zincérgicos en el $\mathrm{BO}$ y su localización ultraestructural en vesículas (Jo y cols., 2000), sugiere que las fuentes de dichos terminales en el $\mathrm{BO}$ son las NROs en el interior glomerular y las fibras centrífugas tanto en la CG como en la CGr. Para conocer el origen de las proyecciones zincérgicas que inervan el $\mathrm{BO}$ se han realizado experimentos tanto de autorradiografía (Takeda y cols., 1997), como de marcaje retrógrado mediado por selenio (Jo y cols., 2002; Airado, 2005; Airado y cols., 2008). En este último caso, el selenito sódico se inyectó en un $\mathrm{BO}$ y se observaron los somas que aparecían en las regiones ipsi y contralaterales a la inyección. Los somas se localizan fundamentalmente en las estructuras olfatorias secundarias, incluyendo el NOA, la TT, la CP y la corteza entorrinal (Jo y cols., 2002). De todas las regiones que inervan el BO la estructura que presenta el mayor número de neuronas ZEN es el NOA. Todas las subdivisiones del NOA ipsilateral están más densamente pobladas con neuronas ZEN que sus respectivas en el NOA contralateral. Además, la distribución de los somas ZEN en las diferentes subdivisiones del NOA varía a lo largo del eje rostro-caudal, siendo la subdivisión medial del NOA la que presenta una mayor 
densidad de somas ZEN (Airado, 2005; Airado y cols., 2008). Respecto a la CP, los somas ZEN aparecen en la capa II a lo largo de todo su eje rostro-caudal. El núcleo cortical amigdaloide posterolateral presenta muy pocas neuronas marcadas y la parte lateral del adyacente núcleo posteromedial no posee ninguna neurona ZEN. Un pequeño número de neuronas marcadas se encuentra localizado en la capa II de la parte lateral de la corteza entorrinal (Jo y cols., 2002). Las fibras centrífugas implicadas en los sistemas moduladores subcorticales no olfatorios, es decir, aquellas procedentes del núcleo de la banda diagonal de Broca, los núcleos dorsal y medial del rafe y el locus coeruleus, no proceden de neuronas ZEN (Jo y cols., 2002).

En resumen, los estudios realizados hasta la fecha proponen la presencia de terminales zincérgicos en el $\mathrm{BO}$ con dos orígenes: a) fibras centrífugas procedentes principalmente del NOA y la $\mathrm{CP}$, que establecen contactos sinápticos con los granos y las células yuxtaglomerulares, b) los terminales de las NROs, que contactan con los procesos dendríticos de las células mitrales, empenachadas y yuxtaglomerulares (Jo y cols., 2000; Airado, 2005; Airado y cols., 2008).

\section{Plasticidad en el sistema olfatorio}

El sistema nervioso tiene la capacidad de experimentar cambios estructurales y funcionales en respuesta a alteraciones normales o patológicas que pueden ocurrir en cualquier momento de la vida del individuo para, de este modo, minimizar o compensar sus efectos (Zilles, 1992). Se denomina plasticidad cerebral a la capacidad para desarrollar una reorganización estructural y funcional del SNC con el fin de adaptarse a una nueva situación.

La vía olfatoria de mamíferos terrestres es excepcionalmente plástica. Por un lado, el bulbo olfatorio recibe un recambio permanente de axones olfatorios procedente de nuevas neuronas receptoras del epitelio olfatorio (Graziadei y Graziadei, 1979). Por otro, a lo largo de la vida adulta, el BO continúa recibiendo el aporte de nuevas neuronas a través de la corriente migratoria rostral (desde la capa subependimal de los ventrículos laterales hasta el BO; Altman, 1969; Luskin 1998). Por ello, el sistema olfatorio representa un modelo perfecto donde estudiar los mecanismos de plasticidad desencadenados a partir de modificaciones exógenas a las que un sistema neuronal responde de modo adaptativo. Existen dos tipos fundamentales de modelos para estudiar la plasticidad neuronal en el sistema 
olfatorio: modelos funcionales, mediante los cuales se consigue la reducción/incremento o la ausencia total de la estimulación periférica y modelos genéticos, consistentes en la carencia o modificación específica de algún gen, de modo que ello induzca la pérdida de selectiva de alguna proteína o grupo celular del sistema olfatorio.

\section{Modelos de deprivación sensorial}

Existen diferentes formas de llevar a cabo la manipulación de la información sensorial que llega a un determinado sistema. Basándose en el grado de preservación física de la vía sensorial tras el proceso de deprivación estos métodos, de forma general, se agrupan en dos. Por un lado, se encuentran los métodos de deaferenciación, en los que la vía sensorial se interrumpe físicamente, de forma parcial o total. Por otro lado, están los métodos de deprivación, caracterizados por preservar la estructura intacta, produciéndose únicamente una reducción drástica de la cantidad o calidad de la información que accede al sistema sensorial.

\section{Deprivación sensorial olfatoria}

La mayoría de los modelos de deprivación sensorial olfatoria se realizan mediante la sutura de una de las narinas, impidiendo así la interacción de las moléculas odorantes con los receptores de las NROs del epitelio nasal sin modificar anatómicamente el sistema (Brunjes, 1994).

El proceso de deprivación sensorial olfatoria acarrea toda una serie de cambios citoarquitectónicos, neuroquímicos y fisiológicos a lo largo de la vía olfatoria primaria (Brunjes, 1994). Citamos, por ejemplo, la disminución del espesor del epitelio olfatorio, el aumento de la expresión de la proteína marcadora olfatoria (OMP) en esta estructura (Cummings y Brunjes, 1994; Waguespack y cols., 2005) o la atenuación de la actividad neuronal en el BOP (Korol y Brunjes, 1990; Best y Wilson, 2003). Además, se han descrito también cambios en el comportamiento en los animales que han sufrido una deprivación olfatoria unilateral, observándose, por ejemplo, que las ratas deprivadas incrementan la frecuencia de agresiones y tienen mayor ansiedad que las ratas control (Loranca y Salas, 2001; Gelhaye y cols., 2006). Respecto a los cambios neuroquímicos, el más drástico es la reducción de la expresión de la tirosina hidroxilasa $(\mathrm{TH})$, enzima limitante de la ruta biosintética de las catecolaminas, y en la actividad NADPH-diaforasa, en las células PGs (Brunjes y 
cols., 1985; Brunjes, 1988, 1994; Baker, 1990; Cho y cols., 1996, Weruaga y cols., 2000). Además, la reapertura nasal de los animales deprivados da lugar a la reexpresión del fenotipo dopaminérgico (Kosaka y cols., 1987). Las evidencias demuestran que la disminución de TH no está acompañada de la degeneración de las neuronas PGs dopaminérgicas, ya que se mantiene la expresión de dopa descarboxilasa y de ácido glutámico decarboxilasa (Kosaka y cols., 1987; Stone y cols., 1991), enzimas que colocalizan con la TH en la mayoría de las células PGs (Baker, 1986).

Por último, las inervaciones centrífugas serotonérgica y noradrenérgica que llegan al BO de ratas deprivadas muestran también cambios plásticos (Gómez y cols., 2006, 2007). La actividad serotonérgica en los BO ipsi y contralateral a la deprivación se encuentra marcadamente disminuida en animales sometidos a deprivación (Gómez y cols., 2007). En cambio, la deprivación olfatoria causa un aumento en la cantidad de noradrenalina y en la densidad de fibras noradrenérgicas tras 60 días de oclusión nasal (Gómez y cols., 2006).

\section{Modelos de enriquecimiento olfatorio}

Otro modelo funcional con el que podemos estudiar la plasticidad neuronal del sistema olfatorio consiste en modificar la entrada de información por exceso en lugar de por defecto, es decir, emplear un ambiente olfatorio enriquecido que incremente la señal olfatoria recibida por el BO. Las condiciones de estos periodos de enriquecimiento dependen del objetivo del estudio, los ensayos varían desde el uso de hierbas aromáticas y cítricos a los odorantes químicos o comerciales. Este tipo de modelos, aunque menos empleados, han dejado resultados de gran relevancia.

Por ejemplo, ratones sometidos a condiciones de enriquecimiento olfatorio durante 40 días sufren un incremento en la cantidad de células proliferativas en la corriente migratoria rostral del sistema olfatorio, así como una mejora en la memoria olfatoria (Rochefort y cols., 2002). Además, el enriquecimiento olfatorio durante los primeros días de vida postnatal produce una disminución de la muerte celular en la CG y en la CGr del BO (Woo y cols., 2006). Por último, partiendo de la base de que existen neuronas de nueva generación también en la CP de ratones adultos (Seki y Arai, 1991; Pekcec y cols., 2006), el trabajo de Shapiro y cols. (2007) muestra que aquellos ratones sometidos a un enriquecimiento olfatorio presentan un incremento en el número de células de nueva generación en la CP debido a un aumento en el 
periodo de supervivencia de estas células (Shapiro y cols., 2007). Este dato corrobora la evidencia de que el procedimiento de enriquecimiento olfatorio incrementa la neurogénesis de nuevas neuronas en el sistema olfatorio, siendo otro modelo a tener en cuenta en el estudio de los cambios plásticos que ocurren a lo largo de la vía olfatoria.

\section{Modelos genéticos}

Otra forma de estudiar el sistema nervioso es a través del uso de animales mutantes, con alteraciones en el desarrollo cerebral o en determinadas poblaciones neuronales del cerebro maduro. El empleo de animales geneticamente modificados permite estudiar los efectos de la carencia o modificación de uno o varios genes que lleven a la pérdida selectiva de alguna proteína o grupo celular del sistema olfatorio.

\section{El ratón knock- out para NOSn}

Los ratones knock-out (KO) son herramientas de gran utilidad, puesto que en ellos se modifica el gen de interés ad hoc. En la presente Tesis Doctoral hemos tomado como uno de los modelos genéticos de plasticidad el ratón KO para la enzima óxido nítrico sintasa neuronal (NOSn). Los animales KO para NOSn (en nuestro trabajo nos referiremos a ellos como animales NOS), carecen de la enzima NOSn en su genoma. Son fenotípicamente indistinguibles de sus hermanos silvestres $(+/+)$. El único rasgo interno que es diferente es que poseen estómagos ligeramente más grandes que los de los animales control; además, tienen alterados los potenciales inhibitorios implicados en la motilidad gastrointestinal (Huang, 1999). Cuando a los mutantes NOS se les provoca isquemias locales, desarrollan infartos más pequeños que los animales control, lo que es consistente con el papel de la NOSn en la neurotoxicidad que sigue a los episodios de isquemia cerebral (Huang, 1999).

La carencia del ON proveniente de la enzima NOSn, influye de manera notable en el comportamiento y las funciones cognitivas. Así, los ratones KO presentan disfunciones en la memoria espacial y el aprendizaje bajo condiciones de estrés, disminución del comportamiento depresivo, hiperactividad y conductas sociales anormales (Weitzdoerfer y cols., 2004; Tanda y cols., 2009). No en vano, ha sido propuesto como modelo animal para el estudio de desórdenes psiquiátricos (Weitzdoerfer y cols., 2004). En relación con el sistema zincérgico, los ratones NOS presentan una disminución en la densidad de terminales ZEN en determinadas 
regiones del hipocampo. Por tanto, la homeostasis normal de zinc se ve afectada cuando no existe ON neuronal. Hasta la fecha se desconoce si este resultado está o no relacionado con las modificaciones cognitivas que muestran los animales NOS. En el caso del BO, existe una gran variedad de poblaciones neuronales que expresan la enzima NOSn: una subpoblación de céulas PGs, la mayoría de los granos, las células superficiales y profundas de axón corto y algunas interneuronas de la CPE (Briñón y cols., 1997; Weruaga y cols., 1998; Kosaka y Kosaka, 2007). A pesar de la importancia de las células que expresan NOSn en el BO, a día de hoy carecemos de estudios comportamentales, neuroquímicos o fisiológicos, en los que se analice si el funcionamiento general del sistema olfatorio en los animales KO para NOSn está o no afectado.

\section{El ratón mutante pcd}

Las mutaciones que provocan degeneraciones postnatales y selectivas de determinados tipos neuronales maduros constituyen una alternativa a los modelos de lesión experimental en el cerebro adulto. Si una mutación induce la neurodegeneración directa de una población neuronal específica, sin la necesidad de intervención de ningún agente externo, contaremos con un modelo más económico, reproducible, constante y sencillo que el obtenido con un procedimiento invasivo.

La mutación pcd produce la degeneración postnatal de aquellas poblaciones neuronales que transcriben el gen nna1 (Fernández-González y cols., 2002). Degeneran las células de Purkinje del cerebelo, las células mitrales del BO, los fotorreceptores y determinadas neuronas de los núcleos talámicos (Mullen y cols., 1976; Landis y Mullen, 1978; Greer y Shepherd, 1982; Valero y cols., 2006; Recio y cols., 2007). La expresión fenotípica de la mutación pcd se manifiesta como una ataxia moderada a partir de la tercera semana de vida postnatal, lo que permite diferenciar a simple vista los individuos mutantes de los normales (Mullen y cols., 1976). A nivel neurohistológico, los individuos mutantes presentan un tamaño del encéfalo menor que el de sus hermanos normales, mostrando una reducción muy significativa en el cerebelo y los BOs. Su peso corporal también es inferior, incluso antes de los primeros síntomas neurológicos (Mullen y cols., 1976).

La pérdida de células mitrales provoca toda una serie de alteraciones en la estructura del BO. En la CG, el tamaño de los glomérulos se reduce con respecto a los animales control. Como causa de esta reducción, se apunta la pérdida de las 
dendritas apicales de las células mitrales que se ramifican en los glomérulos (Greer y Shepherd, 1982). La CPE aparece reducida en grosor y como consecuencia la densidad de células aumenta (Caviness y Sidman, 1972; Caviness y Rakic, 1978). La CPI del ratón mutante parece más gruesa, tal vez sólo como consecuencia de la desaparición de la CCM. Recientemente, se ha demostrado que las capas inframitrales, y en especial la CGr también es responsable de la disminución de volumen del BO en los animales mutantes (Valero y cols., 2007).

Existen algunos aspectos llamativos relacionados con el sistema olfatorio de los ratones mutantes pcd que suceden en relación con la pérdida de las células mitrales. Como resultado lógico de la desaparición del principal elemento de proyección del $\mathrm{BO}$, se observa también una reducción de tamaño del TOL, donde los axones de las células mitrales desaparecen, aunque siguen presentes los axones de las células empenachadas (Mullen y cols., 1976; Bartolomei y Greer, 1998; Recio y cols., 2007). En estos animales, desaparece la mayor parte de la CA, uno de los principales sistemas de comunicación interhemisférica en el cerebro anterior (Baker y Greer, 1990). En los últimos años también se ha descrito un refuerzo en la cantidad de proyecciones procedentes del NOA que se dirigen al BO en estos animales, tras la pérdida de las células mitrales (Recio y cols., 2007). Por último, también se han descubierto modificaciones en algunas de las fases del proceso de neurogénesis de las células de nueva generación que acceden al BO a través de la corriente migratoria rostral (Valero y cols., 2007).

Recientemente estudiamos la situación del sistema zincérgico en el ratón mutante pcd (Airado y cols., 2008). Los resultados de dicho estudio muestran que, en el BO del ratón mutante pcd no se aprecian cambios en el marcaje de los terminales ZEN tanto con el $\mathrm{ZnSe}^{\mathrm{AMG}}$ como con la inmunohistoquimica para $\mathrm{ZnT}$, con respecto a los animales control. No obstante, la distribución de los somas del NOA que proyectan al $\mathrm{BO}$ presenta importantes diferencias entre animales pcd y animales control: por un lado en los animales pcd desaparecen las proyecciones zincérgicas contralaterales del NOA al BO, y por otro, la cantidad de somas ZEN del NOA que inervan al BO se incrementa significativamente en los animales pcd (Airado, 2005; Airado y cols., 2008). De este modo, hoy sabemos que el sistema zincérgico centrífugo que proyecta desde el NOA al BO posee una capacidad plástica en su respuesta a la pérdida neurodegenerativa de las principales celulas de proyeccion del BO (Airado, 2005; Airado y cols., 2008). 


\section{Justificación y Objetivos}

La importancia del zinc en el procesamiento de la información olfatoria se conoce desde hace más de 20 años, hasta tal punto que la deprivación en la dieta de este elemento causa una pérdida significativa en la capacidad de discriminación olfatoria. Sin embargo, hasta el momento, los estudios de los que disponemos acerca de las conexiones zincérgicas que modulan el procesamiento de la información olfatoria son de naturaleza descriptiva, centrándose fundamentalmente en la localización general de los terminales ZEN en el BO de animales control. De hecho, a la vista de los principales estudios mencionados (Jo y cols., 2000, 2002: Airado y cols., 2008), se nos presenta un interrogante respecto al marcaje de los terminales zincérgicos en la $\mathrm{CG}$ del $\mathrm{BO}$, que a nuestro juicio merece atención: mientras que con la inmunohistoquímica para ZnT3 aparece marcada toda la $\mathrm{CG}$, incluyendo el neuropilo glomerular, el marcaje $\mathrm{ZnSe}^{\mathrm{AMG}}$ muestra terminales casi exclusivamente en la región yuxtaglomerular (Jo y cols., 2000; Airado, 2005; Airado y cols., 2008).

Por otro lado, carecemos de estudios pormenorizados que detallen la distribución de las proyecciones zincérgicas en el BO en relación con los elementos intrínsecos a éste. Además, el amplio bagaje de que disponemos actualmente acerca de la sinaptología y neuroquímica de las poblaciones bulbares facilita y propicia el estudio en detalle del sistema zincérgico en esta estructura.

Desde la publicación de los primeros estudios descriptivos acerca del sistema zincérgico en el sistema olfatorio, hace ahora más de 10 años, el sistema zincérgico en general y el del sistema olfatorio en particular, han resultado además estar involucrados no sólo en enfermedades neurodegenerativas como el Alzheimer y el Parkinson sino en la modulación de procesos esenciales en el sistema nervioso, desde la neurotransmisión hasta la neurogénesis. Además, los últimos estudios demuestran que la actuación del zinc como modulador de la sinapsis no se restringe únicamente al sistema glutamatérgico, sino que también puede encontrarse en vesículas presinápticas junto a otros neurotransmisores, modulando la actividad de gran variedad de receptores, pudiendo tener incluso un receptor específico propio.

Por todo ello, el papel que el zinc juega en el sistema nervioso y en concreto en el sistema olfatorio, es más importante de lo que hasta el momento se había considerado, y por tanto, se hace indispensable una revisión y actualización de los conocimientos del sistema zincérgico en el sistema olfatorio. Hemos de comprobar si 
su regulación varía en función de modificaciones fisiológicas, anatómicas y neuroquímicas del propio sistema olfatorio.

En la presente Tesis Doctoral nos hemos propuesto dos grandes objetivos:

1. Realizar un análisis pormenorizado de las proyecciones zincérgicas en el BO de animales control. Para conseguir este objetivo nos propusimos:

a. Estudiar, a microscopía óptica y electrónica, la localización intraglomerular de los terminales ZEN y la aparición, en su caso, de patrones espaciales de marcaje zincérgico en la capa glomerular.

b. Investigar las posibles causas de la aparición de patrones de marcaje diferentes en la $\mathrm{CG}$ con las técnicas inmunohistoquímica para ZnT3 y $\mathrm{ZnSe}{ }^{\mathrm{AMG}}$.

c. Determinar el patrón de distribución del transportador de zinc 3 (ZnT3) en la capa glomerular con respecto a los marcadores neuroquímicos propios de las principales células yuxtaglomerulares.

2. Examinar la plasticidad del sistema modulador zincérgico en el BO. La consecución de este objetivo se hará posible siguiendo las propuestas detalladas a continuación:

a. Analizar las proyecciones ZEN en animales sometidos a condiciones de modulación de la entrada de la información olfatoria, tanto por enriquecimiento como por deprivación olfatoria.

b. Estudiar la implicación del ON en el sistema zincérgico del BO.

c. Comprobar si el proceso neurodegenerativo que ocurre en las células mitrales de los animales mutantes pcd conlleva cambios plásticos en la inervación zincérgica del $\mathrm{BO}$ de estos animales.

d. Establecer un modelo de funcionamiento del sistema zincérgico en el BO relacionando cada componente del sistema zincérgico con los elementos intrínsecos del BO.

Consideramos que estos objetivos nos permitirán un mayor conocimiento de las características estructurales y ultraestructurales del sistema zincérgico en el cerebro olfatorio, así como su capacidad plástica ante cambios enzimáticos, anatómicos y fisiológicos. 

MATERIAL Y MÉTODOS 



\section{Material y métodos}

\section{Animales de experimentación}

Para la consecución de los distintos objetivos planteados en la presente Tesis Doctoral, hemos empleado diferentes modelos experimentales: animales deprivados y animales sometidos a enriquecimiento olfatorio (para comprobar el estado de la inervación zincérgica en el $\mathrm{BO}$ en relación a la información olfatoria recibida); animales mutantes pcd (para estudiar la capacidad plástica del sistema zincérgico tras la pérdida de las principales neuronas de proyección bulbares, las células mitrales); y animales knock-out para la enzima NOSn (para conocer si existe una relación directa entre la reducción de ON y la modulación llevada a cabo por el zinc en el BO).

Todos los animales se mantuvieron, manipularon y sacrificaron según las líneas establecidas en la directiva de Consejo de las Comunidades Europeas (86/609/EEC) y la legislación española (RD 1201/2005 y Ley 32/2007) vigentes para el uso y cuidado de animales de laboratorio. Además, los procedimientos que se han empleado fueron previamente aprobados por el Comité de Bioética de la Universidad de Salamanca.

\section{Animales control}

Como control se utilizaron ratones silvestres $(+/+)$ C57/6J-DBA/2J de entre 90 y 120 días de edad postnatal. En el caso de los estudios de plasticidad relacionados con el $\mathrm{ON}$, utilizamos como animales control, ratones silvestres $(+/+)$, machos y hembras de la estirpe B6; 129S4-Nos1 ${ }^{\text {tm1Plh }}$, de entre 60 y 90 días de edad postnatal.

\section{Animales knock- out para NOSn}

Los ratones KO para la enzima NOSn pertenecen a la estirpe B6; 129S4Nos $1^{\text {tm1Plh }}$. Los ratones KO para NOSn se cruzaron con animales silvestres de la estirpe 129 para obtener los ratones silvestres $(+/+)$ y los $\mathrm{KO}$ (nos/nos) empleados en esta Tesis Doctoral. Puesto que fenotípicamente los animales NOS no se distinguen de los controles, se empleó la técnica de la PCR (Polymerase chain reaction), para amplificar los marcadores moleculares adecuados que nos permitieron la correcta identificación del genotipo de los animales de esta colonia. 


\section{Animales mutantes pcd}

Empleamos ratones mutantes homocigotos para la mutación Purkinje Cell Degeneration $(p c d / p c d)$, machos y hembras, de 120 días de edad. La estirpe C57BL/6J, portadora de la mutación pcd (Purkinje Cell Degeneration), se cruzó con individuos de la estirpe DBA/2J. De este modo, la estirpe "híbrida" resultante es portadora de la mutación y además prolífica. Los animales mutantes se distinguen fácilmente porque presentan ataxia cerebelosa detectable desde temprana edad (2030 días).

\section{Animales deprivados}

Para los modelos de deprivación y enriquecimiento tomamos animales control. A los 20 días tras su nacimiento, los ratones fueron sometidos a la manipulación quirúrgica dirigida a producir la deprivación sensorial olfatoria unilateral. La operación fue llevada a cabo bajo anestesia inducida mediante la inyección intramuscular de $1 \mathrm{ml} / \mathrm{kg}$ de peso corporal de la mezcla de xilacina (Rompun ${ }^{\circledR}$, Química Farmacéutica Bayer, Barcelona. Fabricado por Bayer, Leverkusen. Alemania) y clorhidrato de ketamina (Imalgene ${ }^{\circledR}$ 1000, Merial Laboratorios Barcelona. Fabricado por Merial, Lyon. Francia) en una proporción 3:4. Una vez anestesiados, fueron colocados bajo la lupa donde, mediante un electrocoagulador (Electrobisturí Coagulador, modelo 970, AB Médica, Barcelona), se les aplicó pulsos de corriente tanto en la pared interna como externa de la fosa nasal, consiguiendo que la piel de ambos lados de la narina se uniera entre sí y se produjera el cierre completo de la parte externa de la cavidad nasal. Posteriormente, los ratones fueron reanimados bajo una fuente de calor y devueltos a sus jaulas correspondientes. La correcta oclusión de la narina fue comprobada periódicamente bajo la lupa y sólo aquellos animales cuya narina permaneció perfectamente cerrada, en todos los exámenes (30 días), fueron utilizados para nuestros estudios. Dos de los animales se utilizaron como control de deprivación, les realizamos la operación quirúrgica sometiéndolos al mismo procedimiento pero sin llegar a cerrar el orificio nasal por completo.

\section{Animales sometidos a enriquecimiento olfatorio}

El enriquecimiento olfatorio se llevó a cabo de dos formas. Un grupo de animales fue sometido a un proceso de enriquecimiento de larga duración temporal 
con 20 odorantes naturales diferentes, mientras que el otro, fue enriquecido únicamente durante el momento del sacrificio del animal con una única sustancia odorante. Los ratones silvestres que participaron en la primera prueba se sometieron durante 20 días al proceso de enriquecimiento olfatorio según el modelo de Rochefort y cols. (2002), que emplea bolas de té como soporte para colocar las fragancias aromáticas naturales en $\mathrm{su}$ interior. Colocamos el odorante correspondiente en el interior de la bola de té y ésta en el interior de la jaula, colgando de la rejilla de la misma. Los animales fueron expuestos a 20 sustancias olorosas diferentes consecutivamente durante 20 días, haciéndose el intercambio siempre a la misma hora, de modo que los animales estuviesen cercanos a cada fragancia 24 horas. La lista de odorantes se adjunta en la tabla 1.

Los animales control utilizados en estos experimentos se mantuvieron en iguales condiciones pero con una bola de té vacía que diariamente se les quitaba y se les volvía a colocar de nuevo a la misma hora que se hacía el cambio de fragancia en el grupo experimental.

\begin{tabular}{|c|c||c|c||c|c||c|c|}
\hline Día & Odorante & Día & Odorante & Día & Odorante & Día & Odorante \\
\hline 1 & Espliego & 6 & Romero & 11 & Hinojo & 16 & Anís \\
\hline 2 & Ajo & 7 & Nuez moscada & 12 & Valeriana & 17 & Jengibre \\
\hline 3 & Pimentón & 8 & Tomillo & 13 & Clavo & 18 & Limón \\
\hline 4 & Menta & 9 & Eneldo & 14 & Chocolate & 19 & Naranja \\
\hline 5 & Curry & 10 & Eucalipto & 15 & Canela & 20 & Plátano \\
\hline
\end{tabular}

Tabla 1. Sustancias olorosas empleadas en el proceso de enriquecimiento olfatorio siguiendo el modelo de Rochefort y cols., (2002).

Los animales sometidos a enriquecimiento durante su sacrificio, no fueron sometidos a una prueba de enriquecimiento mantenida durante 20 días, sino que contaron únicamente con una fuente odorífera cercana a las fosas nasales durante la perfusión (ver apartado sacrificio y disección). Los odorantes empleados fueron acetona, xileno o clavo. 


\section{Procedimientos previos al sacrificio}

\section{Inyecciones de selenito sódico}

De todos los métodos nombrados para marcar el zinc, elegimos el método indirecto del selenio por su efectividad y sencillez en la aplicación, en comparación con el resto de métodos indirectos descritos. Con este procedimiento, los iones zinc se unen in vivo y, en función del tiempo de espera entre la inyección y el sacrificio, somos capaces de observar el marcaje en los terminales zincérgicos o en los somas ZEN de origen.

\section{Marcaje de terminales ZEN}

Para el trazado de los terminales ZEN los ratones fueron anestesiados con una inyección intramuscular de $1 \mathrm{ml} / \mathrm{kg}$ de peso corporal de la misma anestesia empleada para la deprivación olfatoria (ver apartado anterior), y posteriormente se les inyectó vía i.p. una solución de $20 \mathrm{mg}$ de selenito sódico $\left(\mathrm{Na}_{2} \mathrm{SeO}_{3}\right) / \mathrm{kg}$ de peso corporal del animal, en agua destilada. Transcurrida una hora, los animales se sacrificaron por perfusión intracardiaca (ver apartado siguiente).

\section{Controles de la técnica}

Para detectar posibles precipitados inespecíficos de los iones de plata sobre el tejido que no se deban a la presencia de zinc, se llevaron a cabo inyecciones previas de DEDTC (dietilditiocarbamato sódico trihidrato, Merck, Alemania) en dos animales control. Dicha sustancia es un agente quelante de zinc, que elimina el zinc disponible para su unión con el selenio en las vesículas presinápticas. La dosis de DEDTC para cada animal fue de $1 \mathrm{~g} / \mathrm{kg}$ de peso corporal, disuelto en agua destilada e inyectado i.p. $1 \mathrm{~h}$ antes de que el tejido entrase en contacto con el selenito sódico. En ninguno de los animales inyectados con DEDTC se observó precipitado de plata sobre las secciones reveladas, confirmándose la especificidad del marcaje.

\section{Inyecciones de cloruro de zinc}

Para intentar provocar una sobrecarga de zinc en las neuronas ZEN y por sugerencia personal del Profesor Gorm Danscher (Instituto de Anatomía de la Universidad de Aarhus, Dinamarca), tras la anestesia, realizamos inyecciones i.p. de cloruro de zinc $\left(\mathrm{ZnCl}_{2}, 2 \mathrm{mg} / \mathrm{kg}\right.$ peso corporal, en agua destilada), $1 \mathrm{~h}$ antes del tratamiento i.p. con $\mathrm{Na}_{2} \mathrm{SeO}_{3}$. Empleamos dos ratones como control, de modo que 
uno de ellos no fue inyectado con $\mathrm{ZnCl}_{2}$ pero sí con $\mathrm{Na}_{2} \mathrm{SeO}_{3}$ y el otro sí con $\mathrm{ZnCl}_{2}$ pero no con $\mathrm{Na}_{2} \mathrm{SeO}_{3}$. En el último caso no observamos ningún tipo de marcaje tras el revelado AMG normal del tejido.

\section{Obtención y preparación del tejido para técnicas morfológicas}

\section{Sacrificio y disección}

Los animales fueron profundamente anestesiados con $1,5 \mathrm{ml} / \mathrm{kg}$ de peso corporal de la misma mezcla de anestesia. El efecto anestésico se comprobó por la ausencia de reflejo palpebral. Posteriormente, se procedió a la fijación del tejido mediante perfusión intracardiaca. Tras la apertura de la caja torácica se inyectaron 0,1 $\mathrm{ml}$ de heparina sódica (1000 u.i./ml, Sigma-Aldrich, St. Louis, MO, EE.UU.) en el ventrículo izquierdo, evitando así la formación de coágulos sanguíneos. A continuación se conectó, mediante una cánula, una bomba peristáltica a la aorta y, sólo en el caso de los animales destinados a las pruebas inmunohistoquímicas, se hizo pasar por ella una solución lavadora. Después, todos los animales se perfundieron haciendo pasar $100 \mathrm{ml}$ de una solución fijadora. En el caso del $\mathrm{ZnSe}^{\mathrm{AMG}}$ para la detección de zinc vesicular, la solución fijadora fue glutaraldehído al 3\% en tampón Sørensen 0,15 M, pH 7.4. (TS). La solución fijadora empleada en los animales destinados a las pruebas inmunohistoquímicas fue paraformaldehído al 4\% en tampón fosfato 0,1 M pH 7.4 (TF). Tras la perfusión, se extrajo el encéfalo y con la ayuda de una matriz cerebral con planos coronales (Electron Microscopy Sciences, Fort Washington, PA, EE.UU.), se dividió en dos bloques: rostral y caudal.

Los bloques de tejido se postfijaron por inmersión durante 3 horas en la misma solución fijadora, a temperatura ambiente y en agitación. Posteriormente, los bloques procesados para microscopía óptica se sumergieron en una solución crioprotectora de sacarosa al $30 \%(\mathrm{p} / \mathrm{v})$ en TS en agitación a $4{ }^{\circ} \mathrm{C}$ para su posterior almacenamiento en congelación. Los bloques destinados al procesamiento para microscopía electrónica se lavaron varias veces en TS tras la postfijación, antes de proceder a su seccionamiento. 


\section{Corte del tejido}

Los bloques de tejido para microscopía óptica se cortaron en secciones de 40 $\mu \mathrm{m}$ de grosor en planos coronales, en un microtomo de deslizamiento (Leica, Jung, SM 2000, Nussloch, Alemania) acoplado a una fuente de frío (Leica Frigomóbil, Nussloch, Alemania). Las secciones se recogieron en flotación en 6 series consecutivas, en TS si se iban a revelar seguidamente, o en TF, si se iban a emplear para técnicas inmunohistoquímicas. Las series que no iban a ser procesadas en el momento, se almacenaron a $-20{ }^{\circ} \mathrm{C}$ en una mezcla congeladora compuesta de $20 \%$ de

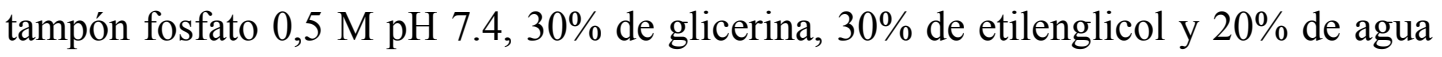
destilada.

Los bloques de tejido destinados a ser procesados para su visualización al microscopio electrónico se cortaron en un vibratomo (vibratomo HM650V, Microm, Termo Fisher Scientific, Walldorf, Alemania) en secciones coronales de $100 \mu \mathrm{m}$ de grosor. Las secciones se recogieron en TS en una placa de 12 pocillos.

\section{Revelado autometalográfico}

Inmediatamente después del corte, las secciones se montaron manteniendo el orden rostro-caudal sobre portaobjetos de cristal previamente sumergidos en la solución limpiadora de Farmer (ferricianuro potásico al 10\% y tiosulfato sódico al $10 \%$ en proporción 1:9) y posteriormente gelatinizados. Una vez secas, las secciones se sumergieron en un medio revelador a $26-28{ }^{\circ} \mathrm{C}$ en oscuridad y agitación durante 60 minutos. Los componentes para $100 \mathrm{ml}$ de revelador son los siguientes:

- Goma arábiga $(50 \%$ p/v, 60 ml, Panreac, Barcelona). Se prepara en agua destilada; se mantiene en agitación hasta su completa disolución (cuatro días aproximadamente) y posteriormente se filtra tres veces con una, dos y tres gasas, respectivamente. La goma arábiga actúa como coloide, inhibiendo las interacciones autocatalíticas entre los iones de plata y las moléculas reductoras y además mantiene una distribución homogénea de los iones de plata durante el revelado.

- Tampón citrato sódico $(0,2 \mathrm{M}, 10 \mathrm{ml}$, Merck). Se prepara mezclando 2,35 g de ácido cítrico monohidrato (Merck) con 2,55 g de citrato trisódico dihidrato (Merck), enrasando hasta $10 \mathrm{ml}$ con agua destilada.

- Hidroquinona (5,6\% p/v, $15 \mathrm{ml}$, Merck). Se disuelve en $15 \mathrm{ml}$ de $\mathrm{H}_{2} \mathrm{O}$ destilada a $40^{\circ} \mathrm{C}$. Actúa como agente reductor. 
- Lactato de plata $(0,8 \% \mathrm{p} / \mathrm{v}, 15 \mathrm{ml}$, Electron Microscopy Sciences). Disuelto en $\mathrm{H}_{2} \mathrm{O}$ destilada a $40{ }^{\circ} \mathrm{C}$ en un recipiente protegido de la luz. Es la fuente de iones de plata. Se prepara en último lugar y se añade inmediatamente después de su preparación, para prevenir la aparición de precipitados autocatalíticos.

Transcurrida la hora de incubación, los portaobjetos se pasaron por tiosulfato sódico al 5\%(p/v) durante 10 minutos para detener la reacción. Después de un lavado en $\mathrm{H}_{2} \mathrm{O}$ destilada, las secciones fueron contrastadas con azul de toluidina al $0,1 \% \mathrm{p} / \mathrm{v}, \mathrm{pH} 4$ durante 5-10 minutos y enjuagadas de nuevo en $\mathrm{H}_{2} \mathrm{O}$ destilada. Finalmente, todas las secciones fueron deshidratadas en una batería de alcoholes, aclaradas en xilol y montadas con Entellán (Merck) y cubreobjetos para su posterior visualización bajo el microscopio.

Con objeto de observar por un lado, la posible existencia de precipitados formados de modo autocatalítico en el revelador; y por otro si el tejido presentaba de modo natural algún compuesto de características similares a los complejos de selenio y zinc que actuase por sí mismo como centro activo para el proceso autometalográfico, realizamos el siguiente control negativo: tomamos secciones de tejido de un ratón control no tratado con selenito sódico y las sometimos al revelado autometalográfico. Dichas secciones aparecieron completamente limpias de cualquier precipitado inespecífico que pudiera enmascarar los resultados obtenidos en los animales tratados con selenito sódico.

Las secciones destinadas a su observación a microscopía electrónica se revelaron en flotación. Para ello el TS de la placa se sustituyó por la misma solución reveladora anteriormente descrita, durante 60 minutos en las mismas condiciones de oscuridad y agitación a $26-28{ }^{\circ} \mathrm{C}$. Posteriormente, se lavaron durante 10 minutos con tiosulfato sódico al 5\% y finalmente se mantuvieron en TS hasta su inclusión en resina.

\section{Procesado final de las muestras para microscopía electrónica}

Las secciones seleccionadas de BO se postfijaron durante media hora con tetróxido de osmio al 1\% (p/v) junto con ferricianuro potásico al 1\% (p/v) diluidos en agua destilada. Posteriormente, se lavaron toda la noche con agua destilada, se deshidrataron en pasos de 10 minutos siguiendo una batería de alcoholes de 
gradación creciente $\left(50^{\circ}-100^{\circ}\right)$ continuando con una inmersión en óxido de propileno (dos pasos de 10 minutos).

Al día siguiente realizamos la inclusión en resina EPON (Electron Microscopy Sciences) en distintos pasos de concentración creciente (óxido de propileno:resina en proporciones $3: 1,1: 1$; y $1: 3)$ y por último, las muestras en resina pura se dejaron en la estufa a $65{ }^{\circ} \mathrm{C}$ durante una noche para que la resina polimerizase.

Finalmente los bloques se cortaron con un ultramicrotomo (Leica Ultracut UCT, Nussloch, Alemania). Se practicaron cortes semifinos de $1 \mu \mathrm{m}$ de grosor que se tiñeron con azul de toluidina para seleccionar las zonas del BO más adecuadas para su posterior estudio ultraestructural. En las regiones de interés, se realizaron secciones ultrafinas de $50 \mathrm{~nm}$ de espesor que se recogieron en rejillas niqueladas recubiertas de una película de Formvar (Sigma-Aldrich) y se contrastaron con acetato de uranilo al 2\% (p/v Merck) y una solución de citrato de plomo (compuesta por 2,66 $\mathrm{g}$ de nitrato de plomo, 3,52 $\mathrm{g}$ de citrato sódico dihidratado y $0,8 \mathrm{~g}$ de hidróxido sódico, disueltos en agua destilada, según Reynolds, 1963) para su observación con un microscopio electrónico ZEISS EM 900 (Jena, Alemania).

\section{Detecciones inmunohistoquímicas}

\section{Tinciones de Inmunofluorescencia}

Para llevar a cabo los dobles marcajes (ZnT3 - marcadores de las poblaciones celulares del BO) empleamos la técnica de inmunofluorescencia. Las secciones se lavaron con TFS (3 x $10 \mathrm{~min}$ ). A continuación realizamos una recuperación antigénica de los epítopos de la proteína que, tras diferentes pruebas, observamos mejoraba considerablemente el marcaje fluorescente. Para ello incubamos los cortes en una solución compuesta por Tris pH $7.420 \mathrm{mM}, \mathrm{NaCl} 30 \mathrm{mM}$, SDS 0,2\% p/v y EDTA 2,5 mM. A continuación, las secciones se incubaron durante 72 horas en un medio que contenía TFS, suero normal de cabra (5\% v/v) y Triton X-100 al 0,2\% p/v y donde se diluyeron los dos anticuerpos primarios según la tabla 2. Transcurridas las 72 horas de incubación, las secciones se lavaron en TFS (3 x 10 min). A continuación se incubaron durante 2 horas, en agitación constante, a temperatura ambiente y en oscuridad, los dos anticuerpos secundarios conjugados con partículas 
fluorescentes (tabla 2), que previamente habían sido diluidos en TFS a una concentración de 1:200.

En aquellos casos en los que se necesitó un contrastado celular, se añadió ioduro de propidio (IP) en concentración 1:2000 en TFS. Se incubó en oscuridad durante la última media hora junto con los anticuerpos secundarios. Por último, se lavaron las secciones en TFS ( 3 x $10 \mathrm{~min}$ ), se montaron sobre portaobjetos gelatinizados y se cubrieron con una solución "anti-desvanecimiento" que permitía mantener la fluorescencia de los cortes, constituída por glicina $0,42 \%(\mathrm{p} / \mathrm{v}), \mathrm{NaOH}$ $0,021 \%(\mathrm{p} / \mathrm{v}), \mathrm{NaCl} 0,51 \%(\mathrm{p} / \mathrm{v}), N$-propil-galato $5 \%(\mathrm{p} / \mathrm{v})$, glicerol $70 \%$ y timerosal $0,002 \%(\mathrm{p} / \mathrm{v})$.

\section{Controles de especificidad}

Para verificar la especificidad de la reacción se realizaron los siguientes controles:

1. Eliminación del anticuerpo primario en la primera incubación, para detectar posibles uniones inespecíficas del anticuerpo secundario al tejido. En el caso de las dobles inmunofluorescencias también realizamos la incubación con uno de los dos anticuerpos primarios y adición del anticuerpo secundario correspondiente al anticuerpo primario omitido para detectar uniones cruzadas.

2. Omisión de los anticuerpos secundarios para detectar la emisión de fluorescencia inespecífica.

En ninguno de los casos se observaron elementos marcados debido a falsos positivos por uniones inespecíficas, aunque sí una tinción de fondo inespecífica muy ligera. 


\begin{tabular}{|c|c|c|c|c|c|}
\hline $\begin{array}{l}\text { Anticuerpos } \\
\text { primarios }\end{array}$ & {$[A c]$} & $\begin{array}{c}\text { Casa } \\
\text { comercial }\end{array}$ & $\begin{array}{l}\text { Anticuerpos } \\
\text { secundarios }\end{array}$ & {$[A c]$} & $\begin{array}{c}\text { Casa } \\
\text { comercial }\end{array}$ \\
\hline $\begin{array}{c}\text { Conejo } \\
\text { A-ZnT3 } \\
\text { Policlonal } \\
\text { (IP) } \\
\end{array}$ & $1: 400$ & $\begin{array}{l}\text { Cedido por Dr. } \\
\text { Palmiter }\end{array}$ & $\begin{array}{c}\text { CY3-Burro anti- } \\
\text { conejo } \\
\text { (CY5-Cabra } \\
\text { anti-conejo) }\end{array}$ & $1: 200$ & $\begin{array}{c}\text { Jackson } \\
\text { Immunoresearch } \\
711-165-152 \\
111-175-084 \\
\end{array}$ \\
\hline $\begin{array}{c}\text { Cabra } \\
\text { A-OMP } \\
\text { Monoclonal }\end{array}$ & 1:10000 & $\begin{array}{c}\text { Wako } \\
\text { 544-10001-Wako }\end{array}$ & $\begin{array}{c}\text { CY2-Burro anti- } \\
\text { cabra }\end{array}$ & $1: 200$ & $\begin{array}{c}\text { Jackson } \\
\text { Immunoresearch } \\
115-225-003\end{array}$ \\
\hline $\begin{array}{c}\text { Ratón } \\
\text { A-MAP2 } \\
\text { Monoclonal }\end{array}$ & 1:1000 & $\begin{array}{l}\text { Sigma } \\
\text { M9942 }\end{array}$ & $\begin{array}{l}\text { CY2-Cabra } \\
\text { anti-ratón }\end{array}$ & $1: 200$ & $\begin{array}{c}\text { Jackson } \\
\text { Immunoresearch } \\
115-225-003\end{array}$ \\
\hline $\begin{array}{c}\text { Ratón } \\
\text { A-GAD67 } \\
\text { Monoclonal }\end{array}$ & 1:1000 & $\begin{array}{l}\text { Chemicon } \\
\text { Millipore } \\
\text { MAB5406 }\end{array}$ & $\begin{array}{l}\text { CY2-Cabra } \\
\text { anti-ratón }\end{array}$ & $1: 200$ & $\begin{array}{c}\text { Jackson } \\
\text { Immunoresearch } \\
115-225-003\end{array}$ \\
\hline $\begin{array}{c}\text { Ratón } \\
\text { A-TH } \\
\text { Monoclonal }\end{array}$ & 1:7000 & $\begin{array}{c}\text { Chemicon } \\
\text { Millipore } \\
\text { P07101 }\end{array}$ & $\begin{array}{l}\text { CY2-Cabra } \\
\text { anti-ratón }\end{array}$ & $1: 200$ & $\begin{array}{c}\text { Jackson } \\
\text { Immunoresearch } \\
115-225-003\end{array}$ \\
\hline $\begin{array}{c}\text { Ratón } \\
\text { A-CB } \\
\text { Monoclonal }\end{array}$ & 1:2000 & $\begin{array}{c}\text { Swant } \\
300\end{array}$ & $\begin{array}{l}\text { CY2-Cabra } \\
\text { anti-ratón }\end{array}$ & $1: 200$ & $\begin{array}{c}\text { Jackson } \\
\text { Immunoresearch } \\
115-225-003\end{array}$ \\
\hline $\begin{array}{c}\text { Ratón } \\
\text { A-GFAP } \\
\text { Monoclonal }\end{array}$ & $1: 2000$ & $\begin{array}{l}\text { Sigma } \\
\text { G6171 }\end{array}$ & $\begin{array}{l}\text { CY2-Cabra } \\
\text { anti-ratón }\end{array}$ & $1: 200$ & $\begin{array}{c}\text { Jackson } \\
\text { Immunoresearch } \\
115-225-003\end{array}$ \\
\hline $\begin{array}{l}\text { Ratón A-CR } \\
\text { Monoclonal }\end{array}$ & 1:2000 & $\begin{array}{c}\text { Swant } \\
6 B_{3}\end{array}$ & $\begin{array}{l}\text { CY2-Cabra } \\
\text { anti-ratón }\end{array}$ & $1: 200$ & $\begin{array}{c}\text { Jackson } \\
\text { Immunoresearch } \\
115-225-003 \\
\end{array}$ \\
\hline $\begin{array}{c}\text { Oveja } \\
\text { A-NOSn } \\
\text { Monoclonal }\end{array}$ & 1:15000 & $\begin{array}{l}\text { Cedido por Dr. } \\
\text { Emson }\end{array}$ & $\begin{array}{c}\text { anti-oveja } \\
\text { biotinado y } \\
\text { estreptavidina } \\
\text { CY2 }\end{array}$ & $1: 200$ & $\begin{array}{c}\text { Jackson } \\
\text { Immunoresearch } \\
016-220-084\end{array}$ \\
\hline
\end{tabular}

Tabla 2. Anticuerpos utilizados en las dobles inmunofluorescencias realizadas en este trabajo.

\section{Documentación}

Tras la realización de las técnicas de tinción (revelado por AMG de las inyecciones de selenio e inmunoflurescencias) las secciones fueron estudiadas al microscopio. Las imágenes que ilustran la presente Tesis se seleccionaron de entre todas las preparaciones obtenidas y se captaron mediante un fotomicroscopio (Olympus Provis AX70, Tokio, Japón) equipado con campo claro y epifluorescencia, conectado a una cámara digital (Olympus U- DP70). Las imágenes de fluorescencia se obtuvieron bien mediante este mismo microscopio o bien mediante microscopía 
confocal (Leica TCS SP2, Mannheim, Alemania). Las imágenes tomadas con la cámara acoplada al microscopio electrónico fueron procesadas con el programa Image SP viewer (Tröndle Restlichtverstärkersysteme, TRS \& Sys Prog, Alemania) para ajustar las barras de escala. Posteriormente, todas las imágenes se procesaron digitalmente con Adobe Photoshop 7.0 (Adobe Systems Incorporated, San José, EE.UU.) para igualar el brillo, el contraste y el balance de color.

\section{Análisis de imágenes}

\section{Distribución del ZnT3 en la CG}

Para el análisis de la distribución de la proteína ZnT3 en la CG tomamos fotografías de planos focales del doble marcaje ZnT3-OMP correspondientes a 114 glomérulos, de todas las regiones del $\mathrm{BO}$ en diferentes niveles rostro-caudales. Puesto que el marcaje de OMP en el glomérulo olfatorio es exclusivo de las terminaciones del nervio olfatorio (NO), todos los puntos de colocalización de ambos marcadores situarán al transportador de zinc en el NO mientras que los que no lo hagan, indicarán que el transportador de zinc no pertenece a los axones de las NROs. Para realizar el análisis empleamos el software del propio microscopio confocal Leica (Leica Confocal Software versión 2.5). Delimitamos el contorno de cada glomérulo de estudio. Determinamos los píxeles positivos para cada marcador por separado, eliminando el marcaje de fondo. De este modo, los píxeles que fueron positivos para ambos marcadores en la zona delimitada se correspondían con puntos de colocalización. Para excluir las irregularidades debidas a la individualidad de cada glomérulo (mayor o menor tamaño de cada uno, vasos o huecos delimitados o no a la hora de hacer el contorno, etc.) referimos los datos como \% de píxeles ZnT3 positivos que colocalizan con OMP en cada glomérulo de estudio.

\section{Estudio de las células ZnT3 positivas}

El estudio de colocalización de ZnT3 con otros marcadores lo realizamos a partir de planos focales tomados en la CG del BO tanto de animales control como de animales KO para NOSn y mutantes pcd. En cada uno de los planos focales, todos realizados al mismo aumento, contamos el número total de células positivas para cada marcador (enzimas TH, ácido glutámico descarboxilasa 67 o GAD67 y NOSn, y las proteínas ligantes de calcio calbindina o $\mathrm{CB}$, y calretinina o $\mathrm{CR}$ ), el número de células ZnT3-positivas y el número de células doblemente marcadas (ZnT3-marcador 
correspondiente). La densidad de células positivas para cada uno de los marcadores por separado la expresamos como $\mathrm{n}^{\mathrm{o}}$ de células/área. La proporción de células ZnT3 que pertenecen a cada una de las poblaciones estudiadas se calculó como el producto del número de células ZnT3 que colocalizan/ no células ZnT3 totales x 100. Para el estudio de las células empenachadas ZnT3-positivas empleamos las mismas fotos de las colocalizaciones ZnT3-GAD67. En dichas fotos realizamos un recuento de la cantidad de células empenachadas-ZnT3 positivas que aparecían en cada glomérulo. Los resultados se expresan en $\mathrm{n}^{0}$ de células empenachadas ZnT3-positivas/glomérulo.

\section{Densidad de ZnT3 en la CG}

Para el análisis de la densidad de la proteína ZnT3 en la CG de los ratones KO para NOSn y mutantes pcd, tomamos fotografías de planos focales del marcaje ZnT3 correspondientes a glomérulos seleccionados aleatoriamente tanto en animales control como en los animales pcd y NOS.

En cada glomérulo, seleccionamos los píxeles positivos y los tapamos con la máscara (fig. 32, cuadros en la esquina superior derecha de cada foto). Para eliminar los píxeles correspondientes al fondo y que pueden enmascarar los resultados, colocamos tres líneas en cada glomérulo en los lugares donde consideramos que el color de la imagen no era marcaje específico. Teniendo en cuenta que el píxel 0 es el de menor intensidad y el 255 el de intensidad máxima, anotamos los valores de máxima intensidad para cada una de las líneas y eliminamos los píxeles desde el 0 hasta el valor máximo anotado. De esta forma que sólo realizamos el recuento de densidad con los píxeles que eran verdaderamente positivos. Tomamos el número de píxeles cubiertos por la máscara dentro de cada glomérulo y expresamos los valores en porcentajes, como píxeles ZnT3 positivos/píxeles totales que conforman un glomérulo x 100 .

\section{Técnicas de Biología Molecular}

\section{Extracción de RNA}

Los animales se sacrificaron mediante dislocación cervical. Se extrajeron rápidamente los $\mathrm{BOs}$ (ambos analizados como una única muestra de cada animal) y bloques de tamaño equivalente de cerebelo, hígado, músculo y testículo. Seguidamente, se homogeneizó el tejido, utilizando un Poly-tron (PT2100, 
Kinematica AG, Littau, Suiza), en $350 \mu 1$ de TRIzol y se dejó reposar durante 5 min a temperatura ambiente. Posteriormente, se añadieron $70 \mu 1$ de cloroformo, se mezcló bien y se centrifugó a $4{ }^{\circ} \mathrm{C}$ durante 15 min a 12.000 g. A continuación, se recogió la fase acuosa y se transfirió a un eppendorf estéril, donde se añadieron $175 \mu \mathrm{l}$ de isopropanol, mezclándolo bien para conseguir precipitar el ARN. Se dejó reposar a temperatura ambiente $(10 \mathrm{~min})$ y posteriormente se centrifugó a $4{ }^{\circ} \mathrm{C}$ durante $20 \mathrm{~min}$, a una velocidad de $12.000 \mathrm{~g}$. Se eliminó el sobrenadante, y se lavó el pellet con $35 \mu 1$ de etanol frío $\left(-20{ }^{\circ} \mathrm{C}\right)$ al $75 \% \mathrm{v} / \mathrm{v}$. De nuevo, se centrifugó $(5 \mathrm{~min})$ a $4{ }^{\circ} \mathrm{C}$ y a una velocidad de $7.500 \mathrm{~g}$. Se eliminó el sobrenadante, se dejó secar el pellet de ARN y se resuspendió en un volumen de $12 \mu \mathrm{l}$ de $\mathrm{H}_{2} \mathrm{O}_{\text {DEPC }}\left(\mathrm{H}_{2} \mathrm{O}\right.$ destilada que tratada previamente durante $12 \mathrm{~h}$ con $1 \mathrm{ml} / 1$ de dietilpirocarbonato (Sigma), y autoclavada posteriormente). El ARN resultante se cuantificó (Nanophotometer, IMPLEN, Munich, Alemania) y almacenó a $-80^{\circ} \mathrm{C}$ hasta se utilización. Durante todo el proceso se utilizó material libre de RNAasas, esterilizado previamente en el autoclave.

\section{Retrotranscripción}

El proceso de retrotranscripción se realizó utilizando el kit $\operatorname{ImPromII}^{\mathrm{TM}}$ Reverse Transcription System (Promega). Este proceso se llevó a cabo en dos pasos. En el paso 1 se mezclaron $100 \mathrm{ng}$ de ARN de cada muestra con $1 \mu 1$ de hexámeros de secuencias al azar (como cebadores) y $\mathrm{H}_{2} \mathrm{O}_{\text {DEPC }}$, hasta un volumen final de $5 \mu 1$ por muestra. A continuación, las muestras se sometieron a un ciclo de $70{ }^{\circ} \mathrm{C}$ durante 5 min en el termociclador (Primus, MWG- Biotech, Vernon Hills, Illinois, EE.UU.). Posteriormente (paso 2) se añadieron a cada muestra $15 \mu 1$ de un medio que contenía:

$\mathrm{H}_{2} \mathrm{O}$ DEPC $(6,1 \mu \mathrm{l})$

$\mathrm{MgCl}_{2}(25 \mathrm{mM} ; 2,4 \mu \mathrm{l})$

Inhibidor de nucleasas $(1 \mathrm{U} / \mu \mathrm{l} ; 0,5 \mu \mathrm{l})$

Desoxinucleótidos trifosfato $(10 \mathrm{mM} ; 1 \mu \mathrm{l})$

Tampón ImpromII 5X (4 $\mu 1)$

Transcriptasa inversa $(1 \mu \mathrm{l})$

Y se llevó a cabo la retrotranscripción según los siguientes ciclos de temperatura (tabla 3): 


\section{Paso Tiempo $\mathbf{T}^{\mathrm{a}} \quad$ Función}

\begin{tabular}{|l|l|l|l|}
\hline 1 & $5 \mathrm{~min}$ & $70^{\circ} \mathrm{C}$ & Desnaturalización de cebadores y ARN \\
\hline 2 & $5 \mathrm{~min}$ & $4^{\circ} \mathrm{C}$ & Preservación del ARN durante la adición del medio \\
\cline { 2 - 4 } & $5 \mathrm{~min}$ & $25^{\circ} \mathrm{C}$ & Anillamiento de los cebadores al ARN \\
\cline { 2 - 4 } & 1 hora & $42^{\circ} \mathrm{C}$ & Extensión de la cadena \\
\cline { 2 - 4 } & $15 \mathrm{~min}$ & $70^{\circ} \mathrm{C}$ & Inactivación de la transcriptasa inversa \\
\cline { 2 - 4 } & $\infty$ & $4^{\circ} \mathrm{C}$ & Mantenimiento del ADNc \\
\hline
\end{tabular}

Tabla 3. Ciclos de temperatura para la retrotranscripción.

A partir de $100 \mathrm{ng}$ de ARN se obtuvo una concentración final de $5 \mathrm{ng} / \mu \mathrm{l}$ de ADNc en un volumen final de $20 \mu 1$.

\section{Reacción en cadena de la polimerasa (PCR)}

La técnica de la reacción en cadena de la polimerasa (PCR) permite obtener un gran número de copias de un fragmento de ADN determinado a partir de muy poca cantidad de ADN original, en un corto periodo de tiempo (Mullis y cols., 1986). Los cebadores empleados para amplificar secuencias correspondientes al ADNc del ZnT3 fueron: ZnT3 Sentido 5'- GGA GGT GGT TGG TGG GTA TTT AGC- , ZnT3 Antisentido 5'- GAT GGA GAT CAT GGG TTG CTC G-3'.

El medio para la realización de la PCR contenía: tampón comercial de la Taq polimerasa (5X, Promega, Madison, Wisconsin, EE.UU.), desoxinucleótidos trifosfato $(0,2 \mathrm{mM}$, Promega), Taq polimerasa $(0,013 \mathrm{U} / \mu 1$, Promega), dimetilsulfóxido (DMSO; 5\% p/v), $\operatorname{MgCl} 2(1,5 \mathrm{mM})$, cebadores $(5 \mu \mathrm{M}), \operatorname{ADNc}(4 \mu \mathrm{l}$ de muestra) y $\mathrm{H}_{2} \mathrm{O}$ Mili-Q.

Como control negativo se utilizó el medio anterior sustituyendo el volumen de $\mathrm{ADN}$ por $\mathrm{H}_{2} \mathrm{O}$ Mili-Q. La PCR se realizó en un termociclador (Primus), utilizando los ciclos de temperatura detallados a continuación (tabla 4): 


\begin{tabular}{|c|c|c|c|c|}
\hline Paso & Tiempo & \multicolumn{2}{|c|}{ ZnT3 } & \\
\hline 1 & $5 \mathrm{~min}$ & \multicolumn{2}{|l|}{$94^{\circ} \mathrm{C}$} & Desnaturalización del ADN \\
\hline 2 & $1 \mathrm{~min}$ & $94^{\circ} \mathrm{C}$ & $\mathrm{X} 40$ & Desnaturalización del ADN \\
\hline 3 & $1 \mathrm{~min}$ & $65^{\circ} \mathrm{C}$ & $\mathrm{X} 40$ & Hibridación de los cebadores \\
\hline 4 & $1 \mathrm{~min} 30 \mathrm{~s}$ & $72^{\circ} \mathrm{C}$ & $\mathrm{X} 40$ & Elongación de la cadena \\
\hline 5 & $10 \mathrm{~min}$ & \multicolumn{2}{|l|}{$72^{\circ} \mathrm{C}$} & Elongación de la cadena \\
\hline 6 & $\infty$ & \multicolumn{2}{|l|}{$4^{\circ} \mathrm{C}$} & $\begin{array}{l}\text { Mantenimiento de los productos } \\
\text { de PCR }\end{array}$ \\
\hline
\end{tabular}

Tabla 4. Ciclos de temperatura empleados en la PCR

\section{Electroforesis}

Los productos de la PCR de las regiones correspondientes a la secuencia amplificada del ADNc para ZnT3, de $701 \mathrm{pb}$, se visualizaron mediante electroforesis en un gel de agarosa (D-1, Pronadisa, Madrid, España) al 2\% (p/v) en tampón Tris-boratoEDTA (TBE) 0,5X. Al gel se añadieron $0,4 \mu \mathrm{g} / \mathrm{ml}$ de bromuro de etidio (Sigma) para la visualización de las bandas del ADN amplificado, observándolo bajo una lámpara de luz ultravioleta (Gel

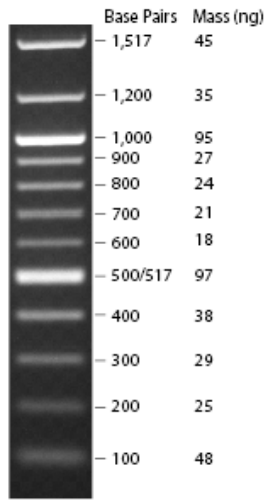
Doc XR, BioRad Laboratories, Barcelona, España). El marcador de peso molecular empleado fue $100 \mathrm{bp}$ DNA Ladder (fig. 4, New England BioLabs, Ipswich, MS, EE.UU.).

Figura 4. Visualización del marcador 100 bp DNA Ladder mediante electroforesis en un gel de agarosa y bromuro de etidio. Imagen tomada de www.neb.com

\section{Análisis estadísticos}

Para realizar los diferentes análisis, utilizamos el programa SPSS 18.0 (SPSS, Chicago, IL, EE.UU.), llevando a cabo diferentes test estadísticos dependiendo del carácter paramétrico o no paramétrico de los datos a analizar. Para el análisis de la distribución de ZnT3 en la población glomerular empleamos los estadísticos descriptivos (media, desviación estándar, etc.). 

RESULTADOS 



\section{Resultados}

\section{Consideraciones técnicas}

Los animales sujetos a deprivación olfatoria muestran una drástica reducción en el número de neuronas yuxtaglomerulares positivas a TH en la capa glomerular del BO ipsilateral a la deprivación (Brunjes, 1988; Briñón y cols., 2001). Mientras que el número y distribución de las células positivas a TH es similar en el BO de animales control y en el contralateral de animales deprivados, el BO ipsilateral de los animales experimentales demuestra una extensa disminución de la expresión del fenotipo dopaminérgico (Brunjes, 1988). La observación de la disminución del número de células yuxtaglomerulares dopaminérgicas en nuestros animales confirmó la eficacia de la deprivación olfatoria (fig. 31E y F).

Los animales mutantes pcd sufren una reducción significativa del volumen del BO con respecto al control, que afecta a todas sus capas y produce un incremento en la densidad celular de esta estructura (Greer y Shepherd, 1982; Valero, 2006). En el caso de la CG, la reducción del volumen en los animales pcd es de un 25,2\% (Valero, 2006). Para observar posibles variaciones en la densidad celular de la CG de animales $p c d$, debidas a cambios reales en el número de células y no así a la disminución en volumen que sufre esta capa, ajustamos todos los datos de densidad obtenidos en estos animales pcd en función de esta pérdida de volumen.

Puesto que hasta la fecha no se ha descrito si los animales KO para NOSn sufren o no variaciones en el volumen del BO, realizamos un estudio para comparar las áreas del $\mathrm{BO}$ en animales control y KO. En dicho estudio no obtuvimos diferencias significativas entre ambos animales en el área de la $\mathrm{CG}$ del $\mathrm{BO}$, por lo no necesitamos corregir los datos de densidad de los animales KO para NOSn. 


\section{Modulación zincérgica en el BO}

\section{Caracterización de terminales ZEN en el BO}

\section{Terminales zincérgicos en el BO}

El análisis del sistema zincérgico en el BO se llevó a cabo mediante el método del selenio y la inmunohistoquímica para el transportador ZnT3. Al igual que lo descrito previamente (Airado, 2005; Airado y cols., 2008), la mayor cantidad e intensidad de marcaje $\mathrm{ZnSe}^{\mathrm{AMG}}$-positivo se encontró en la CGr del BO. La CPE apenas mostró algún grano de precipitado de plata (fig. 20A). En la CG aparecíeron algunos gránulos de plata en la región yuxtaglomerular y en ocasiones en el interior de células periglomerulares (fig. 20A, C y E). En cambio, el marcaje para ZnT3 aparecía, además de en la CGr en toda la CG, incluyendo el neuropilo glomerular (fig. 20B, D y F). La diferencia notada en el marcaje de la CG con ambas técnicas ha sido analizada en la presente Tesis Doctoral. Así, observamos que la diferencia entre ambas técnicas en los glomérulos sucedía a lo largo de toda la $\mathrm{CG}$, excepto en algunos glomérulos situados normalmente en la región ventro-lateral del BO. En todos los animales procesados con el método del selenio para la observación de terminales ZEN aparecieron unos glomérulos intensamente marcados, rellenos de gránulos de plata (fig. 21A). A diferencia del resto de glomérulos, donde el marcaje se situaba únicamente en la zona yuxtaglomerular, estos glomérulos parecían tener una carga especial de terminales ZEN en su neuropilo, muy evidente cuando se compara con sus convecinos (fig. 21B). Además, en la mayoría de los casos, las células yuxtaglomerulares de estos glomérulos se encontraban rodeadas y/o rellenas de precipitado de plata (fig. 21C). Dichos glomérulos se encontraban únicamente en determinadas secciones coronales, apareciendo como máximo tres por BO. De ellos, el más llamativo es el localizado aproximadamente en el nivel 3,74 rostral respecto a Bregma (fig. 21A), de acuerdo con el atlas de Franklin y Paxinos (1997). En esta Tesis Doctoral, nos referiremos a este tipo de glomérulos como glomérulos ZEN.

\section{Ultraestructura de los terminales ZnSe ${ }^{A M G}$ - positivos}

Observando el BO de la capa más superficial a la más profunda, los primeros terminales zincérgicos aparecen en la CG. Dicha capa se distingue a microscopía electrónica por la regionalización del neuropilo en compartimentos: el compartimento sensorial o zona NO, y el compartimento sináptico o zona no-NO 
(Kasowski y cols., 1999). El compartimento sensorial está formado por porciones terminales del NO (distinguibles por su contenido muy electrodenso, fig. 22A), y perfiles dendríticos de células principales (mitrales y empenachadas, con un citoplasma muy poco electrodenso) y células PGs. En este compartimento sensorial, los terminales del NO realizan contactos sinápticos asimétricos con perfiles dendríticos de células principales y de células PG. En nuestro estudio, encontramos marcaje $\mathrm{ZnSe}^{\mathrm{AMG}}$-positivo localizado en algunos terminales axónicos del NO (fig. 22A). Aunque la densidad de aparición de estos terminales ZEN positivos fue muy baja, algunos mostraron contactos sinápticos asimétricos con dendritas de lo que podrían ser células PG (fig. 23A). Incluso, en algún caso, encontramos marcaje en la hendidura sináptica, lo que podría representar el comienzo del proceso de exocitosis de las vesículas presinápticas ricas en zinc (fig. 23B). El compartimento sináptico o zona no-NO, a diferencia del sensorial, no presenta porciones terminales del NO, sino perfiles dendríticos de células principales, de células PG y terminales axónicos de diferentes orígenes centrífugos. En estas regiones no-NO, no encontramos terminales $\mathrm{ZnSe}^{\mathrm{AMG}}$-positivos en las secciones analizadas. En la CCM se encuentran casi en exclusiva los somas de las células mitrales y las dendritas de los granos. Las células mitrales se distinguen al microscopio electrónico por su gran tamaño y contenido poco electrodenso (fig. 23C). En ninguna de las células mitrales observadas a microscopía electrónica encontramos marcaje $\mathrm{ZnSe}^{\mathrm{AMG}}$-positivo. Sin embargo, en la CPI, formada fundamentalmente por el neuropilo delimitado entre la CCM y los somas de los granos más superficiales, sí observamos algunos terminales marcados (fig. 23C), que, por sus características ultraestructurales, se correspondían con terminaciones moduladoras centrífugas. Al igual que observábamos a microscopía óptica, es la CGr donde encontramos la mayor densidad de terminales positivos para el marcaje $\mathrm{ZnSe}^{\mathrm{AMG}}$ (fig. 22C). Además de los somas de los granos, en esta capa aparecen también axones mielínicos. Una gran densidad de terminales ricos en vesículas cargadas con granos de plata realiza contactos sinápticos sobre las dendritas de los granos (fig. 23D).

Además del marcaje $\mathrm{ZnSe} \mathrm{AMG}^{\mathrm{AM}}$ asociado a terminales presinápticos $\mathrm{ZEN}$, observamos otras estructuras con depósitos de precipitados de plata, específicos por su forma redondeada, y que, sin embargo, no se encontraban en terminales axónicos. Así, en baja frecuencia, observamos granos de plata dentro de estructuras vesiculares, en algunos cuerpos celulares localizados en el límite entre la CG y la 
CPE (fig. 24A). Por su localización, por su tamaño y por sus características ultraestructurales, como las invaginaciones en el núcleo y la abundante cromatina condensada (Pinching y Powell, 1971a,b) hemos identificado a dichas células como PGs. Además, en ocasiones los somas de las células PG aparecen envueltos en una o más capas de prolongaciones gliales (Pinching y Powell, 1971a,b), elementos que también aparecían acompañando a algunas células $\mathrm{ZnSe}^{\mathrm{AMG}}$-positivas (fig. 24A). Igualmente llamativo fue el caso del marcaje presentado por los astrocitos que conforman la limitante glial subpial en la periferia bulbar (fig. 24B). En el cuerpo celular de estas células encontramos, con gran frecuencia, marcaje $\mathrm{ZnSe}^{\mathrm{AMG}}$-positivo en endosomas/lisosomas (fig. 24C) y/o en pequeñas vesículas asociadas siempre a la cara trans del aparato de Golgi (AG; fig. 24D).

Nuestro análisis ultraestructural del método $\mathrm{ZnSe}^{\mathrm{AMG}}$ para la localización de zinc, confirmó la distribución mayoritaria de terminales centrífugos ZEN en la CGr del BO. Confirmamos también la existencia de terminales ZEN procedentes del NO en la CG. Además, describimos la aparición de zinc no sólo en el cuerpo celular de células gliales sino también en el soma de algunas interneuronas bulbares.

\section{Terminales zincérgicos en el BO de animales sobre-expuestos a zinc}

Después de haber observado y analizado la presencia tanto de terminales como de cuerpos celulares zincérgicos en el BO del ratón, decidimos someter a algunos animales a condiciones de exceso de zinc (mediante inyecciones de $\mathrm{ZnCl}_{2}$ ). Con ello pretendímos aumentar las dianas disponibles para el marcaje $\mathrm{ZnSe}^{\mathrm{AMG}}$, considerando la posibilidad de que en la CG la cantidad de iones zinc no fuese lo suficientemente elevada como para ponerse de manifiesto con el método $\mathrm{ZnSe}^{\mathrm{AMG}}$.

En los animales inyectados con $\mathrm{ZnCl}_{2}$ el marcaje a microscopía óptica para el método $\mathrm{ZnSe}^{\mathrm{AMG}}$ presentó las mismas características generales descritas para los animales control (Airado, 2005; Airado y cols., 2008), es decir, un precipitado de color marrón y aspecto granular localizado en los lugares donde se encontraba el zinc vesicular. Sin embargo, la intensidad de marcaje fue muy superior en todas las capas del $\mathrm{BO}$ de animales inyectados con $\mathrm{ZnCl}_{2}$ con respecto a los animales control (fig. $25 \mathrm{~A}$ y B). En este sentido, el cambio más llamativo lo observamos en la CGr, quizá, por ser la que presenta una mayor densidad de terminales ZEN (fig. 25C y D). 
Aunque en los animales control no habíamos observado marcaje $\mathrm{ZnSe}^{\mathrm{AMG}}$ positivo en la CPE, sí encontramos en la misma capa de animales inyectados con $\mathrm{ZnCl}_{2}$, pequeños precipitados de plata en el cuerpo celular y en el origen de algunas prolongaciones de pequeñas interneuronas (fig. 25E y F).

De manera similar, la $\mathrm{CG}$, presentó un ligero incremento en la cantidad de granos de plata, no tanto en el neuropilo glomerular, que continuó apareciendo prácticamente ausente de marcaje, sino en la zona yuxtaglomerular, que mostró marcaje superpuesto con los somas de las células yuxtaglomerulares y el inicio de algunas de sus prolongaciones (fig. $25 \mathrm{G}$ y H). Además, los glomérulos ZEN continuaban siendo visibles en las regiones ventro-laterales de estos animales.

A pesar de modular la homeostasis de zinc para incrementar la carga zincérgica y aunque la inyección de $\mathrm{ZnCl}_{2}$ produjo un incremento general en la cantidad de terminales ZEN en el BO, el marcaje que obtuvimos en la CG seguía sin corresponderse con el marcaje obtenido para el transportador ZnT3, por lo que el desfase en el marcaje entre ambas técnicas no se debe a un problema de sensibilidad del método $\mathrm{ZnSe} \mathrm{AMG}^{\mathrm{AMG}}$.

\section{Correlación ultraestructural}

Las características del marcaje en los terminales axónicos fueron similares a las que encontramos en los animales que no fueron inyectados con $\mathrm{ZnCl}_{2}$. Los precipitados granulares fueron variables en número y tamaño entre terminales, encontrándose mayoritariamente asociados a vesículas presinápticas. De modo general, la mayor densidad de terminales con marcaje $\mathrm{ZnSe}^{\mathrm{AMG}}$ apareció igualmente en la CGr (fig. 22D y fig. 26B) y en la CG (fig. 22B y fig. 26A). No obstante, la cantidad de terminales que aparecían en la CGr fue superior a la que encontrábamos en los animales no inyectados (fig. 22A y C). Al igual que en las muestras procedentes de animales control, los perfiles sinápticos de los terminales zincérgicos observados en esta capa eran contactos asimétricos con terminales dendríticos de los granos (fig. 26B), que se corresponden con terminaciones zincérgicas centrífugas.

En la CG, a nivel ultraestructural, no observamos un incremento en la densidad de terminales del NO ZEN-positivos. En los animales inyectados con $\mathrm{ZnCl}_{2}$, al igual que describimos para los animales control, fue frecuente la aparición de depósitos granulares positivos dentro de algunos somas neuronales (fig. 26D-F), 
junto a la cara trans del AG (fig. 26D), en vesículas citosólicas, en lisosomas (fig. $26 \mathrm{E}$ y F) o en el interior de mitocondrias (fig. 26E).

Del mismo modo que describimos para los animales control, en esta capa también encontramos cuerpos celulares marcados, que hemos identificado como astrocitos, dado su elevado contenido en filamentos intermedios (fig. 26C). Los depósitos intracelulares de marcaje $\mathrm{ZnSe}^{\mathrm{AMG}}$ se localizaron igualmente en vesículas junto a la cara trans del $\mathrm{AG}$ y en estructuras vesiculares del tipo endosomas/lisosomas (fig. 26C).

Estos datos demuestran que la mayor disponibilidad de zinc en el medio interno no es la condición limitante para provocar una mayor carga en terminales zincérgicos provenientes del $\mathrm{NO}$ en la $\mathrm{CG}$ del $\mathrm{BO}$, pero sí en los axones de procedencia centrífuga que tienen sus dianas en la CGr.

\section{Estudio del transportador ZnT3 en la CG}

\section{Distribución en los compartimentos intraglomerulares}

Aunque los estudios previos muestran un marcaje de la proteína ZnT3 coincidente con la localización de los terminales $\mathrm{ZnSe}^{\mathrm{AMG}}$-positivos (Palmiter y cols., 1996a; Cole y cols., 1999; Wang y cols., 2001, 2002a, b), en el caso del BO, en concreto en la CG, existe un desfase entre ambas técnicas que no parece ser debido a la sensibilidad del revelado autometalográfico (Jo y cols., 2000; Airado, 2005; Airado y cols., 2008). Puesto que ésta es la primera vez en la bibliografía que se detecta este tipo de diferencia, quisimos conocer con exactitud dónde estaba localizado el transportador ZnT3 en la CG ayudándonos de su localización en relación al marcaje para la proteína olfactory marker protein (OMP). Para ello realizamos un análisis de la distribución intraglomerular de dicho transportador. La proteína OMP únicamente se expresa en los terminales de las NROs, y por tanto, en la CG marcará la región NO del glomérulo, mientras que las regiones glomerulares no marcadas con OMP se corresponderán con las zonas no-NO, según la regionalización glomerular establecida por Kosaka y cols. (1995, 1997, 1998). Por lo tanto, el marcaje ZnT3 que se encuentre exactamente en las mismas regiones donde está la proteína OMP se corresponderá con los terminales ZnT3 positivos que proceden de las NROs, mientras que aquellos que no colocalicen con OMP se corresponderán principalmente con aferencias centrífugas. 
Nuestros resultados muestran que la distribución del transportador ZnT3 en la zona OMP positiva, o zona NO y la zona glomerular OMP negativa o zona no-NO es muy variable entre glomérulos (fig. 27A-D), por lo que decidimos realizar un análisis de confocalidad con glomérulos individualizados. Para realizar este estudio analizamos 114 glomérulos de secciones procedentes de 2 animales diferentes. En cada glomérulo individual obtuvimos los datos para cada marcador: el porcentaje de ZnT3 que se encuentra en la zona del NO y el porcentaje de OMP (de NO) que contiene ZnT3 (tabla 5). En función de estas variables y empleando el programa estadístico SPSS, realizamos una clasificación de conglomerados que dividió a la población glomerular analizada en 3 grupos diferentes (tabla 5).

\begin{tabular}{|c|l|r|r|r|r|}
\hline TABLA 5 & & \multicolumn{2}{|c|}{ \% OMP con ZnT3 } & \multicolumn{2}{c|}{ \% ZnT3 en NO } \\
\hline & & Media & EEM & Media & \multicolumn{1}{c|}{ EEM } \\
\hline \multirow{3}{*}{ Conglomerado } & 1 & 67,2046 & 2,0136 & 57,1086 & 1,6309 \\
\cline { 2 - 6 } & 2 & 34,6491 & 1,3819 & 72,4943 & 2,1354 \\
\cline { 2 - 6 } & 3 & 70,6025 & 1,7537 & 85,1368 & 1,2831 \\
\hline
\end{tabular}

Tabla 5. Valores medios del \% de OMP que posee ZnT3 (verde) y del \% de ZnT3 que se encuentra en la zona del NO (rojo), para cada uno de los tres grupos de glomérulos obtenidos tras el análisis de conglomerados.

El primer grupo de glomérulos se caracteriza porque la mayoría del OMP, el $67,2 \%$, colocaliza con ZnT3 (fig. 5 y fig. 27E), mientras éste se reparte prácticamente de forma equitativa entre la región del NO (57\%) y la región no-NO (43\%). Los glomérulos pertenecientes al grupo 2 contienen una baja cantidad de ZnT3, situado principalmente en la zona del NO (fig. 5 y fig. 27F). El tipo 3, se corresponde con glomérulos con una gran cantidad de ZnT3 localizado en la región del NO (85,13\% del ZnT3 colocaliza con OMP), dejando poco marcador OMP libre de ZnT3 (únicamente el 29,4\% del OMP no colocaliza con ZnT3). En nuestras imágenes, simplificadas a 3 tonos para cada situación de marcadores, estaríamos hablando de glomérulos básicamente amarillos (la mayoría de píxeles del glomérulo localizados en la región del NO colocalizan, fig. 5 y fig. 27G). 


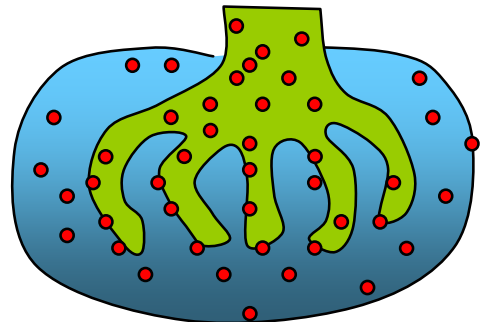

Glomérulo tipo 1

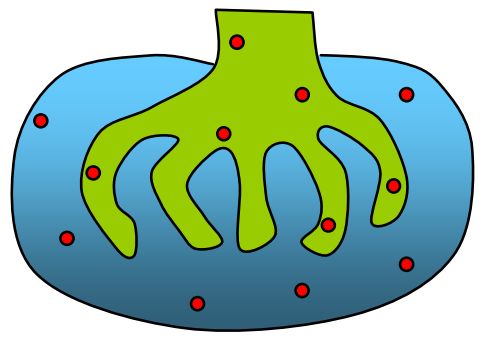

Glomérulo tipo 2

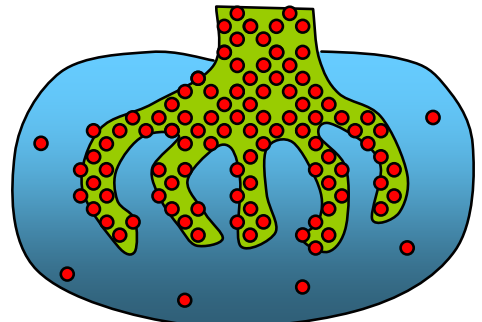

Glomérulo tipo 3
- Transportador ZnT3

Zona no-NO

Zona NO (OMP-positiva)
Figura 5. Esquemas de los tres tipos de glomérulos que podemos encontrar en el $\mathrm{BO}$, en función de la distribución del inmunomarcaje ZnT3 con respecto a las regiones $\mathrm{NO}$ y no-NO.

Nuestros resultados muestran que el ZnT3, en el grueso de la población glomerular analizada, se localiza en la zona NO siendo la media del 71\%, es decir, el $71 \%$ del marcaje ZnT3 de la CG procede de las NROs, mientras que el $29 \%$ restante se correspondería, en principio, con axones zincérgicos centrífugos.

A modo de resumen, nuestros resultados indican que el transportador de zinc ZnT3 no se encuentra distribuido de forma homogénea en la CG, sino que existe una gran variabilidad interglomerular, pudiendo incluso distinguirse 3 tipos de glomérulos en función de su distribución de ZnT3 en su zona NO y no-NO. A pesar de la heterogeneidad glomerular, de forma general, la mayor parte del transportador de zinc colocaliza con OMP (71\%), por lo que es lógico pensar que en la CG la mayor parte de este transportador se encuentra localizado en terminales aferentes del NO.

\section{Células ZnT3 positivas en la CG}

Al analizar en detalle las secciones de inmunofluorescencia para ZnT3, a parte del consabido marcaje punteado característico de los terminales axónicos donde el transportador se encuentra predominantemente en vesículas presinápticas, aparecían pequeñas estructuras circulares inmunopositivas, que dejaban un hueco en el centro que recordaba a cuerpos celulares (fig. 28A). Incluso, en ocasiones se observaba el comienzo de alguna proyección dendrítica. De ser así, estos resultados concordarían con los obtenidos con el marcaje $\mathrm{ZnSe}^{\mathrm{AMG}}$ tanto a microscopía óptica, donde observamos células yuxtaglomerulares con gránulos de plata en su interior, como a microscopía electrónica, donde vimos algunas células PGs con gránulos en vesículas citosólicas del soma celular. Realizamos un doble marcaje 
inmunofluorescente de la proteína ZnT3 con ioduro de propidio (fig. 28B y C) para ver si las estructuras donde se acumulaba el marcaje ZnT3 poseían núcleo o no. Los resultados a microscopía confocal nos muestran que cada una de las estructuras esféricas contenía en su interior un núcleo bien diferenciado (fig. 28C). Por lo tanto, todo parece apuntar a que en la CG existen células que expresan la proteína ZnT3. No obstante dado que el marcaje se observaba en la periferia celular desconocemos si la proteína $\mathrm{ZnT3}$ se encontraba en el interior de la célula o si por el contrario estábamos observando terminales zincérgicos ZnT3-positivos, adyacentes a esos somas celulares.

\section{Expresión de ZnT3 en el BO}

Para confirmar la existencia de expresión de ZnT3 en las células PGs de la CG del BO, pusimos de manifiesto la presencia de ARNm que codifica la proteína ZnT3. Tradicionalmente, se ha considerado la aparición de ribosomas y polirribosomas en los axones neuronales como un fenómeno con una frecuencia de aparición muy baja (Tennyson, 1970; Peters y Feldman, 1973). Con el paso del tiempo, se ha conocido que existe una maquinaria traduccional completa en las dendritas de algunas neuronas (Tiedge y Brosius, 1996) e incluso en determinados axones de neuronas hipotalámicas, y de ciertas neuronas en desarrollo (Vogelaar y cols., 2009). No obstante, nada se ha descrito acerca de la presencia de ARNm en los axones centrífugos que inervan el BO. De hecho, hoy en día aún se considera que la mayoría de axones adultos del SNC no son capaces de llevar a cabo una traducción local (Verma y cols., 2005). Por todo ello, consideraremos que si existe una amplificación de nuestro fragmento en el BO, existirá ARNm de la proteína ZnT3 en el $\mathrm{BO}$, que se corresponderá con ARNm localizado en los somas que observamos en la CG.

Tras realizar la electroforesis nuestros resultados demuestran que, efectivamente, en el BO existe transcripción del gen ZnT3 (fig. 6). Hecho que no observamos en otras estructuras utilizadas como control negativo: cerebelo, músculo e hígado. 


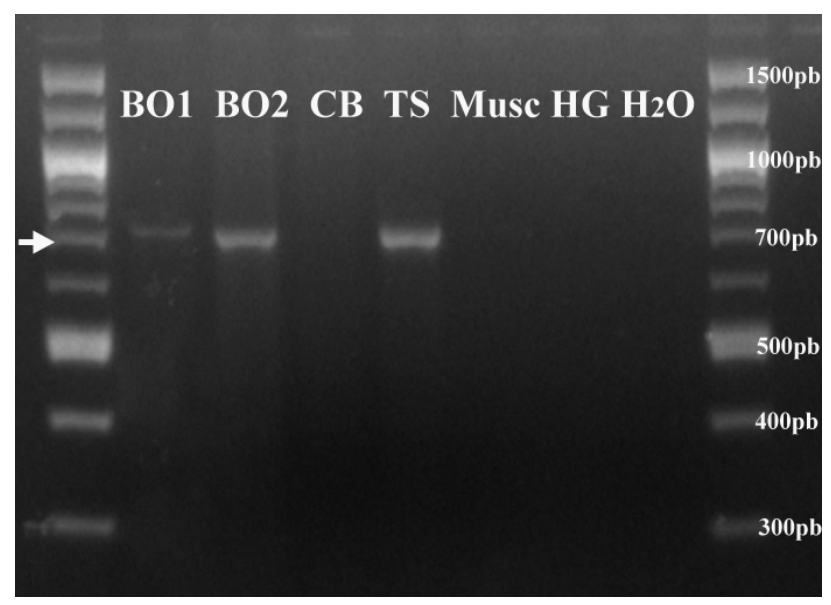

Figura 6. Gel de agarosa donde se realizó la electroforesis con los productos de PCR para amplificar el gen ZnT3 (amplicón de $701 \mathrm{pb}$ ). Las muestras donde el ADNc se amplificó corresponden con 2 muestras diferentes de BO y una de testículo (TS). No apareció expresión en la muestra de cerebelo (CB), en músculo (Musc), en hígado (HG), ni en el carril con agua, empleado como control negativo.

Para asegurarnos de que la no aparición del producto de PCR en las muestras de cerebelo, músculo e hígado se debía efectivamente a la inexistencia del ARNm para

ZnT3 y no a una deficiencia de la muestra de partida, realizamos un control positivo de la PCR en el que amplificamos parte del gen correspondiente al ribosoma 18S, concretamente al "Ribosomal Protein Large P0" (RPLP0), cuyo amplicón tiene un tamaño de $156 \mathrm{pb}$. Todas las muestras amplificaron el gen correspondiente al ribosoma 18S (fig. 7). Por lo que los ADNc empleados en la PCR para ZnT3, se encontraban en perfectas condiciones, indicando que nuestros resultados de expresión de ZnT3 son correctos.

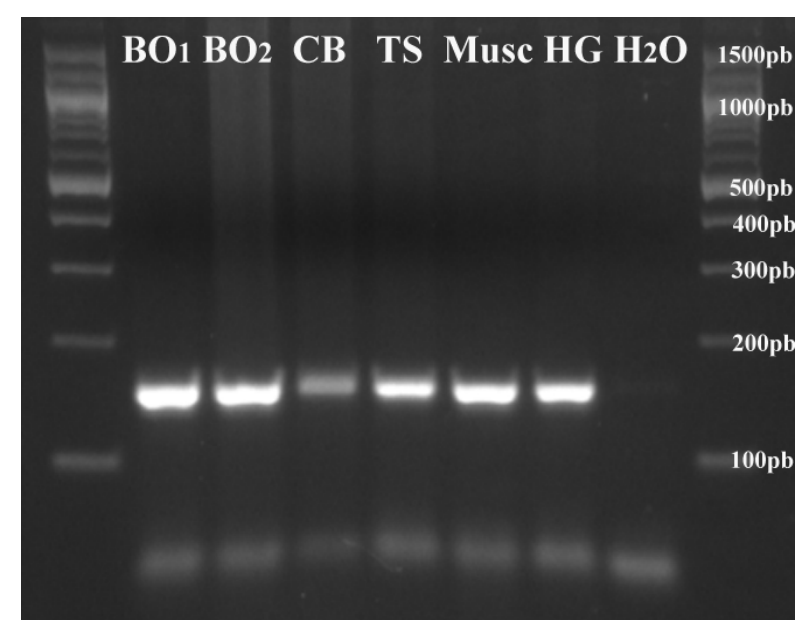

Figura 7. Gel de agarosa donde se realizó la electroforesis con los productos de PCR para amplificar el gen correspondiente al ribosoma $18 \mathrm{~S}$ (amplicón de $156 \mathrm{pb}$ ). Todas las muestras tomadas, los 2 BOs, el cerebelo, el testículo, el músculo y el hígado, amplificaron el gen.

Para cerciorarnos de que el producto de la PCR amplificado en el BO correspondía con la secuencia e ZnT3 elegida, llevamos a cabo la secuenciación de nuestro fragmento en el Servicio de Secuenciación de la Universidad de Salamanca (www.usal.es/ secuenciacionADN/). Los resultados de la secuenciación fueron comparados y alineados con el programa CLC DNA Workbench 5.1 (CLC bio, 
Aarhus, Dinamarca), con la secuencia completa del gen para la proteína ZnT3 para ratón, (slc30a3, fig. 8). Salvo los primeros y últimos pares de bases de los cebadores, la coincidencia del grueso del amplicón fue prácticamente perfecta.

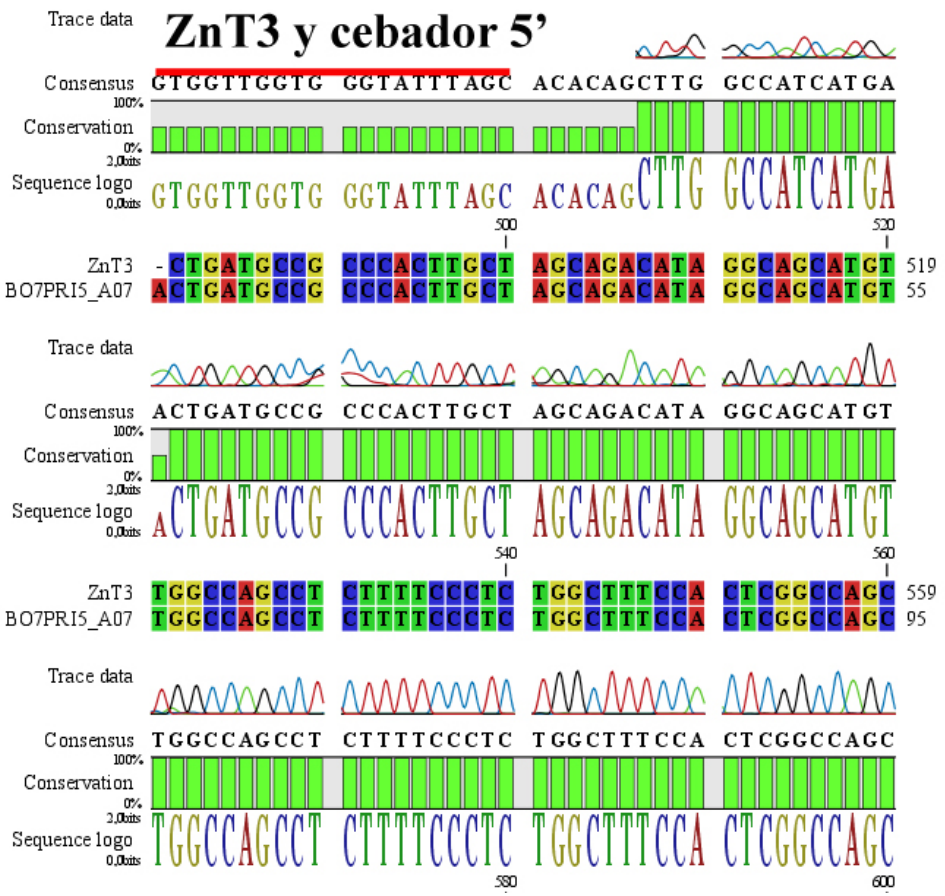

Figura 8. Representación del comienzo del alineamiento del gen ZnT3 (Slc30a3) con nuestro amplicón de $701 \mathrm{pb}$. Bajo la linea roja se encuentran los pb que constituyen el cebador en 5'. Las barras de color verde a media altura representan los pb que conforman la secuencia del gen para la proteína ZnT3. Las barras completas a doble altura representan coincidencia en los pb entre la secuencia del gen y la secuencia amplificada.

Después de confirmar que en el BO existe ARNm del ZnT3, quisimos comprobar si la expresión de ZnT3 se localizaba concretamente en la CG del BO. Para ello, consultamos el denominado "Allen Brain" (www.brain-maps.org) donde observamos imágenes y niveles de expresión del gen ZnT3 (slc30a3) realizadas mediante hibridación in situ en diferentes secciones coronales y sagitales del cerebro del ratón. La expresión del gen es evidente en la CG del BO y no así en el resto de capas (fig. 9A y B). Es más, se puede comparar la expresión del gen en la CG del BO con la expresión de ZnT3 en las primeras secciones coronales de NOA (fig. 9A y B, flechas), donde ya sabíamos que existían células ZnT3 positivas. Como control positivo de la técnica, mostramos una sección coronal a nivel del hipocampo y de la corteza entorrinal, que expresan el gen ZnT3 en grandes cantidades (fig. 9C, flechas mediales y laterales, respectivamente). 


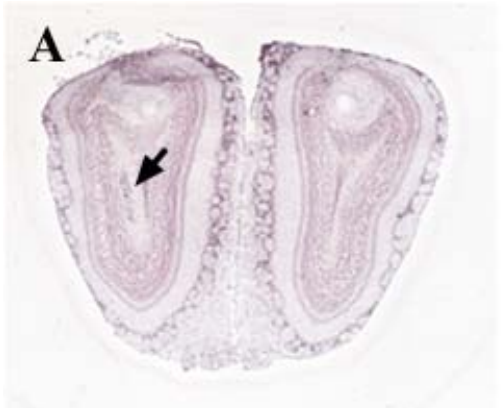

\section{B}
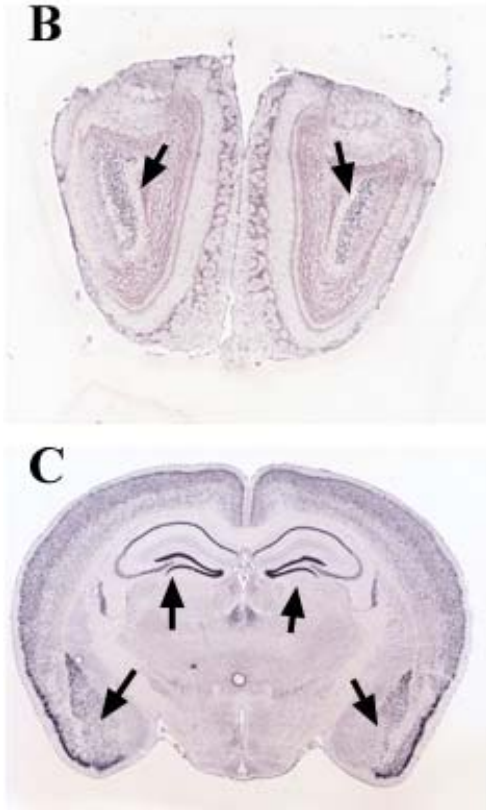
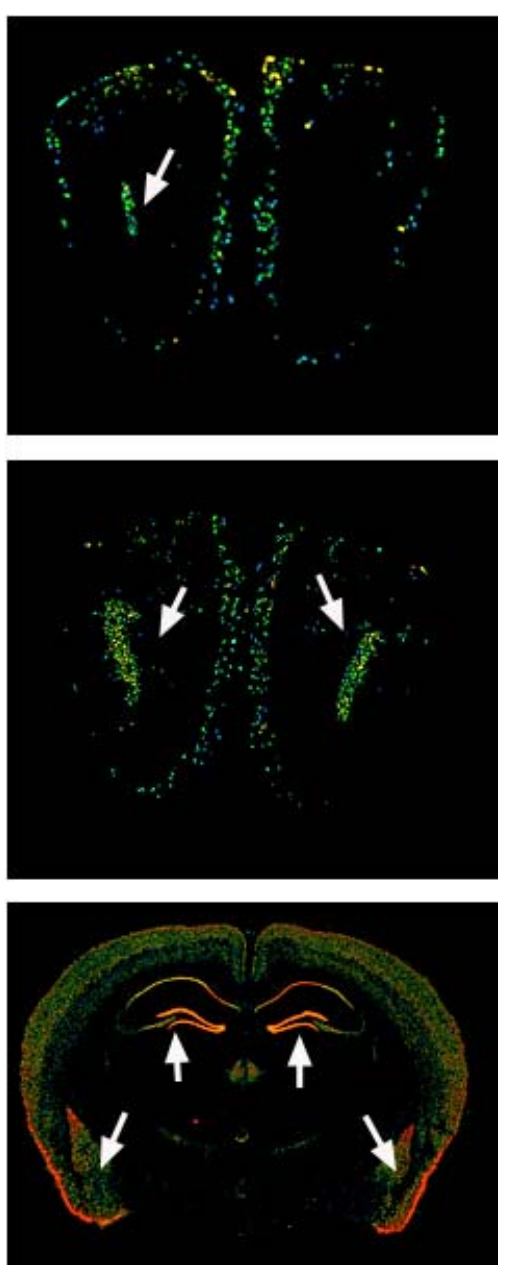

Figura 9. Secciones coronales de 3 niveles rostro-caudales diferentes del cerebro de ratón en las que se ha realizado una hibridación in situ para el gen ZnT3 (slc30a3; extraído de www.brainmaps.org). En la columna derecha se muestra el análisis de expresión correspondiente a cada sección, en el que los colores en tonos azulados indican una expresión baja, mientras que los tonos anaranjados y rojos indican una expresión más fuerte del gen. En el BO (A y B), el gen se expresa únicamente en la CG. El NOA incipiente (Flechas en A y B), expresa también ZnT3. Para comprobar la expresión en el $\mathrm{BO}$, observamos regiones donde conocíamos la alta expresión de $\mathrm{ZnT} 3$ como el hipocampo y la corteza entorrinal lateral (flechas en $\mathrm{C}$ ).

\section{Caracterización neuroquímica de las células ZnT3}

Confirmada la existencia de células que expresan ZnT3 en la CG del BO, quisimos averiguar si dichas células eran neuronas o células gliales. Para ello, llevamos a cabo dobles inmunofluorescencias ZnT3 y MAP2 como marcador de neuronas adultas y ZnT3 y GFAP, como marcador de astrocitos, puesto que aunque característicamente la glía no contiene zinc vesicular (Valente y Auladell, 2002), habíamos observado astrocitos marcados ultraestructuralmente. Mientras que en las secciones marcadas con ZnT3 y GFAP no vimos cuerpos celulares doblemente positivos (fig. 28D), muchos de los somas que contenían la proteína ZnT3 eran también MAP2-positivos (fig. 28G). Por lo tanto, según nuestros resultados, las células ZnT3-positivas de la CG son, en su mayoría, interneuronas yuxtaglomerulares. 
Por el tamaño y la localización de la mayoría de células ZnT3-positivas, las identificamos como células PGs. Tradicionalmente se conocen 2 poblaciones principales de células PGs, que en ratón son mayoritariamente GABAérgicas. Las células PGs tipo 1, caracterizadas porque contactan directamente con el NO y las células PGs tipo 2, que no contactan directamente con el NO (Kosaka y Kosaka, 2004). Para conocer a qué población glomerular pertenecen las células ZnT3positivas realizamos dobles inmunofluorescencias con ZnT3 y toda una batería de marcadores neuroquímicos. Puesto que la mayor parte de las células PGs son GABAérgicas, el primer marcador que empleamos fue GAD67, enzima limitante de la síntesis de GABA. El marcaje que ofrece la localización para GAD67 complica la diferenciación de elementos positivos por dos razones: a) aunque la enzima es citosólica, el marcaje se encuentra bordeando el soma celular de forma paralela a lo que ocurre con la proteína ZnT3; y b) los terminales sinápticos que contienen GAD67 se encuentran en alto número rodeando a otras neuronas, lo que hace difícil distinguir una célula GAD67-negativa rodeada por terminales marcados, de una GAD67-positiva (fig. 29B). En la doble inmunofluorescencia, vemos los marcajes de las células que colocalizan, dejando un hueco en el lugar correspondiente al núcleo, mientras que se observan con claridad los somas de algunas células GAD67-positivas que no se marcan con el transportador ZnT3 (fig. 29C). En todas las secciones analizadas observamos una colocalización casi total entre GAD67 y ZnT3 (fig. 29A, B y C), de forma que el 94,39 \pm 1,6\% de las células ZnT3-positivas eran también GAD67, aunque no todas las GAD67 contenían el transportador ZnT3.

Por tanto, la población de células ZnT3-positivas es una subpoblación de las PGs GABAérgicas del ratón. Para caracterizar los subtipos de PGs 1 y 2 llevamos a cabo dobles inmunofluorescencias ZnT3 con uno de los siguientes marcadores: TH, para caracterizar el subtipo principal de PG de tipo 1 y calbindina (CB) o calretinina (CR) para identificar si pertenecen a alguno de los subtipos principales de PGs tipo 2 del ratón.

El marcaje citoplasmático para la enzima TH mostró una población glomerular menos numerosa que la población GABAérgica, con células bien definidas que se sitúan rodeando los glomérulos (fig. 29E). La doble inmunofluorescencia demostró la existencia tanto de células marcadas únicamente para uno de los marcadores (ZnT3 o TH), como de células doblemente marcadas (fig. 29F). El análisis cuantitativo mostró que el 11,45 \pm 2,6\% de las células ZnT3- 
positivas pertenecen a la subpoblación de células PGs tipo 1 que son TH-positivas, es decir, son dopaminérgicas y contactan directamente con el NO.

En relación con el estudio de las células PG tipo 2, los resultados de la doble inmunofluorescencia CB-ZnT3 muestran que las células CB-positivas poseen un marcaje citoplásmico ocasionalmente rodeado por proteína ZnT3 que, sin embargo, en ningún caso colocalizó con la proteína ligante de calcio (fig. 29G, H e I). En lo que se refiere a la $\mathrm{CR}$, observamos que el marcaje para $\mathrm{CR}$ es mayoritariamente citoplasmático, aunque también presenta un componente nuclear (fig. 30B). Tras el doble marcaje ZnT3-CR, observamos elementos marcados con cada uno de los dos marcadores por separado y elementos doblemente marcados (fig. 30D). De hecho, una gran proporción de células ZnT3-positivas $(43,75 \pm 4,1 \%)$ eran también CRpositivas, indicando que prácticamente la mitad de las células ZnT3 son PGs del tipo II.

Se conoce, por una parte, que el 50\% de la población CR-positiva en la CG del ratón colocaliza con NOSn. Esta subpoblación de células CR-NOSn-positivas supone a su vez el 70\% de la población NOSn-positiva en este animal. Por otra parte, sabemos que el ON regula la homeostasis del zinc intracelular. Por ello, nuestro último análisis comprobó la existencia de ZnT3 en las células nitrérgicas del BO. Tras realizar el marcaje para la enzima NOSn junto con el transportador ZnT3, observamos, de igual modo, la existencia de elementos exclusivamente ZnT3positivos (fig. 30E) o NOSn-positivos (fig. 30F) y de elementos doblemente marcados (fig. $30 \mathrm{H})$. El recuento celular demostró que prácticamente la mitad (49,74 $\pm 4,8 \%$ ) de las células $\mathrm{ZnT3}$ colocalizaron con este marcador, es decir, eran neuronas capaces de sintetizar ON y que no contactan con el NO (PGs del tipoII).

Todos estos datos indican que existen células ZnT3-positivas en la CG del BO, que son neuronas PGs inhibitorias, y que, a falta de estudios ultraestructurales que confirmen los contactos con el NO, según nuestros resultados pertenecen en una pequeña proporción a la población de PGs tipo 1, puesto que colocalizan con $\mathrm{TH}, \mathrm{y}$ en su mayoría a la población de PGs tipo 2 del subtipo CR-NOSn-positivas.

\section{Plasticidad de las proyecciones zincérgicas}

Una vez analizadas las características de la modulación zincérgica en el BO de animales control, donde encontramos dos diferencias principales con respecto a lo 
descrito previamente: 1) la existencia de células ZnT3 positivas, 2) la existencia de glomérulos modulados por gran cantidad de terminales ZEN; analizamos los posibles cambios plásticos que ocurren en el sistema zincérgico en diferentes condiciones experimentales: cambios en la entrada de la señal olfatoria recibida desde el epitelio olfatorio (animales enriquecidos, animales deprivados); tras la pérdida de las principales neuronas de proyección del BO, las células mitrales (animales mutantes pcd) y cambios en condiciones de carencia de la enzima productora de óxido nítrico neuronal (animales knock-out para NOSn).

\section{Modificaciones en la entrada de la información olfatoria}

Pensando en la aparición del marcaje en el neuropilo glomerular como manifestación de una actividad diferencial entre los glomérulos ZEN y el resto, realizamos ensayos cambiando la intensidad de la información olfatoria entrante recibida por el epitelio olfatorio, bien incrementándola en los animales enriquecidos, o bien eliminándola, en los animales deprivados.

\section{Proyección zincérgica en animales enriquecidos}

En el caso de los animales sometidos al proceso de enriquecimiento olfatorio durante 20 días no observamos diferencias en el marcaje $\mathrm{ZnSe}{ }^{\mathrm{AMG}}$ en el $\mathrm{BO}$ con respecto a los animales no enriquecidos. Continuaba apareciendo el mismo patrón de marcaje con precipitados de gran intensidad en la CGr y glomérulos cuyos neuropilos prácticamente carecían de gránulos, a excepción de los glomérulos ZEN, que seguían apareciendo en la misma proporción, es decir, 3 glomérulos máximo por BO (fig. 31B).

Nos preguntamos entonces si los glomérulos ZEN pudiesen estar reflejando actividad olfatoria de un modo mucho más inmediato, es decir, puesto que dichos glomérulos aparecían en todos los animales analizados localizados en la misma región, ¿Sería posible que reflejasen la actividad olfatoria común a todos los animales en el momento del sacrificio?, ¿Estarían reflejando la actividad glomerular como resultado del ambiente olfatorio rico en el fijador; glutaraldehído? Johnson y cols. (2009), mediante estudios de 2-deoxiglucosa, han mostrado que cada odorante, en ratas y ratones, provoca la activación de unos glomérulos concretos en el BO. En su trabajo, los odorantes de la familia de los aldehídos alifáticos, a la que pertenece el glutaraldehído, aparecen representados en las zonas ventrales. Nos preguntamos si la 
diferencia de marcaje en el neuropilo glomerular entre la técnica inmunohistoquímica para el transportador ZnT3 y el método $\mathrm{ZnSe}^{\mathrm{AMG}}$, sería producto de una activación diferencial por causa del olor a glutaraldehído durante el sacrificio de los animales. De ser así, este hecho explicaría la activación diferencial de los glomérulos ventrales. Para comprobarlo, realizamos un segundo experimento de enriquecimiento, en el que los animales, en el momento del sacrificio fueron expuestos a 3 olores diferentes: xileno, acetona o clavo. Tras la realización del método $\mathrm{ZnSe}^{\mathrm{AMG}}$ en dichos animales, el patrón de marcaje en el BO fue exactamente el mismo descrito para los animales control. En estos animales también aparecía un máximo de 3 glomérulos con neuropilo ZEN-positivo en la región ventro-lateral del BO (fig. 31C).

Estos resultados indican que incrementos en la entrada de información olfatoria durante un periodo largo o en el mismo momento del sacrificio, no parecen ser el detonante del patrón diferente de marcaje entre glomérulos ZEN y los glomérulos no-ZEN en la modulación zincérgica proveniente del NO.

\section{Pruebas de deprivación}

Nos planteamos si los glomérulos ricos en neuropilo $\mathrm{ZnSe}^{\mathrm{AMG}}$-positivo podrían ser precisamente los que no estaban siendo estimulados por la actividad olfatoria en nuestros animales. Para averiguarlo provocamos el efecto contrario, es decir, eliminar toda fuente de entrada de información, manteniendo el sistema anatómicamente intacto, y observar así si todos los glomérulos de la CG presentaban el mismo aspecto que los glomérulos ZEN.

Una vez comprobada la reducción de la expresión de TH y por tanto de la actividad olfatoria (fig. 31E y F), analizamos el marcaje para el método $\mathrm{ZnSe}^{\mathrm{AMG}}$ y para la inmunohistoquímica contra el transportador ZnT3. En ningún caso encontramos diferencias entre los animales deprivados y los animales control. Los glomérulos ZEN, en especial el localizado en la posición ventral en el punto 3,74 rostral respecto a Bregma con el neuropilo más marcado para $\mathrm{ZnSe}^{\mathrm{AMG}}$, continuaron apareciendo en las secciones correspondientes en los animales deprivados (fig. 31D).

La ausencia de cambios plásticos en los terminales ZEN de la CG del BO tras la deprivación de los animales así como después de someterlos a condiciones de enriquecimiento olfatorio nos permite decir que el marcaje diferencial obtenido con el método $\mathrm{ZnSe}^{\mathrm{AMG}}$ y la inmunohistoquímica para el transportador ZnT3 no 
dependen de la actividad olfatoria. Por lo tanto, debía existir otro motivo por el cual observáramos un marcaje diferente entre ambos métodos $\mathrm{y}$, muy probablemente, relacionada con la causa de la aparición del marcaje más intenso en el neuropilo de los glomérulos ZEN. Puesto que el ON regula de manera intensa los movimientos de zinc intracelular, nuestro siguiente estudio se dirigió a analizar el sistema zincérgico bajo condiciones de reducción de $\mathrm{ON}$ en el sistema olfatorio.

\section{Sistema zincérgico en el BO del ratón KO para NOSn}

En el BO de los animales KO para NOSn, la carencia de esta enzima no produjo ningún cambio en el marcaje zincérgico con el método $\mathrm{ZnSe}^{\mathrm{AMG}}$. El patrón de distribución de los terminales ZEN para cada una de las capas del BO fue el mismo que el resto para los animales control, incluyendo la aparición de los glomérulos más intensos en marcaje en la región ventro-lateral. No obstante, al realizar la inmunohistoquímica para el transportador ZnT3 observamos una disminución uniforme en la intensidad del marcaje en la $\mathrm{CG}$ de los animales $\mathrm{KO}$, que no detectamos en la CGr. Empleando el microscopio láser confocal tomamos fotomicrografías de planos focales de distintas regiones de la CG de animales control y NOS (fig. 32A y B) y mediante el software del propio microscopio confocal, obtuvimos datos del porcentaje ocupado por el transportador ZnT3 en la totalidad del área de cada glomérulo analizado. Nuestros resultados muestran la existencia de diferencias altamente significativas entre ambos grupos experimentales (fig. 10).

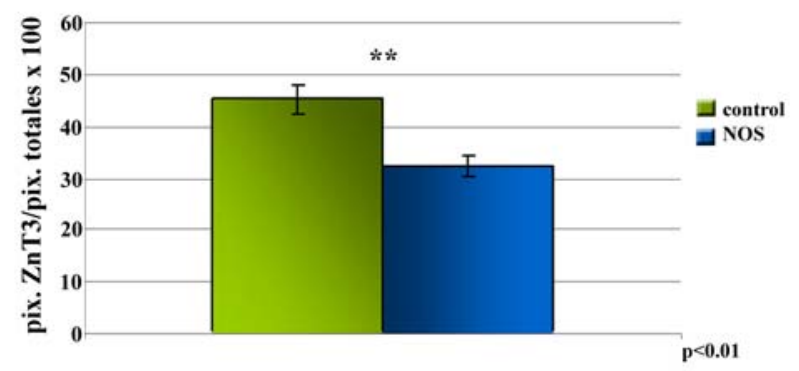

Figura 10. Estimación de la proporción de terminales con ZnT3 por glomérulo en animales control y KO para NOSn. Los datos muestran el porcentaje de píxeles ocupados por el marcador ZnT3 respecto al total de píxeles en un glomérulo.

Estos resultados indican que la ausencia de la enzima NOSn no tiene consecuencias directas sobre la cantidad de zinc que reclutan los terminales zincérgicos del BO, pero sí parece influir en la cantidad de proteína ZnT3 que se encuentra presente en la CG del BO. Además, el análisis de los cuerpos celulares ZnT3-positivos demuestró que la densidad de células ZnT3-positivas en la CG de los 
animales NOS era significativamente mayor a la correspondiente en los animales control (fig. 11, fig. 33A y B, fig. 34A y B).

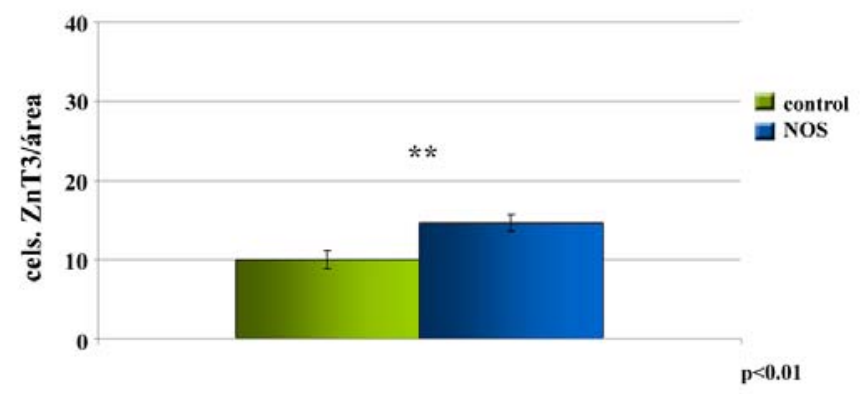

Figura 11. Comparación de la densidad de células ZnT3positivas en la $\mathrm{CG}$ de animales control y KO para NOSn.

Para conocer si el incremento en el número de células ZnT3-positivas se debía al aumento de una población neuroquímica concreta realizamos dobles inmunofluorescencias ZnT3 con los mismos marcadores analizados en los animales control (GAD67, TH, CB, CR y NOSn). Unicamente observamos diferencias significativas en los porcentajes de colocalización ZnT3-CR y ZnT3-NOSn (fig. 12 y fig. $33 \mathrm{G} \mathrm{yH)}$.

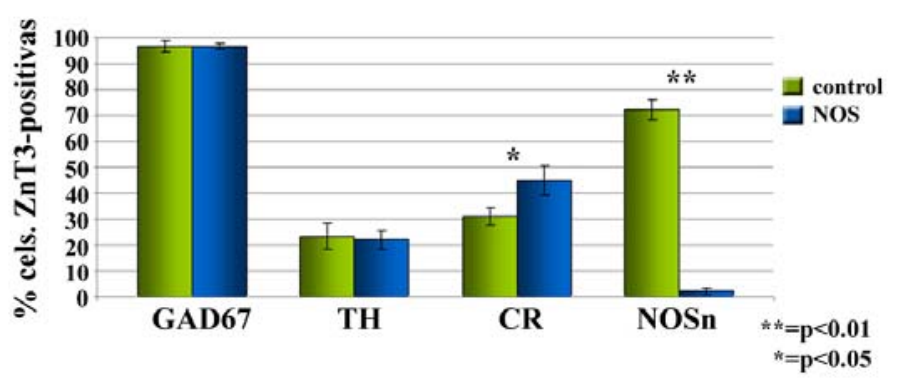

Figura 12. Porcentaje de células ZnT3-positivas que colocalizan con GAD67, TH, CR o NOSn, en la CG del $\mathrm{BO}$ de animales control y $\mathrm{KO}$ para NOSn. Los datos para el marcador $\mathrm{CB}$ no están representados en la gráfica puesto que en ningún caso (tanto para animales control como para los KO para NOSn) colocalizó con $\mathrm{ZnT3}$.

Puesto que existen variaciones en los porcentajes de colocalización, quisimos comprobar si la pérdida del gen NOSn producía cambios en la densidad celular de cada marcador por separado (GAD67, TH, CB, CR y NOSn). Obtuvimos diferencias significativas únicamente en el caso del marcador $\mathrm{CR}$, entre animales control y $\mathrm{KO}$ para NOSn (fig. 13 y fig. 33D y E). Es decir, la población de células ZnT3-CRpositivas parece aumentar debido al incremento en la densidad de las poblaciones ZnT3 y CR por separado. 


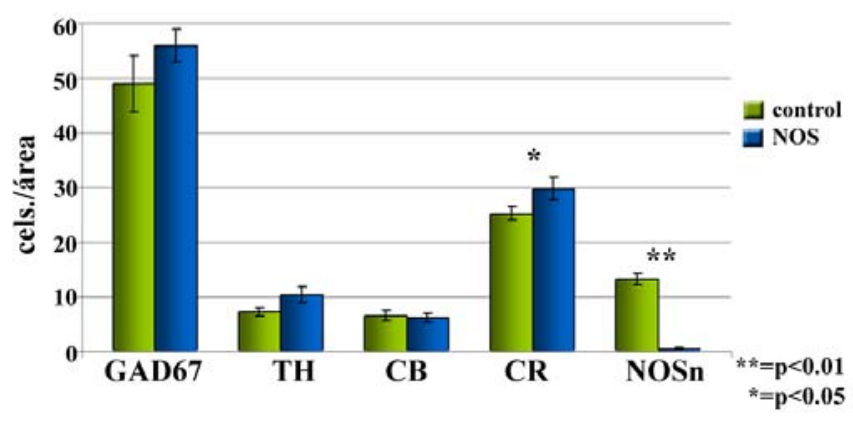

Figura 13. Comparación de la densidad de células GAD67, TH, $\mathrm{CB}, \mathrm{CR}$ y NOSn-positivas en la $\mathrm{CG}$ entre animales control y $\mathrm{KO}$ para NOSn.

Por tanto, en los animales KO con ausencia de la enzima NOSn, existen también células ZnT3-positivas en la CG del BO, que son neuronas PGs inhibitorias que se corresponden con células PGs tipo I, puesto que colocalizan con TH, y, en su mayoría, con células PGs tipo II del subtipo CR-NOSn-positivas, al igual que ocurría en los animales control. Sin embargo, la densidad de células ZnT3 totales, CR totales y de la proporción de células ZnT3-CR se ve incrementada en relación a lo observado en animales control.

Quisimos descartar por completo la implicación de otro tipo de células yuxtaglomerulares en el incremento de densidad de células ZnT3-positivas en los animales KO para NOSn. Para ello, realizamos un recuento de otro tipo de neurona yuxtaglomerular, las células empenachadas. Empleamos las imágenes de ZnT3-GAD para llevar a cabo este estudio. Consideramos células empenachadas aquellas que además de presentar las características morfológicas de estas células, eran ZnT3positivas y GAD67-negativas. No observamos diferencias significativas en la densidad de células empenachadas entre animales control y KO para NOSn (fig. 14 y fig. 33A y B), por lo que el incremento en el número total de células ZnT3-positivas no debe estar relacionado con su expresión en células empenachadas externas, sino con variaciones de la población de PGs de tipo II CR-positivas.

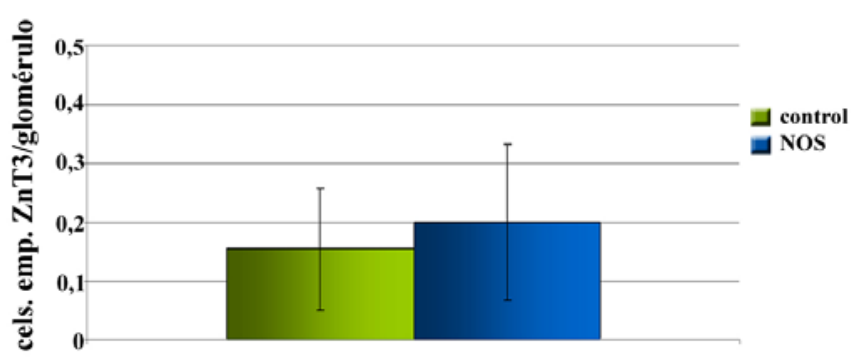

Figura 14. Densidad de células empenachadas ZnT3-positivas por glomérulo en animales control y $\mathrm{KO}$ para NOSn. 


\section{Sistema zincérgico en el BO del ratón mutante pcd}

Sabemos que existen cambios plásticos en la inervación zincérgica que llega al BO de los animales mutantes pcd (Airado y cols., 2008). Además, se ha descrito que parte de los terminales ZEN de la CG pertenecen a axones centrífugos (Jo y cols., 2000). En nuestra búsqueda de indicios que nos llevasen a conocer lo que ocurre en la CG y a qué se debe el marcaje de los glomérulos ZEN, decidimos comprobar si la pérdida de las células mitrales en los mutantes pcd implicaba también variaciones en el marcaje zincérgico. Tras el análisis del método del selenio, confirmamos en los animales mutantes pcd la misma distribución y cantidad de marcaje $\mathrm{ZnSe}^{\mathrm{AMG}}$-positivo que en los animales control. También observamos la existencia de glomérulos ZEN con las mismas características morfológicas y de localización que presentaban en los controles. No obstante, en nuestro trabajo, quisimos conocer cuál es la situación del transportador de zinc 3 en la CG tras la pérdida de las células mitrales. Para ello, analizamos por un lado, la cantidad de proteína ZnT3 contenida en cada glomérulo; y por otro, las características neuroquímicas de la población de células ZnT3-positivas en la CG de estos animales.

Al igual que hicimos con el análisis en los animales KO para NOSn, a partir de fotomicrografías de la CG de animales control y pcd (fig. 32C y D) obtuvimos datos del porcentaje ocupado por dicho marcador. Nuestros resultados corregidos para el descenso de volumen en la CG del pcd, muestran que en este caso no existen diferencias significativas entre ambos grupos experimentales, es decir, el marcaje neuropilar ZnT3-positivo no varía tras la pérdida de las células mitrales (fig. 15). Esto corrobora los datos previos relativos al marcaje $\mathrm{ZnSe}^{\mathrm{AMG}}$ de terminales $\mathrm{ZEN}$ en estos animales (Airado y cols., 2008).

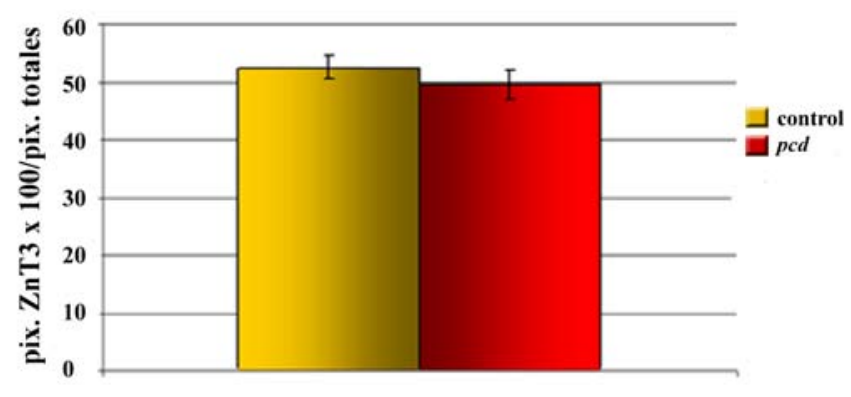

Figura 15. Estimación de la proporción de marcaje ZnT3-positivo por glomérulo en animales control y mutantes pcd. Los datos, corregidos para el descenso de volumen en la CG del pcd, muestran el porcentaje de píxeles ocupados por el marcador $\mathrm{ZnT3}$ con respecto al total de píxeles ocupados por glomérulo. 
A pesar de que el neuropilo ZnT3-positivo no varía entre genotipos, el análisis del número de somas positivos para este transportador en la CG demostró que existe un incremento real en la cantidad de células ZnT3-positivas, puesto que tanto en los datos sin corregir por el volumen como en los mismos datos corregidos, las diferencias fueron significativas (fig. 16, fig. 33A y C, fig. 34A y C).

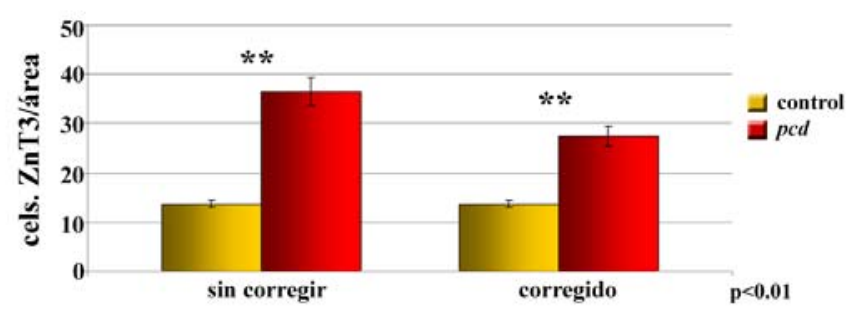

Figura 16. Comparación de las densidades sin corregir y corregidas por el volumen, de células ZnT3positivas en la $\mathrm{CG}$ de animales control y mutantes $p c d$.

Para conocer si el aumento en el número de células ZnT3-positivas estaba correlacionado con su aumento en alguna población neuroquímica en concreto, realizamos el análisis de colocalización de ZnT3 con los marcadores GAD67, TH, CB, CR y NOSn. En ningún caso observamos diferencias significativas entre los porcentajes de colocalización de animales control y mutantes pcd (fig. 17). Es decir, el aumento de células ZnT3-positivas en la CG de los mutantes pcd no va ligado al incremento en las diferentes poblaciones de PGs ZnT3-positivas analizadas.

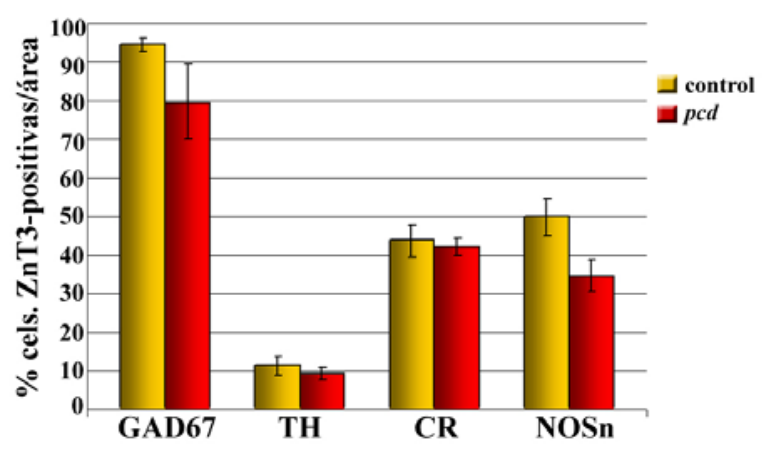

Figura 17. Porcentaje de células ZnT3positivas que colocalizan con los marcadores GAD67, TH, CR y NOSn en la CG del BO de animales control y mutantes pcd. Los datos para el marcador $\mathrm{CB}$ no están representados en la gráfica puesto que ni en ningún caso (tanto para animales control como para los mutantes pcd) colocalizó con ZnT3.

Aunque no habíamos observado diferencias significativas en la densidad de células ZnT3-positivas que colocalizaban con cada uno de los marcadores, quisimos conocer si la densidad de células positivas para cada uno de ellos individualmente variaba en los animales pcd. Nuestro análisis cuantitativo no reveló diferencias significativas en el número de células de cada población neuroquímica entre genotipos (fig. 18, fig. 33D y F, fig. 34D y F). 


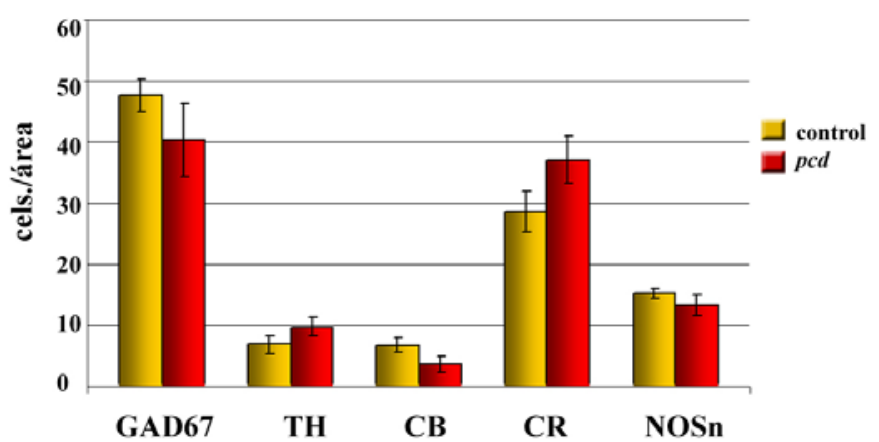

Figura 18. Comparación de la densidad de células yuxtaglomerulares GAD67, TH, CB, CR y NOSn-positivas en la CG de animales control y mutantes $p c d$.

Así, en los animales mutantes $p c d$, al igual que en los controles, observamos células ZnT3-positivas en la CG del BO, que identificamos mayoritariamente como PGs de tipo II, CR-NOSn-positivas y en menor proporción PGs de tipo I, THpositivas. No obstante, pese a no existir cambios significativos en las proporciones de colocalización entre animales control y pcd, sí existe un incremento significativo en la cantidad de células yuxtaglomerulares ZnT3 positivas en la CG (fig. 16). Consideramos entonces la posibilidad de que las células ZnT3 que aparecen en la CG de animales pcd y que no colocalizan con ninguno de los marcadores anteriores (puesto que los porcentajes de colocalización no varían), sean células empenachadas que expresan ZnT3 tras la pérdida de las células mitrales. Con el fin de comprobarlo, realizamos un recuento de las células empenachadas ZnT3-positivas que aparecen en la CG de animales control y pcd. Para una mejor identificación de dichas células, seleccionamos las fotos correspondientes a las dobles inmunofluorescencias ZnT3GAD67 (fig. 34A, C, G e I). Tomamos como células empenachadas externas aquellas células situadas en la región yuxtaglomerular, GAD67-negativas (Ribak y cols., 1977; Mugnaini y cols., 1984) y con un tamaño de soma considerablemente mayor al que presentan las células PGs $(13 \mu \mathrm{m}$ los somas de las células empenachadas externas mientras que el de las células PGs es de $6 \mu \mathrm{m}$ ). Los resultados del análisis cuantitativo muestran que tanto en los datos originales, como en los mismos corregidos en función del volumen en el animal pcd, existe un aumento significativo de células empenachadas ZnT3 positivas en los animales mutantes pcd (fig. 19). Por lo que, en este caso, el aumento de células ZnT3-positivas no se debe a un incremento en una población de células PGs concreta sino probablemente a que algunas células empenachadas comienzan a expresar este transportador tras la pérdida de las principales células de proyección del BO. 


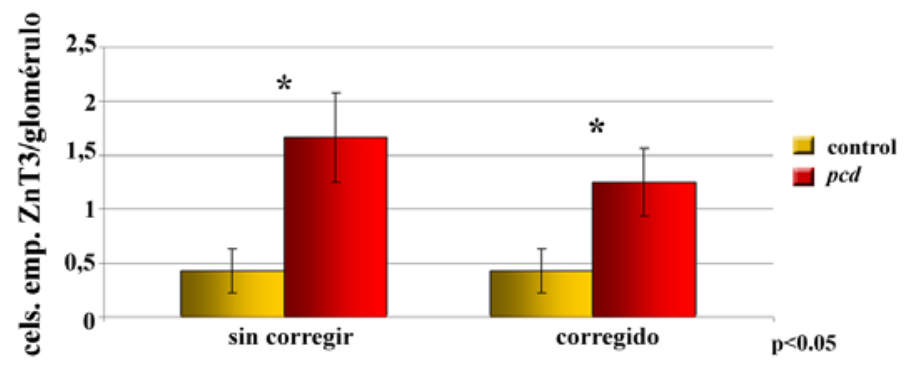

Figura 19. Número de células empenachadas ZnT3-positivas que aparecen por glomérulo en animales control y mutantes $p c d$. A la izquierda se representan los datos originales y a la derecha los mismos valores corregidos para la disminución de volumen que sufren los animales pcd. En ambos casos, la densidad de células empenachadas en los mutantes pcd es significativamente superior a la de los animales control.

A modo de resumen de todos los resultados recogidos en este trabajo, podemos decir que confirmamos el patrón de distribución de la inervación zincérgica en el BO principalmente en la CGr y en la CG. Observamos por primera vez en esta capa a nivel ultraestructural algunos cuerpos celulares positivos para el marcaje $\mathrm{ZnSe}^{\mathrm{AMG}}$. Describimos el marcaje para ZnT3 en algunos cuerpos celulares también de la CG, caracterizados como células PGs de tipo I y II, y detectamos el propio ARNm para ZnT3 en el BO. Estos hechos nos indican que la aparición de la proteína ZnT3 en esta estructura no se restringe a su presencia en los terminales zincérgicos, como hasta ahora se pensaba, sino que el BO posee células ZnT3-positivas propias. Además, comprobamos que las diferencias en el marcaje $\mathrm{ZnT} 3$ y $\mathrm{ZnSe}^{\mathrm{AMG}}$ en la CG del BO, así como la localización y el número de glomérulos ZEN, no son el resultado de una falta de sensibilidad del método del selenio, ni están relacionadas con los caracteres cuantitativos o cualitativos de la información olfatoria entrante. Por último, también hemos visto que el óxido nítrico está implicado en la aparición de la proteína ZnT3 en la CG y que la pérdida de las células mitrales en los animales ped supone un cambio en la expresión de algunas células empenachadas, que comienzan a expresar la proteína ZnT3. 



\section{ICONOGRAFÍA}



DISCUSIÓN 



\section{Discusión}

En esta sección examinaremos los resultados obtenidos, analizando sus posibles causas y planteando nuevas hipótesis de trabajo para futuros estudios. Así, para facilitar el seguimiento y la comprensión de este apartado seguiremos el mismo esquema que en la sección anterior. Analizaremos primero los nuevos aspectos de la modulación zincérgica en el BO: la presencia de astrocitos ZEN, la diferencia de marcajes en la CG y la presencia de glomérulos ZEN. Seguidamente, analizaremos la diferencia de marcaje en la CG comprobando la desaparición del marcaje ZnSeAMG por transporte retrógrado así como la sensibilidad de la técnica ZnSeAMG. A continuación, discutiremos los aspectos más relevantes sobre el papel de la proteína ZnT3 en el BO. Por último, indagaremos en la capacidad plástica del sistema zincérgico olfatorio a partir de los resultados obtenidos con los animales sometidos a enriquecimiento y deprivación olfatoria en primer lugar, y con los modelos genéticos (KO para nos y mutantes ped) en segudo lugar.

\section{Aspectos de la modulación zincérgica en el BO de animales silvestres}

\section{Astrocitos ZEN}

Nuestros datos demuestran que algunos astrocitos localizados en la zona externa de la CG y en la CFNO, contienen zinc. Así, observamos pequeños depósitos positivos, próximos a la superficie extracelular (fig. 24B); mientras que en regiones más internas observamos endosomas/lisosomas de mayor tamaño con depósitos de plata (fig. 24C). Según la primera descripción del marcaje de zinc obtenido con el $\mathrm{ZnSe}^{\mathrm{AMG}}$, la glía del SNC no presentaría marcaje positivo, con la excepción de algunos astrocitos del cerebelo y del hipotálamo que contienen precipitados granulares dentro de su cuerpo celular (Danscher, 1982). A tenor de este primer trabajo, la población glial y la homeostasis vesicular de zinc no parecían tener nexos comunes. No obstante, trabajos posteriores demostraron que las células gliales son capaces de sobrevivir y volverse reactivas bajo concentraciones de zinc que serían letales para las neuronas (Dineley y cols., 2000; Choi y cols., 1988; Ordy y cols, 1993; Lin y cols., 1998; Sheline y cols., 2002, 2004; Suh y cols., 2001). Se sabe que 
los astrocitos tienen un papel relevante, no sólo en la eliminación de los neurotransmisores de la hendidura sináptica, sino también en la captación del zinc extracelular (Varea y cols., 2006). Hoy en día sabemos que el zinc puede introducirse en el citoplasma astrocitario atravesando la membrana plasmática mediante canales de calcio regulados por voltaje y salir por ella a través del transportador de zinc ZnT1 (Sheline y cols., 2004). No obstante, el fenómeno más llamativo es la captación de zinc por vía microfagocítica, mediante la cual los astrocitos captarían el zinc en pequeñas vesículas, probablemente recubiertas de clatrina, que seguirían la vía endosomal-lisosomal (Holm, 1989; Varea y cols., 2006). Estos endosomas y lisosomas, con zinc en su interior, se han denominado zincosomas (Haase y Beyersmann, 2002). El hecho de que observemos una gran cantidad de depósitos de plata en las vesículas endosomiales-lisosomiales de los astrocitos del BO podría indicar que el zinc se haya incorporado al interior celular siguiendo una ruta microfagocítica.

Algunos astrocitos expresan proteínas encargadas de la unión de zinc intracelular, las MTs. Por ejemplo, en el SNC las MT-I y MT-II aparecen en astrocitos tanto durante el desarrollo como a lo largo de toda la vida adulta (Penkowa y cols., 1999). En el BO, se ha documentado la existencia de inmurreactividad a MTI en los astrocitos que se sitúan en la superficie pial, junto a la CFNO (Penkowa y cols., 1999). En función de la caracterización realizada por Bailey y Shipley (1993), de los 6 subtipos de astrocitos que aparecen en el BO, los localizados junto a la CFNO se corresponderían con los astrocitos de tipo 1 y 2, de morfología unipolar e irregular respectivamente, y de localización exclusiva en la CFNO. Estos hechos concuerdan con nuestras observaciones de marcaje $\mathrm{ZnSe}^{\mathrm{AMG}}$-positivo en los astrocitos de esa zona. Se sabe que la expresión de las proteínas MT-I y II es inducible por zinc (Malaiyandi y cols., 2004), lo que explica el comportamiento protector de los astrocitos frente a incrementos de zinc. El zinc induce un aumento en la expresión de las proteínas MT-I y II, que en última instancia tamponan la concentración de zinc citoplasmático (Malaiyandi y cols., 2004). Los astrocitos positivos para MT-I y II también aparecen en el hipocampo y la corteza cerebral, regiones en las que ya se sugirió la captación por estos astrocitos del exceso de zinc, que de otro modo podría causar graves daños neuronales (Koh y cols., 1996; Penkowa y cols., 1999). Esto supone un nexo de unión común entre el BO y otras zonas ricas en proyecciones zincérgicas. Todos estos datos indican que en el BO 
existe un subtipo especial de astrocitos que está directamente relacionado con la eliminación de zinc en zonas con una gran densidad de terminales ZEN, sugiriendo que en la CG existe una gran liberación de zinc que ha de ser rápidamente tamponada por los astrocitos.

Además del marcaje en endosomas/lisosomas, nuestros resultados muestran que el zinc también se puede acumular en la red trans del AG astrocitario (fig. 24D). Se conocen varios transportadores de zinc, concretamente ZnT4-ZnT7 y ZIP7 que se localizan en la membrana del AG (Lichten y Cousins, 2009). Aunque ZnT4 y ZnT5 son más conocidos por su expresión en las glándulas mamarias y en el páncreas (Huang y Gitschier, 1997; Kambe y cols., 2002), todos ellos se expresan en neuronas del cerebro y algunos, incluso en un tipo glial particular, la glía de Bergmann del cerebelo (Huang y cols., 2002; Kirschke y Huang, 2003; Huang y cols., 2005; Wang y cols., 2005; Gao y cols., 2009). En el AG ocurren las modificaciones postraduccionales y el direccionamiento y empaquetamiento final de las proteínas, luego la localización de zinc en este lugar está relacionada con la formación de proteínas que poseen zinc en su estructura (Wang y cols., 2005). No obstante, se ha sugerido también que el AG actúa como un orgánulo reservorio de zinc, acumulando este elemento cuando la concentración citosólica es elevada y transportándolo al citosol cuando es necesario (Huang y cols., 2005). El marcaje del AG se observa sobre todo tras la inyección de $\mathrm{ZnCl}_{2}$. Además, el marcaje $\mathrm{ZnSe}^{\mathrm{AMG}}$ detecta acumulaciones de zinc. Por ello pensamos que el zinc observado en el AG astrocitario probablemente está siendo almacenado en este orgánulo como protección celular ante el incremento de zinc que ocurre tras la inyección de $\mathrm{ZnCl}_{2}$.

Por otro lado, la localización del transportador ZnT3 en neuronas de la CG del $\mathrm{BO}$ y no así en células gliales, coincide con los resultados descritos en el trabajo de Valente y Auladell (2002). En dicho estudio se describe la localización del marcador glial de astrocitos, GFAP, en células zincérgicas de la sustancia blanca y en distintos neuroepitelios durante las etapas tempranas de vida, mientras que a partir del día postnatal 12 no aparecen células GFAP-positivas con zinc vesicular en su interior. La única excepción descrita hasta la fecha es el caso de la glía de Bergmann del cerebelo del ratón (Wang y cols., 2005). Estas células contienen zinc vesicular y además expresan gran cantidad de transportadores ZnTs, entre ellos, ZnT3. A diferencia de lo observado en nuestro trabajo, la proteína ZnT3 en este tipo celular colocaliza con el marcador glial S-100 y no así con el marcador neuronal MAP2. 
Por todo ello, pensamos que los astrocitos de la CFNO del BO del ratón constituyen un subgrupo celular con identidad propia, con una morfología, localización y función íntimamente relacionadas con los elementos zincérgicos que confluyen en la CG y el mantenimiento de la homeostasis de zinc en el medio extracelular; cualidades que los hacen especiales y diferentes al resto de astrocitos del BO.

\section{Zinc y ácido quinolínico}

El descubrimiento de astrocitos en la CG con zinc en su interior, sugiere la participación de un tipo astroglial concreto, que colaboraría en la eliminación de zinc extracelular en la CG. A partir de las siguientes premisas proponemos una hipótesis acerca del funcionamiento de estos astrocitos:

1. El ácido quinolínico o 2,3 piridino dicarboxílico (QUIN), es un metabolito endógeno tóxico que se forma a partir de la degradación del triptófano, con la participación de la enzima ácido 3-hidroxiantranílico oxigenasa (3HAO). Se degrada hasta formar nicotinamín adenín dinucleótido $\left(\mathrm{NAD}^{+}\right)$, en una reacción catalizada por la enzima ácido quinolínico fosforribosil transferasa (QPRT, Speciale y cols., 1987).

2. La toxicidad causada por el QUIN en los tejidos neuronales se ve contrarrestada tras la adición de zinc, de forma que los iones zinc previenen el daño celular producido por este metabolito (Kida y Matyja, 1990).

3. Buena parte de las moléculas desarrolladas para la visualización fluorescente de zinc, proceden de la familia de la $N$-(6-methoxy-8-quinolyl)-ptoluensulfonamida o TSQ; un derivado del QUIN. Este compuesto es utilizado como grupo ionóforo de unión al zinc, debido a su alta afinidad por el ión (Nolan y cols., 2005).

4. Existe marcaje positivo para $3 \mathrm{HAO}$ y QRPT en astrocitos del hipocampo del ratón (Köhler y cols., 1988).

5. Al igual que ocurre en el hipocampo, la distribución de las enzimas $3 \mathrm{HAO}$ (formadora de QUIN) y QPRT (encargada de su degradación), en el BO del ratón se limita sólo y exclusivamente a células gliales, concretamente a astrocitos. Mientras que los astrocitos que expresan 3HAO se localizan en la región entre la $\mathrm{CG}$ y la $\mathrm{CPE}$, los que poseen QPRT se encuentran en la región entre la CG y la CFNO. Así, existe un gradiente de QUIN en la CG, desde su 
formación junto a la CPE hasta su degradación en los astrocitos de la CFNO (Poston y cols., 1991).

Con todos estos datos, proponemos que las moléculas de QUIN formadas en el límite entre la CG y la CPE (fig. 35), podrían interceptar los iones zinc de la hendidura sináptica, constituyendo un complejo intermedio zinc-QUIN, estable e inocuo. En la región próxima al NO, los astrocitos que expresan QPRT incorporarían los complejos zinc-QUIN, facilitando por un lado, la ruta de catalización del QUIN hasta $\mathrm{NAD}^{+}$, y por otro, uniendo el zinc a las MT-1 y MT-2 que poseen (Penkowa y cols., 1999).

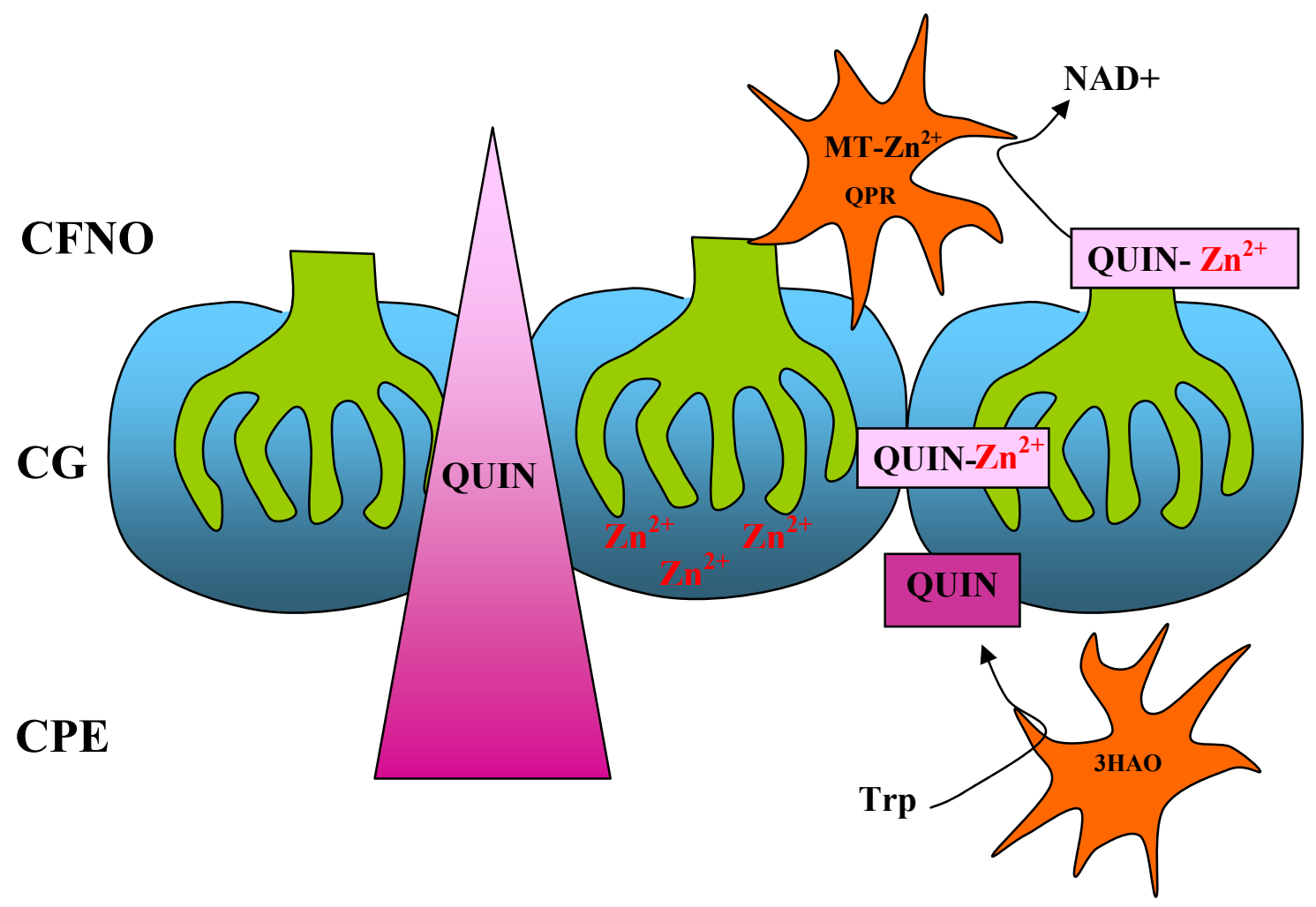

Figura 35. Esquema de la ruta del QUIN formado en la CG desde su producción en los astrocitos (figuras en naranja) situados entre la CPE y la CG, hasta su eliminación en los astrocitos situados entre la CG y la CFNO. El gradiente de QUIN producido en la CG (triángulo rosa), proporciona un estado intermedio QUIN-Zn ${ }^{2+}$ (rosa claro), que previene la toxicidad del QUIN, a la vez que proporciona un sistema sumidero para los iones $\mathrm{Zn}^{2+}$ liberados desde el NO (verde).

Esta hipótesis explicaría, al menos en parte, la rápida desaparición del zinc del neuropilo glomerular $\mathrm{y}$, por tanto, la ausencia de marcaje $\mathrm{ZnSe}^{\mathrm{AMG}}$ detectada en 
nuestro estudio, una vez liberado en la sinapsis. El hecho de que un sistema similar se encuentre en el hipocampo (Köhler y cols., 1988), asociado a regiones donde ocurren grandes liberaciones de zinc (las sinapsis de las fibras musgosas con las células de la capa CA3), indica que el gradiente de QUIN generado entre estos astrocitos puede constituir un sistema sumidero, que colabore en la eliminación de grandes cantidades de zinc del medio externo, al tiempo que procura la neutralización temporal del QUIN. De confirmarse esta hipótesis estaría indicando que, a pesar de la ausencia de marcaje $\mathrm{ZnSe} \mathrm{AMG}^{\mathrm{AM}}$ en la $\mathrm{CG}$, existe una gran liberación de zinc en dicha zona.

\section{Diferencia entre el marcaje inmunohistoquímico y ZnSe ${ }^{\mathrm{AMG}}$ en la CG}

El estudio de la distribución del sistema zincérgico en el BO mediante el $\mathrm{ZnSe}^{\mathrm{AMG}}$ y la inmunohistoquímica para el transportador ZnT3 (Jo y cols., 2000; Airado, 2005; Airado y cols., 2008), plantea un interrogante: ¿Cómo se estructura el sistema zincérgico en la CG del BO para que observemos inmunomarcaje ZnT3 en el interior de todos los glomérulos y sólo observemos marcaje $\mathrm{ZnSe} \mathrm{AMG}^{\mathrm{AM}}$ en el neuropilo de algunos de ellos, los glomérulos ZEN? A microscopía electrónica se observan terminales ZEN en la CG; los describieron Jo y cols. (2000) en los ratones BALB/c y los hemos descrito en este trabajo para los ratones de la colonia C57/6J-DBA72J. Sin embargo, la proporción de marcaje $\mathrm{ZnSe}^{\mathrm{AMG}} / \mathrm{ZnT} 3$ no resulta equivalente. La existencia de zinc en las NROs ha sido observada en este trabajo y anteriormente en un estudio en el que se muestra que buena parte del zinc del BO de la rata se concentra en la CG (Friedman y Price 1984). Entonces, ¿Por qué el neuropilo de los glomérulos no se marca con el $\mathrm{ZnSe}^{\mathrm{AMG}}$ ?

Cuando Jo y cols. (2000) describieron la distribución de los terminales ZEN en el $\mathrm{BO}$ del ratón $\mathrm{BALB} / \mathrm{c}$, emplearon las mismas técnicas utilizadas en éste y otros trabajos previos (Airado, 2005; Airado y cols., 2008), a saber, el $\mathrm{ZnSe}^{\mathrm{AMG}}$ y la inmunohistoquímica para ZnT3. A pesar de que en su estudio consideran que el marcaje entre ellas es equivalente, su iconografía demuestra que el patrón de distribución del transportador ZnT3 ocupa el total de la superficie glomerular, mientras que el marcaje $\mathrm{ZnSe}^{\mathrm{AMG}}$ se distribuye únicamente en la región yuxtaglomerular (fig. 36). Tras comparar nuestros resultados con los suyos, podemos afirmar que la diferencia entre ambos marcajes en la $\mathrm{CG}$ del $\mathrm{BO}$ es un rasgo propio del sistema zincérgico del ratón. 

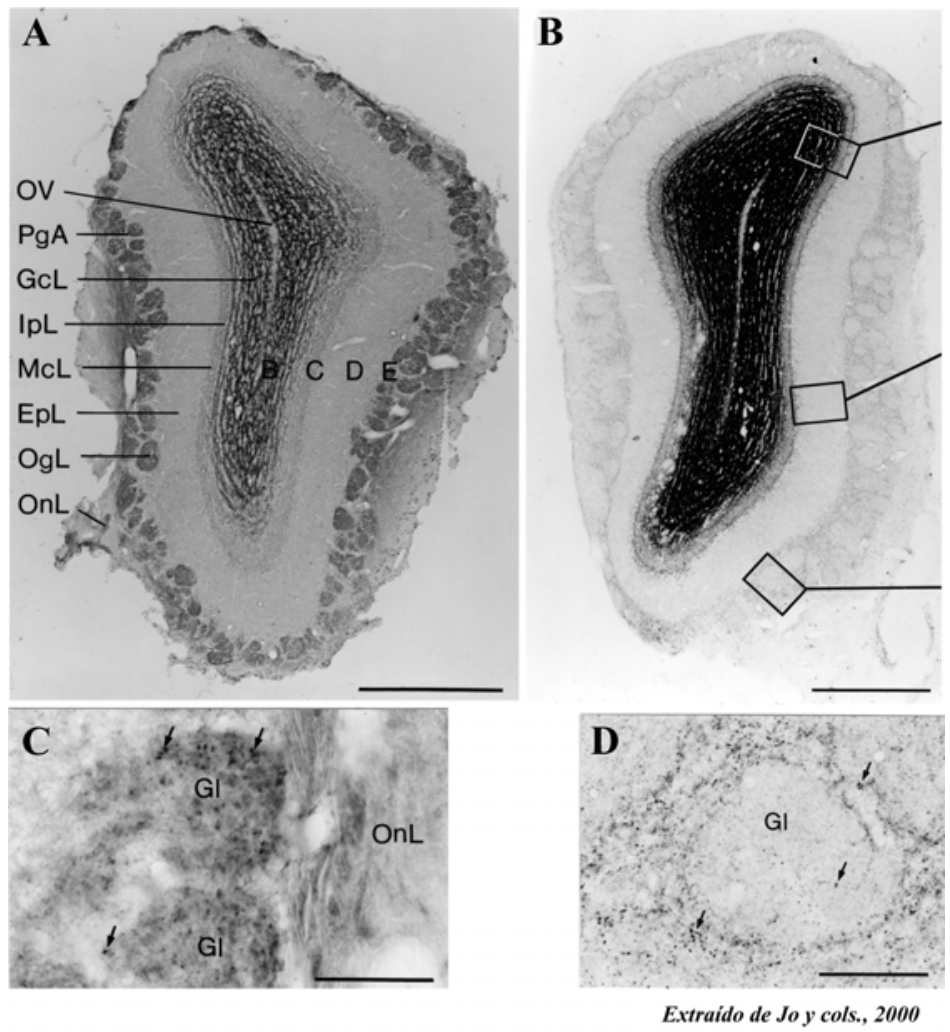

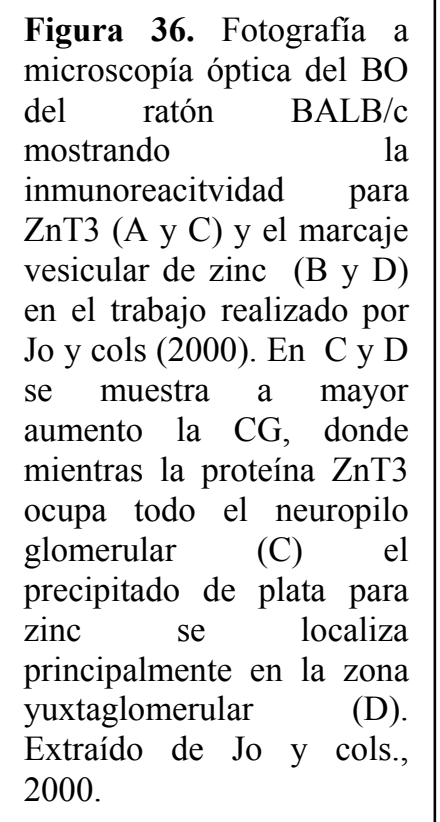

Desde que Cole y cols. (1999), confirmaran la carencia de zinc en el ratón $\mathrm{KO}$ para $\mathrm{ZnT3}\left(\mathrm{ZnT3}^{-/}\right)$, el empleo de la técnica inmunohistoquímica para dicha proteína se ha incorporado como una herramienta al uso para la localización de los elementos zincérgicos. Así, se considera que existe una correlación entre ambos métodos, que se ha demostrado en la mayor parte de los casos (Wenzel y cols., 1997; Cole y cols., 1999; Wang y cols., 2001, 2002a, b; Valente y Auladell, 2002; Redenti y Chappell, 2004; Stoltenberg y cols., 2004, Chi y cols., 2008, Jo y cols., 2008). No obstante, también se han documentado incongruencias en el marcaje entre ambas técnicas: en algunos estadios tempranos del desarrollo postnatal del ratón, el marcaje $\mathrm{ZnSe}^{\mathrm{AMG}}$ aparece antes de que se exprese el ARNm para ZnT3 (Valente y Auladell, 2002). También, en el ganglio cervical superior de ratón se ha observado una mayor 
cantidad de células $\mathrm{ZnSe}{ }^{\mathrm{AMG}}$-positivas que ZnT3-positivas (Wang y cols., 2003). Otro ejemplo es la corteza del ratón, que presenta un patrón de marcaje zincérgico en los barriles que no se corresponde con marcaje para la proteína ZnT3 (Liguz-Lecznar y cols., 2005). Además, en el hipocampo de ratones adrenalectomizados, ocurre a las $24 \mathrm{~h}$ tras la operación una disminución en el inmunomarcaje para el transportador $\mathrm{ZnT} 3$ que no se corresponde temporalmente con el descenso en el marcaje $\mathrm{ZnSe}^{\mathrm{AMG}}$, pues éste ocurre 30 días después del proceso quirúrgico (Suh y cols., 2005). Por último, las dendritas de los granos del giro dentado del hipocampo de ratón poseen inmunomarcaje para ZnT3, pero no presentan marcaje Timm-positivo (Palmiter y cols., 1996a; Wenzel y cols., 1997). Después de este último ejemplo, que presenta un caso paralelo al de la CG del BO, Frederickson y cols. (2000), sugirieron la existencia de neuronas que expresaban ZnT3 pero cuyas vesículas presinápticas no contenían zinc debido a posibles modificaciones postraduccionales del transportador. Sin embargo, la falta de investigaciones posteriores para esclarecer la incongruencia señalada en el hipocampo dejó la cuestión sin resolver.

Todos estos ejemplos demuestran que la correlación entre ambas técnicas no es siempre total, por lo que quizá estén interviniendo otros factores en la homeostasis de zinc que den lugar al desfase final entre ambos marcajes.

\section{Participación de otras proteínas}

Se ha descrito que el contenido en zinc de las vesículas ZnT3-positivas no depende únicamente de los transportadores $\mathrm{ZnT3}$, sino que existen otras proteínas responsables. Por ejemplo, los transportadores de cloruro $\mathrm{ClC}-3$, también se encuentran en la membrana de las vesículas zincérgicas y son co-responsables de su contenido final en zinc (Salazar y cols., 2004). La existencia de diferentes complejos adaptadores AP-3, encargados de la translocación de ZnT3 y ClC-3 a la membrana vesicular (Kantheti y cols., 2003; Seong y cols., 2005), en función de las subunidades que lo conformen, implica la aparición de diferentes patrones zincérgicos en el hipocampo de ratones en lo que a la cantidad de zinc vesicular se refiere. Incluso la proteína vimentina, formadora de filamentos intermedios del citoesqueleto, parece estar implicada en el contenido luminal de las vesículas ZnT3 positivas, puesto que el fenotipo zincérgico alterado de células mutantes para AP3 y vimentina, es idéntico (Styers y cols., 2004). Con todo ello, se pone de manifiesto la intervención de otras proteínas, menos estudiadas pero no por ello menos importantes, en la aparición o no 
de zinc dentro de las vesículas presinápticas ZnT3-positivas, lo que podría explicar la existencia de ZnT3 pero no de zinc en el neuropilo glomerular. No debemos olvidar que ambos marcajes van dirigidos a diferentes dianas: con el $\mathrm{ZnSe}^{\mathrm{AMG}}$ detectamos los iones zinc que se encuentran en el interior de las vesículas presinápticas, mientras que con la técnica inmunohistoquímica para ZnT3 marcamos el transportador vesicular que se encarga de bombear esos iones al interior de dichas vesículas.

Dado que esta diferencia la encontramos en toda la $\mathrm{CG}$, excepto en los glomérulos a los que hemos denominado glomérulos ZEN, pensamos que la homeostasis de zinc en la CG puede seguir unas pautas específicas en función de la actividad olfatoria entrante, lo que nos inclinó a estudiar en detalle los glomérulos ZEN.

\section{Glomérulos ZEN}

Hasta la fecha no existe ninguna documentación acerca de glomérulos olfatorios con una carga zincérgica diferencial ni en el ratón ni en otras especies animales de experimentación. Aún así, no es un suceso extraño, pues la heterogeneidad es uno de los rasgos más característico de la CG del BO.

En función de las aferencias primarias, se han descrito entre otros: glomérulos específicamente positivos para una glicoforma de la molécula de adhesión celular NCAM, llamada NOC-3 (St John y Key, 2001), glomérulos que expresan específicamente el antígeno placentario humano (hPAZ-P2), también llamados necklace por su localización en forma de collar (Shinoda y cols., 1989, 1990), glomérulos positivos a la actividad histoquímica NADPH-diaforasa (Davis, 1991; Alonso y cols., 1993, 1995), glomérulos que se activan únicamente durante la lactancia y que forman el complejo glomerular modificado (Teicher y cols., 1980; Greer y cols., 1982), y glomérulos que expresan la proteína de adhesión celular protocadherina-20 (Lee y cols., 2008).

En lo referente a las dianas glomerulares de las aferencias centrífugas, la existencia de heterogeneidad glomerular está documentada desde hace más de 20 años por Zheng y cols. (1987). Estos autores observaron una población glomerular localizada en las zonas ventro-laterales y dorsales, caracterizada por poseer una fuerte inervación colinérgica. Estudios posteriores han demostrado que estos glomérulos denominados atípicos, se diferencian de los típicos, no sólo en la alta inervación colinérgica, sino también en la inervación selectiva por otros sistemas 
centrífugos (Zheng y cols., 1988; Gómez y cols., 2005), en la presencia de diferentes tipos de aferencias primarias (Zheng y Jourdan, 1988), y en que se encuentran rodeados por subpoblaciones diferentes de neuronas yuxtaglomerulares (Crespo y cols., 1996, 1997b).

La existencia de glomérulos ZEN aumenta la heterogeneidad glomerular, indicando que algunos glomérulos presentan en su neuropilo una gran carga zincérgica con origen bien en las aferencias primarias procedentes del epitelio olfatorio, bien en las fibras centrífugas originadas de centros olfatorios secundarios, o incluso, a la vista de nuestros resultados, podría tener su origen en las células PG del BO.

En este trabajo hemos propuesto diferentes razonamientos para esclarecer por un lado, los mecanismos que hacen que el sistema zincérgico muestre una manifestación histológica tan característica y poco frecuente en esta estructura, y por otro, las implicaciones funcionales que ésta pueda tener. El empleo de modelos animales deprivados, sometidos a enriquecimiento y modelos genéticos, nos ayudará a comprender la implicación de la actividad olfatoria entrante, del óxido nítrico y de las células de proyección del $\mathrm{BO}$ en la aparición de este patrón de marcaje zincérgico característico.

\section{Comprobación de la desaparición de marcaje ZnSe ${ }^{A M G}$ por transporte retrógrado}

Uno de los primeros planteamientos que nos hemos hecho al observar la carencia de terminales $\mathrm{ZnSe}^{\mathrm{AMG}}$ en el neuropilo glomerular en comparación con la cantidad de transportador que allí aparecía (Airado y cols., 2008), es la posibilidad de que el propio transporte retrógrado hacia el soma de los complejos zinc-selenio a lo largo del axón de las NROs, provoque esta "eliminación” del zinc neuropilar. Durante la hora de espera desde la inyección de selenito sódico hasta el sacrificio del animal, los complejos zinc-selenio en las vesículas presinápticas podrían haber recorrido retrógradamente una distancia suficiente para desaparecer del neuropilo glomerular y localizarse en los somas de origen (Brunetti y cols., 1987; Viancour y Kreiter, 1993). Puesto que, nuestro trabajo no se centra en el análisis de los somas del epitelio olfatorio, y considerando la posibilidad de que el zinc sea transportado rápidamente hacia esa región, realizamos una prueba en la que un animal fue 
sacrificado a los 5 minutos tras la inyección de selenito sódico (tiempo en el que los complejos zinc-selenio aún estarían situados en el neuropilo glomerular). El patrón de marcaje $\mathrm{ZnSe}^{\mathrm{AMG}}$ observado en dicho animal en la $\mathrm{CG}$ fue el mismo que el que presentan los animales que siguieron el procedimiento estandarizado. Por lo tanto, el transporte retrógrado del zinc a los somas de las NROs no era el motivo de la falta de marcaje $\mathrm{ZnSe}^{\mathrm{AMG}}$ en el neuropilo glomerular.

\section{Animales sobre- expuestos a zinc: verificación de la sensibilidad del método}

Nos planteamos si la cantidad de iones zinc en los terminales ZEN de la CG no sería lo suficientemente alta como para ser detectada por el selenito sódico. Es decir, si el método empleado no estaba siendo lo suficientemente sensible. Para verificarlo estudiamos el marcaje en animales sobre-expuestos a zinc. Según nuestros resultados, la sobrecarga de zinc conllevó un incremento en la intensidad global del patrón de marcaje en el BO. A pesar de ello, el marcaje $\mathrm{ZnSe}^{\mathrm{AMG}}$ del neuropilo glomerular seguía siendo escaso, por lo que dedujimos que el desfase de marcaje entre las dos técnicas en la CG no era debido a la sensibilidad del método. Esto demuestra que la modulación llevada a cabo por el zinc en la CG es particular y no sigue los patrones observados en otras regiones.

El hecho de que el número de precipitados $\mathrm{ZnSe}^{\mathrm{AMG}}$ se incrementara tras la inyección con $\mathrm{ZnCl}_{2}$, nos hizo plantearnos si estaba ocurriendo una sobrecarga de zinc en los elementos ZEN existentes, o bien, si se estaban incorporando nuevos elementos zincérgicos al sistema, produciéndose, de esta manera, un cambio plástico en las proyecciones, al verse sometido el medio externo a un fuerte incremento de zinc. Nuestros resultados ultraestructurales muestran que, aunque la cantidad de terminales ZEN en la CG parece permanecer estable, la densidad de terminales $\mathrm{ZnSe}^{\mathrm{AMG}}$-positivos se incrementa notablemente en la CGr mientras que la cantidad de vesículas presinápticas marcadas por terminal permaneció constante. Nuestro resultado coincide con una observación previa, en la que se describe la incorporación del zinc en el cerebro a los 6 días tras la inyección de ${ }^{65} \mathrm{ZnCl}_{2}$ (Takeda y cols., 2001). En dicho trabajo se muestra cómo además de incorporarse en la CGr del BO, aparece una mayor cantidad de zinc radiactivo en otras regiones zincérgicas, como el giro dentado del hipocampo, la amígdala y el cerebelo (Takeda y cols., 2001). 
Por un lado, pensamos que el incremento en el número de terminales zincérgicos en la CGr podría tratarse de una manifestación de la sensibilidad de la técnica, de modo que el nuevo grupo de terminales ZEN que observamos en los animales inyectados ya fuesen zincérgicos anteriormente, pero debido a una baja cantidad de zinc en sus vesículas antes no eran detectados y tras el incremento en zinc se hacen visibles. Por otro, un incremento en el número de terminales ZEN podría suponer un cambio real en la identidad de algunas fibras que estaban proyectando a la CGr, que no eran zincérgicas y tras el incremento global de zinc adquieren el fenotipo zincérgico. Así, la manifestación histológica observada sería reflejo de los mecanismos que ponen en marcha las neuronas cuando la concentración de zinc en el medio extracelular aumenta. De hecho, la expresión de gran parte de las proteínas específicas de la homeostasis zincérgica, como ZnT1, ZnT5, ZnT6, ZIP1, ZIP2, ZIP4, ZIP5, ZIP10 o las MTs, está regulada por zinc (Heuchel y cols., 1994; Costello y cols., 1999; Langmade y cols., 2000; Cao y cols., 2001; Liuzzi y cols., 2001; Iguchi y cols., 2002; Devergnas y cols., 2004; Qin y cols., 2004; Wimmer y cols., 2005; Jackson y cols., 2007, 2008; Weaver y cols., 2007). Teniendo en cuenta estos datos, pensamos que ocurre un cambio de identidad en algunos terminales centrífugos, pasando a ser ZEN. Es decir, las fibras zincérgicas de la CGr poseen una capacidad plástica frente a cambios en la concentración de zinc en el organismo que no comparten los elementos ZEN de la CG del BO, lo que resalta el carácter especial de la inervación zincérgica que se localiza en esta capa.

Además, según nuestros resultados, las células PG presentan zinc no sólo en vesículas, como ocurría en los ratones control no inyectados, sino también en la cara trans del AG. Esta modificación podría estar también asociada a la variación en la expresión de los transportadores ZnT implicados en el transporte hacia ese orgánulo, que actuará como reservorio como consecuencia de una sobrecarga de zinc (Devergnas y cols., 2004; Jackson y cols., 2007, 2008; Weaver y cols., 2007).

\section{Estudio de la proteína ZnT3}

\section{Localización de ZnT3 en la CG y heterogeneidad glomerular}

La presencia del transportador ZnT3 en el BO de ratones BALB/c fue descrita en el año 2000 por Jo y cols. Estos autores señalan que el inmunomarcaje en la CG es especialmente denso en el área yuxtaglomerular y en la mitad externa de cada 
glomérulo. Este dato coincide parcialmente con nuestras observaciones previas (Airado, 2005; Airado y cols., 2008) y con las actuales, puesto que al analizar la CG en su conjunto, observamos que la fuente mayoritaria de proteína ZnT3 en esta capa son las NROs, mientras que el resto se repartiría entre las fibras centrífugas y la procedente de las células PGs ZnT3-positivas. Estos resultados confirmarían la existencia de ZnT3 en los terminales de las NROs como principal fuente zincérgica de la CG (Friedman y Price, 1984; Jo y cols., 2000). Sin embargo, los resultados del análisis de doble inmunofluorescencia entre las proteínas ZnT3 y OMP, indican que existen diferencias interglomerulares en cuanto a la distribución de la proteína ZnT3 con respecto a la zona-NO y la no-NO, pudiéndose diferenciar tres tipos de glomérulos. El análisis de confocalidad mostró que tales diferencias no eran el resultado de los distintos niveles de corte en cada glomérulo, puesto que las imágenes seleccionadas para el análisis cuantitativo, se tomaron en el plano medio de grosor para cada glomérulo. Además, los diferentes tipos de glomérulos no tienen una localización precisa en el volumen bulbar, de hecho, no observamos diferencias llamativas entre regiones dorso-ventrales, latero-mediales o antero-posteriores del BO.

Como vimos en la primera parte de la discusión, no es de extrañar que existan glomérulos diferentes en función de la distribución de la proteína ZnT3, puesto que la heterogeneidad es un rasgo característico en la CG (Teicher y cols., 1980; Greer y cols., 1982; Zheng y cols., 1987; Shinoda y cols., 1989, 1990; Davis, 1991; Alonso y cols., 1993,1995; St John y Key, 2001; Lee y cols., 2008). Sin embargo, todos estos casos responden a grupos de glomérulos bien establecidos, además de por su marcaje característico, por su localización constante en el BO, mientras que en este caso, los diferentes patrones de distribución intraglomerular de la proteína ZnT3 parecen encontrarse distribuidos en todos los animales estudiados, de manera aleatoria en la CG. Esto nos lleva a pensar que posiblemente los tres tipos de glomérulos descritos no indiquen una identidad zincérgica predeterminada, sino que presentan estadios diferentes de la expresión del transportador ZnT3 en función de la necesidad glomerular. Puesto que, en nuestro trabajo de Tesis Doctoral hemos descrito que existen tres fuentes zincérgicas en la CG (los terminales de las NROs, los terminales de las fibras centrífugas y las células PG), la regulación traduccional en cada una de estos elementos daría lugar a la generación de los diferentes patrones de distribución intraglomerular de ZnT3. De este modo el estado fisiológico glomerular, así como la 
presencia de determinados factores externos (los glucocorticoides y los estrógenos regulan la expresión de ZnT3; Lee y cols., 2004; Suh y cols., 2005), determinarían la cantidad de proteína presente en cada instante en cada uno de los tres lugares de localización de ZnT3.

\section{¿Posee el BO su propio sistema zincérgico intrínseco?}

Uno de los resultados más relevantes que aporta nuestro estudio es la descripción de células que poseen ZnT3 y que son, en su mayoría, GABA-érgicas en la CG del BO. Este descubrimiento, se contrapone con dos afirmaciones previamente establecidas en el conocimiento del sistema zincérgico en general y del sistema olfatorio en particular: la exclusividad de las neuronas ZEN como una subpoblación de neuronas glutamatérgicas en el cerebro anterior o prosencéfalo y, el origen externo de los terminales ZEN en el BO (las NROs y las fibras centrífugas). Desde las primeras descripciones de las neuronas zincérgicas, se ha considerado como uno de sus rasgos de identidad su carácter glutamatérgico (Frederickson y Moncrief, 1994; Frederickson y cols., 2000; Takeda, 2000; Colvin y cols., 2003). Así, en el trabajo de Wang y Dahlström (2008), la primera de las cinco premisas que debe cumplir toda neurona del cerebro anterior para ser considerada zincérgica es que posea una naturaleza glutamatérgica. Incluso algunos autores denominan a las neuronas zincérgicas, neuronas gluzinérgicas (gluzinergic neurons, Frederickson, 1989; Frederickson y Bush, 2001). En contraposición con estos datos, nuestros resultados demuestran que en el BO de ratones, existen neuronas ZnT3-positivas inhibitorias, no glutamatérgicas.

A pesar de que en cerebro rostral las neuronas ZEN se consideran glutamatérgicas, la existencia de células ZnT3-GAD-positivas sí se había descrito previamente en estructuras caudales del SNC. Así, en el año 2001 se observaron neuronas zincérgicas en la médula espinal (Wang y cols., 2001). Posteriormente, también se detectaron células GABAérgicas con zinc en el cerebelo: las células de Golgi y las células en cesto (Wang y cols., 2002a). Al igual que hemos observado en las interneuronas ZnT3-positivas del BO, todas las células de Golgi y las células en cesto del cerebelo de ratón son GAD-positivas, pero no todas las GAD-positivas lo son también para el marcador ZnT3. De esta forma, el BO y el cerebelo parecen coincidir en la existencia en ambas estructuras de una subpoblación de interneuronas inhibitorias que expresan ZnT3. 
La caracterización detallada de las células ZnT3 bulbares demostró que una subpoblación colocalizaba con la enzima $\mathrm{TH}$, por lo que fue incluida dentro del grupo de PGs de tipo I, que contactan con el NO. No es la primera vez que se observan elementos neuronales dopaminérgicos ZnT3-positivos. Algunas neuronas del sistema nervioso periférico de roedores localizadas en el ganglio lumbar y en el ganglio cervical superior, presentan inmunomarcaje positivo para ZnT3 y TH (Wang y cols., 2002b, 2003; Wang y Dahlström, 2008). Aunque en estos casos, la presencia de $\mathrm{ZnT} 3$ y de marcaje $\mathrm{ZnSe}{ }^{\mathrm{AMG}}$ en somas era escasa, la ruptura del nervio ciático o el tratamiento con colchicina hacían que el zinc se acumulara en el soma celular, facilitando su visualización. Sin embargo, frente a la presencia de ZnT3 en los cuerpos celulares, la imposibilidad de obtener marcaje ZnT3-positivo en sus terminales axónicos, planteó un nuevo interrogante sobre el significado funcional de estas células. Wang y Dahlström, (2008), argumentan la existencia de una baja concentración de ZnT3, o bien la modificación postraduccional de la proteína, como causa de la ausencia de inmunomarcaje en los terminales de estas células. Puesto que, nuestros resultados muestran la existencia de marcaje para la proteína ZnT3 en el soma de células PGs, pero no observamos zinc vesicular en los terminales de las mismas, ambas explicaciones pueden ser aplicadas también en el BO.

En cuanto al significado funcional de las células ZnT3-positivas dopaminérgicas, las NROs en la CG del BO presentan receptores GABA-A y GABA-B (de Blas y cols., 1988; Keller y cols., 1998; Kratskin y cols., 2006). Sabemos que los iones zinc modulan la actividad de ambos receptores, atenuando la inhibición celular que ocurre tras su unión a GABA (Xie y Smart; 1991; Qian y cols., 1996; Ruiz y cols., 2004), por lo que las neuronas ZnT3-GAD-TH-positivas, en caso de liberar zinc durante la sinapsis, llevarían a cabo la disminución de la inhibición de la información olfatoria entrante a través del NO, facilitando por tanto su transmisión hacia el resto de estaciones de relevo.

Además de las PGs TH-positivas, también encontramos colocalización entre PGs ZnT3-positivas con la proteína ligante de calcio CR y con la enzima NOSn. En el ratón, el 70\% de las PGs que expresan NOSn constituyen una subpoblación de las PGs CR-positivas de tipo II (Kosaka y Kosaka, 2007), por lo que, es posible que estemos detectando la misma población de células ZnT3-positivas con los marcadores NOSn y CR, teniendo así una subpoblación de PGs tipo II GAD-CRNOSn-ZnT3-positivas. A día de hoy, no tenemos datos de células que expresen el 
transportador ZnT3 junto con CR o NOSn, por lo que desconocemos si la proteína ZnT3 desempeña una función especial en relación con este tipo neuroquímico de interneuronas. Conocemos que las células PGs de tipo II no contactan con el NO sino que modulan directamente a las células mitrales y empenachadas (Kosaka y Kosaka, 2007). En las células ZnT3-NOSn/ZnT3-CR-positivas, el zinc se encargaría de disminuir la inhibición sobre las dendritas de células mitrales y empenachadas, que expresan receptores GABA-A y GABA-B en sus dendritas (Bonino y cols., 1999; Margeta-Mitrovic y cols., 1999; Panzanelli y cols., 2005). Por lo tanto, el carácter zincérgico de una subpoblación de PGs de tipo II, las que poseen ZnT3, estaría implicado en el refinamiento de la modulación llevada a cabo por las PGs sobre las células de proyección bulbares. Al igual que las fibras zincérgicas centrífugas que contactan con los granos constituyen un mecanismo de modulación del sistema regulador inhibitorio que forman estas interneuronas, las PGs zincérgicas constituirían un sistema modulador de la señal olfatoria intrínseco al BO que actuaría en la CG, disminuyendo la inhibición de la información olfatoria.

El descubrimiento y caracterización de interneuronas ZnT3-positivas en el BO por vez primera, supone un resultado de gran relevancia. Por un lado, amplía el conocimiento de las proyecciones zincérgicas del cerebro anterior, pues es el primer caso en el que en esta estructura se encuentran neuronas inhibitorias ZnT3-positivas, y por otro, abre un nuevo camino hacia el conocimiento del sistema zincérgico en el BO como poseedor de un mecanismo zincérgico intramodulador propio. Pese a no haber localizado terminales $\mathrm{ZnSe}^{\mathrm{AMG}}$-positivos a nivel ultraestructural en células PGs, la presencia de zinc en su soma, indica que pueden estar implicadas en la homeostasis de zinc vesicular. De este modo las subpoblación de PGs ZnT3positivas constituirían un sistema zincérgico intrínseco al $\mathrm{BO}$, aunque sus funciones específicas y su participación en el procesamiento de la información olfatoria, aún estén por descubrir.

\section{Zinc y autoinhibición en las PGs ZnT3- positivas}

Para intentar comprender el significado de la localización de ZnT3 en el soma de algunas células PGs planteamos una hipótesis de funcionamiento del zinc y la proteína ZnT3 en dichas células, según los siguientes puntos de partida: 
1. El zinc modula la actividad fisiológica de las células PGs del BO, provocando cambios en la conductancia de algunas de estas interneuronas (Puopolo y Belluzzi, 1998).

2. Durante la actividad sináptica neuronal se ha demostrado la translocación de zinc desde la neurona presináptica a la postsináptica (Suh, 2009).

3. La entrada de zinc al citoplasma celular hace que estos iones bloqueen al intercambiador de $\mathrm{K}^{+} / \mathrm{Cl}^{-}, \mathrm{KCC} 2$, produciéndose un incremento en la concentración de $\mathrm{Cl}^{-}$intracelular (Hershfinkel y cols., 2009).

4. Al perderse el equilibrio de $\mathrm{Cl}^{-}$intracelular, las características del potencial de membrana se invierten, haciendo que el GABA funcione como neurotransmisor excitatorio (despolarizante), en lugar de inhibitorio (Hershfinkel y cols., 2009). Por lo tanto, durante periodos de actividad neuronal intensa, la entrada de iones zinc a la neurona postsináptica puede modular su acción.

5. La liberación de GABA desde algunas células PGs puede provocar su autoinhibición, mediante la unión de este neurotransmisor a receptores GABA-A localizados en su propia membrana. Sin embargo, en las PGs que contienen altos niveles de $\mathrm{Cl}^{-}$intracelular, la unión de GABA sobre sus receptores causa un fenómeno despolarizante (Smith y Jahr, 2002).

Teniendo en cuenta todos estos datos, proponemos que las NROs del BO tienen zinc en sus vesículas presinápticas (junto con el transportador ZnT3), que observamos en muy bajo número debido a su constante liberación, por la elevada actividad de estas neuronas. Una vez liberado a la hendidura sináptica, el zinc se transloca al interior de las células PGs tipo 1 ZnT3-positivas que contactan con el NO (fig. 37B), causando el bloqueo del transportador KCC2, con la subsiguiente acumulación de $\mathrm{Cl}^{-}$en su citoplasma. Así, las células PGs ZnT3-positivas tipo I, se verían afectadas por su propia liberación de GABA, de modo que el fenómeno de autoinhibición natural que ocurre en ellas (fig. 37A), resultaría modelado, menos intenso, debido al efecto despolarizante causado por el zinc en estas neuronas. 


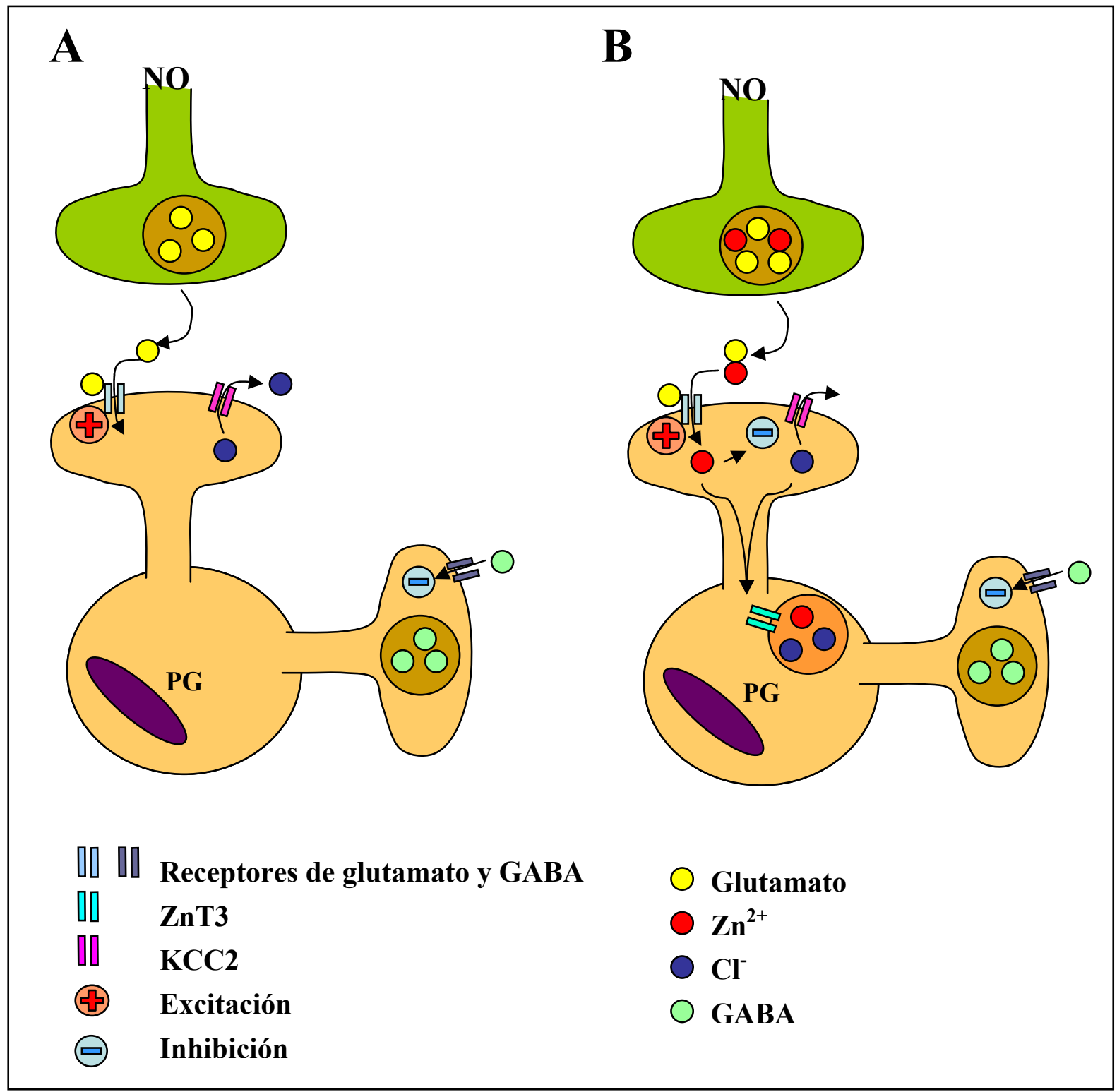

Figura 37. Esquema del proceso de autoinhibición que ocurre en las células PGs sin zinc (A) y con zinc (B).

El exceso de $\mathrm{Cl}^{-}$intracelular se aliviaría por la inclusión de estos iones en vesículas ZnT3-ClC-3 positivas, lo que incrementaría su acidez luminal (Xie y cols., 
1989). El contenido extremadamente ácido de estas vesículas, evitaría que el zinc se marque al contacto con el selenito sódico o sulfuro de sodio empleados en las técnicas histológicas (Danscher y cols., 1994). Aunque no hemos encontrado experimentos previos que demuestren la pérdida de marcaje $\mathrm{ZnSe}^{\mathrm{AMG}}$ en vesículas con alto contenido en iones cloruro, sí sabemos que el contenido acídico de las vesículas afecta a la estabilidad de los complejos zinc-sulfuro y zinc-selenio (Danscher y cols., 1994). De hecho, la acidez existente en el lumen de los lisosomas es la causa de que, mientras los

complejos $\mathrm{Zn}$-Se permanecen estables durante un tiempo, facilitando el marcaje retrógrado $\mathrm{ZnSe}{ }^{\mathrm{AMG}}$, los complejos $\mathrm{Zn}-\mathrm{S}$ no permitan dicho marcaje, por su débil unión en las condiciones ácidas del medio lisosomial (Danscher y cols., 1994; Danscher y Stoltenberg, 2005). El transportador ZnT3 serviría en este caso como almacén de iones zinc junto con iones cloruro, bien para su posterior reutilización o bien, para su eliminación vía lisosomal. Según esta teoría, los glomérulos ZEN estarían formados por terminales de NROs bien de muy bajo nivel de activación, o bien, con una carga en zinc especialmente elevada, de forma que permitiese el marcaje de estos iones en sus vesículas. A su vez, las células PGs que los rodean no se verían sometidas a incrementos intracelulares de zinc que producirían el bloqueo de KCC2 y la consiguiente formación de vesículas acídicas invisibles a los métodos histológicos. Debido a esto, las células yuxtaglomerulares que rodean a los glomérulos ZEN se marcan mucho más con el método $\mathrm{ZnSe}^{\mathrm{AMG}}$ que las de los glomérulos vecinos. Aunque esta parece la explicación más plausible, no podemos olvidar la posibilidad de que, por otro lado, estos glomérulos reciban una excepcional cantidad de inervación zincérgica centrífuga y que sea ésta la responsable del marcaje que observamos en su neuropilo.

\section{Otras posibles funciones de $\mathrm{ZnT3}$}

Por un lado, hemos visto que, aunque la principal fuente zincérgica en la CG se localizaría en las NROs, donde hemos encontrado la mayor parte de la proteína ZnT3, el marcaje $\mathrm{ZnSe}^{\mathrm{AMG}}$ para zinc vesicular en el neuropilo de la CG es prácticamente inexistente. Por otro, pese a que la presencia de marcaje $\mathrm{ZnSe}^{\mathrm{AMG}}$ a microscopía óptica y electrónica en el interior de ciertas PGs muestra, efectivamente, un carácter zincérgico en dichas interneuronas, ultraestructuralmente, en ningún caso observamos el marcaje $\mathrm{ZnSe}^{\mathrm{AMG}}$ en los terminales de las células PGs sino en 
estructuras vesiculares localizadas en el soma. Esto nos impide confirmar la actuación del zinc como neuromodulador sináptico asociado a la actividad inhibitoria de estas células, como sí se ha sugerido, en cambio en el sistema zincérgico intrínseco que constituyen las interneuronas del cerebelo (Wang y cols., 2002a). Debido a esto, tenemos que plantearnos la posibilidad de que la proteína ZnT3 en la CG del BO no esté realizando la función que conocemos como suya propia sino una función alternativa, no relacionada con la homeostasis de zinc. Los estudios precedentes, donde se observan células que poseen $\mathrm{ZnT3}$ en sus dendritas pero no zinc (Palmiter y cols., 1996a; Wenzel y cols., 1997) y células que presentan el transportador en su soma pero no en sus terminales axónicos (Wang y Dahlström, 2008), nos hacen pensar en una función secundaria de este transportador, quizá incluyendo zinc u otros iones en vesículas para su almacenamiento y no para su exocitosis durante la sinapsis. Además, se ha comprobado que algunas de las proteínas transportadoras de zinc pueden verse implicadas en el transporte de otros elementos. Por ejemplo, se sabe que las proteínas ZIP, así como ZnT1 y las MT-I y II, en ocasiones participan en la ruta de eliminación del cadmio del organismo (Hasumi y cols., 2003; Dalton y cols., 2005; Ohana y cols., 2006; Kaisman-Elbaz y cols., 2009). Aunque a día de hoy no se ha observado una implicación directa en el transporte de otros iones por ZnT3 (Shimada y cols., 2008), quizá no debamos descartar que no es zinc el sustrato que ZnT3 está transportando en la CG del BO.

\section{Animales enriquecidos y deprivados: la actividad olfatoria}

\section{Animales enriquecidos}

Puesto que la diferencia entre los marcajes en la CG no es debida a un problema de la sensibilidad de la técnica por $\mathrm{AMG}$, el marcaje que observábamos con el $\mathrm{ZnSe}^{\mathrm{AMG}}$ en el $\mathrm{BO}$ estaba reflejando la situación real de los iones zinc: los glomérulos ZEN se encuentran cargados de terminales zincérgicos, mientras que el neuropilo del resto de glomérulos está prácticamente desprovisto de fibras $\mathrm{ZnSe}^{\mathrm{AMG}}$ positivas. Pensamos entonces, que podía tratarse de un patrón de actividad olfatoria, de modo que sólo los glomérulos ZEN estaban siendo activados por una fuerte señal odorante entrante $\mathrm{y}$, por lo tanto, eran los que observábamos marcados. Para comprobarlo, sometimos a los animales a condiciones de enriquecimiento olfatorio. 
Diversos estudios indican que un ambiente enriquecido (tanto en el sistema visual, en el sistema auditivo, o en el somatosensorial), produce cambios en la neurogénesis, en el incremento de las respuestas frente a un estímulo o en la reorganización de la información a nivel cortical (Scotto y cols., 2000; Sandeman y Sandeman, 2000; Cancedda y cols., 2004; Engineer y cols., 2004; Polley y cols., 2004). En el caso del sistema olfatorio, se conoce que las experiencias olorosas modulan las funciones del BO adulto (Rosselli-Austin y Williams, 1990; Woo y Leon, 1995). En estudios donde ratas crecieron en ambientes enriquecidos en olores, los animales mostraron un incremento en el número de granos en el BO (RosselliAustin y Williams, 1990). Del mismo modo, se ha comprobado que ratones sometidos a condiciones de enriquecimiento olfatorio durante 40 días incrementan la neurogénesis bulbar y mejoran la memoria olfatoria (Rochefort y cols., 2002). Además, durante la etapa postnatal temprana, el incremento celular que existe en el $\mathrm{BO}$ de ratas enriquecidas, se debe a un descenso en la tasa de muerte celular en estos animales (Woo y cols., 2006). Por otro lado, las ratas sometidas a condiciones de enriquecimiento, no sólo incrementan la neurogénesis en su BO sino también la recientemente descubierta neurogénesis en la corteza piriforme (Pekcec y cols., 2006; Shapiro y cols., 2007).

Todas estas referencias muestran que la cantidad de información entrante en un sistema sensorial puede modificar la actividad neural del mismo. Sin embargo, a pesar del fuerte impulso plástico que supone un aumento en la entrada de información olfatoria, las proyecciones zincérgicas que inervan la $\mathrm{CG}$ del $\mathrm{BO}$ no responden con modificaciones histológicas visibles a microscopía óptica. Por ello, nuestros resultados indican que la presencia de marcaje $\mathrm{ZnSe}^{\mathrm{AMG}}$ en los glomérulos ZEN no es consecuencia de una señal odorante específica muy presente en el ambiente en el que se criaron los animales. Es decir, o bien el sistema zincérgico no se ve afectado por el incremento de actividad, o bien existen mecanismos compensatorios frente al incremento de actividad, tales que el marcaje obtenido en la CG finalmente no varía.

\section{Animales deprivados}

Contrariamente a lo propuesto en el modelo de enriquecimiento, para descubrir si el marcaje de los glomérulos ZEN era el reflejo histológico de aquellos 
glomérulos que no estaban siendo activados, empleamos el modelo de deprivación olfatoria.

Tanto en el sistema visual como en el sistema somatosensorial, la deprivación sensorial (por enucleación mono o biocular; o tras la eliminación de los elementos táctiles receptores, las vibrisas, respectivamente) produce modificaciones en el patrón $\mathrm{ZnSe} \mathrm{AMG}^{\mathrm{AMG}}$ en centros superiores (Land y Akhtar, 1999; Quaye y cols., 1999; Czupryn y Skangiel-Kramska, 2001, 2003; Vizuete y cols., 2001; Brown y Dyck, 2002, 2003; Land y Shamalla-Hannah, 2002; Dyck y cols., 2003; Liguz-Lecznar y cols., 2005; Nakashima y Dyck, 2009). Según nuestros resultados el marcaje $\mathrm{ZnSe}^{\mathrm{AMG}}$ obtenido tanto en el $\mathrm{BO}$ ipsilateral a la deprivación, como en el $\mathrm{BO}$ contralateral a la misma, no presentó variaciones en distribución o intensidad con respecto al $\mathrm{BO}$ de animales no deprivados. El único estudio disponible hasta la fecha en relación al marcaje de iones zinc en condiciones de deprivación olfatoria (Wilson y cols., 2000), indica que la pérdida en la recepción de información olfatoria, no causa diferencias significativas en la distribución e intensidad de marcaje Timmpositivo en la corteza piriforme (Wilson y cols., 2000). Este dato, junto con nuestros resultados, parece indicar que la inervación zincérgica del sistema olfatorio es resistente a los cambios en la cantidad de información recibida en el epitelio olfatorio.

La inervación zincérgica localizada en el sistema olfatorio parece ser una pieza enigmática en la regulación de la información olfatoria. A pesar de la invariabilidad de marcaje $\mathrm{ZnSe}^{\mathrm{AMG}}$, desconocemos la existencia de modificaciones en la formación/eliminación de terminales zincérgicos y en el funcionamiento del zinc en la sinapsis en estas situaciones. No obstante, sí podemos afirmar que pese a la importancia del zinc en el procesamiento olfatorio, siempre que mantengamos el sistema olfatorio intacto, la distribución y densidad de terminales ZEN en el BO de animales sometidos a cambios en la cantidad de información entrante, tal como los planteados en este estudio, permanece estable.

\section{Animales KO para NOSn: implicación del ON}

En el SNC, el ON se ha relacionado con funciones variadas que van desde la modulación de la transmisión sináptica o la modificación del procesamiento sensorial, hasta la regulación de los procesos neurodegenerativos (Yun y cols., 1996; 
Mateo y de Artiñano, 2000; Bruckdorfer, 2005; Guix y cols., 2005). Aunque su implicación en los circuitos neuronales del BO aún no se conoce con exactitud, la alta presencia de la enzima NOSn en diferentes poblaciones neuronales del BO, indica que el $\mathrm{ON}$ juega un papel relevante en el procesamiento de la información olfatoria. Así, se sabe que la expresión de NOSn es necesaria para la correcta organización de los glomérulos olfatorios (Chen y cols., 2004; Moreno-López y González-Forero, 2006), que el ON posee un efecto inhibitorio sobre la neurogénesis en la zona subventricular (Romero-Grimaldi y cols., 2006) y que está implicado en la regulación de la expresión de proteínas relacionadas con la memoria olfatoria a largo plazo (Jüch y cols., 2009).

En este trabajo, empleamos animales carentes de la enzima NOSn, como modelo para el análisis de la inervación zincérgica en el $\mathrm{BO}$ frente a un posible déficit de concentración de ON. La actividad NOS en los animales KO se reduce hasta el $0,2-7 \%$ con respecto a la que presentan los animales control, atribuyéndose la actividad residual a la isoforma de la NOS endotelial (NOSe; Huang y cols., 1993). Es más, el BO es una de las estructuras encefálicas con menor actividad residual de NOS en los animales KO (Huang y cols., 1993). Recientemente se ha observado que las NROs sintetizan ON (empleando como enzima la NOSe), en respuesta a estimulación olorosa (Brunert y cols., 2009). La distancia de difusión del ON (entre 10 - $300 \mu \mathrm{m}$ de diámetro; Lancaster, 1994), conlleva que las estructuras en la vecindad de las células que lo producen, tanto neuronas como elementos no neuronales, están influenciadas por su liberación. Sin embargo, la producción de ON por las NROs ocurre en el epitelio y sabemos que la placa cribiforme se sitúa como pared intermedia, entre el epitelio olfatorio y el BO, por lo que no creemos posible que el ON de origen epitelial pueda paliar en el BO la carencia de ON de la enzima NOSn en los animales KO. Por su parte, también la glía envolvente olfatoria secreta ON proveniente de la NOSi en respuesta a infecciones bacterianas (Harris y cols., 2009). Puesto que el ON proveniente de la glía envolvente olfatoria es sintetizado sólo en circunstancias de infección de la mucosa olfatoria, pensamos que dicho ON tampoco debe tenerse en cuenta como factor implicado en los cambios observados en la $\mathrm{CG}$ en nuestros resultados. Por todo ello, consideramos que la mayor parte de la actividad llevada a cabo por la NOSn en el BO no se suple con la formación de ON por parte de ninguna otra isoforma NOS. 
La falta del ON procedente de la NOSn en la CG del BO de los animales KO, parece influir de manera directa en el sistema zincérgico. Así, cuando realizamos el $\mathrm{ZnSe}^{\mathrm{AMG}}$ y la inmunohistoquímica para $\mathrm{ZnT3}$ en el $\mathrm{BO}$ de animales NOS, observamos un nuevo desfase en el marcaje obtenido con ambas técnicas en la CG. Mientras que el patrón de distribución del zinc vesicular es similar en los animales NOS y en los controles, la intensidad de marcaje de la inmunohistoquímica para ZnT3, resultó ser significativamente inferior en la CG de los ratones KO. Esta diferencia no fue observada en el resto de capas del BO. Algunos granos, células superficiales y profundas de axón corto, interneuronas de la CPE, células empenachadas, y PGs se marcan tanto con la técnica inmunohistoquímica para la proteína NOSn, como con la histoquímica para la actividad NADPH-diaforasa, asociada a dicha enzima (Weruaga y cols., 1998; Kosaka y Kosaka, 2007). Por lo tanto, aunque las células NOSn-positivas se localizan en prácticamente todas las capas del BO, la mayor densidad de éstas se encuentra distribuida en la CG (Weruaga y cols., 1998), donde precisamente encontramos las mayores diferencias en cuanto a la cantidad de ZnT3.

La relación directa entre la ausencia de NOSn y las variaciones en el sistema zincérgico no es extraña, puesto que se conoce que el ON está directamente implicado en el metabolismo del zinc, a través de la liberación de éste de las MTs (Aravindakumar y cols., 1999; Frederickson y cols., 2002; Spahl y cols., 2003). De modo que, en los animales silvestres, debido a la difusión de esta molécula, gran parte de la CG se vería afectada por el ON gracias a las neuronas nitrérgicas que en ella se sitúan. Esto ha de llevar implícito un incremento en la concentración del zinc intracelular, procedente de su liberación desde las MTs, en las células de la CG. Así sucede en la corteza cerebral y el hipocampo de ratas sometidas a episodios de oclusión de la arteria cerebral (Aguilar-Alonso y cols., 2008). Tras la operación, ocurre un incremento de $\mathrm{ON}$ que provoca un aumento en la cantidad de zinc intracelular, que afecta a la expresión de los transportadores ZnT1, ZnT2 y ZnT4 (Aguilar-Alonso y cols., 2008). Con respecto a la regulación del transportador ZnT3, encargado de introducir los iones zinc en las vesículas presinápticas, la información de la que disponemos hasta la fecha es variada. Aunque su expresión sí se ve afectada por la presencia de glucocorticoides y esteroides (Lee y cols., 2004; Suh y cols., 2005), la mayoría de los trabajos que han analizado este gen coinciden en que su expresión se mantiene constante bajo condiciones de deficiencia de zinc (Pfaffl y 
Windisch, 2003; Chowanadisai y cols., 2005; Ni y cols., 2009). Sin embargo, una publicación reciente, muestra un incremento en la expresión del gen, tras eliminar el zinc disponible mediante su unión a agentes quelantes, que, no obstante, se corresponde con una disminución en la cantidad total de proteína (Smidt y cols., 2009). De confirmarse esta manera de regulación, el perfil que observamos en los animales NOS se correspondería con la siguiente sucesión de acontecimientos: la carencia de NOSn produciría una disminución en la cantidad de ON en la CG; ésta, a su vez, implicaría una menor liberación de zinc desde las MTs y por tanto una menor cantidad de zinc citosólico libre que daría lugar a un incremento en la expresión del gen, aunque debido a modificaciones postranscripcionales/postraduccionales (Smidt y cols., 2009), la cantidad total de proteína ZnT3 disminuye, lo que explicaría la reducción en el marcaje inmunohistoquímico demostrado en este trabajo.

Se sabe que las moléculas ZnT3 forman dímeros (Salazar y cols., 2009), necesarios no sólo para la capacidad transportadora de zinc, sino para regular su localización subcelular. Además, esta dimerización se ve favorecida en condiciones de estrés oxidativo, en las que se incrementa la concentración de ON (Salazar y cols., 2009). La dimerización producida mediante la formación de puentes de tirosina entre los residuos 357 y 372 de ZnT3, produce un cambio conformacional en el extremo carboxilo terminal de la proteína (Salazar y cols., 2009), donde precisamente está dirigido el anticuerpo para ZnT3 utilizado en este estudio (Palmiter y cols., 1996a). Así, las proteínas diméricas formadas podrían quedar invisibles a nuestro anticuerpo, debido al cambio conformacional sufrido. Sin embargo, en el estudio de Smidt y cols. (2009), se utilizó un anticuerpo dirigido contra el dominio N-terminal de la proteína y el resultado fue igualmente un descenso en la cantidad de proteína. Por ello, pensamos que la disminución en el marcaje ZnT3 en la CG del BO no supone una falta de especificidad del anticuerpo frente al cambio conformacional de la proteína sino un descenso real en la cantidad de transportador como consecuencia del descenso de ON.

Otro hecho que confirma la especificidad de nuestro anticuerpo anti-ZnT3 a pesar de dirigirse al extremo en el que ocurre la dimerización de la proteína, son los resultados obtenidos correspondientes al incremento en el marcaje celular en la CG de los animales KO. El aumento en la densidad de células Znt3-positivas no está reñido con la disminución en el marcaje ZnT3 total por glomérulo, ya que el ZnT3 en la CG procede no sólo de las células ZnT3-positivas sino también del NO y de los 
terminales centrífugos. Por lo tanto, aunque las células ZnT3-positivas se incrementen en los animales $\mathrm{KO}$, la cantidad global de $\mathrm{ZnT} 3$, tanto en los terminales del NO como en los centrífugos parece verse reducida.

En nuestro estudio hemos demostrado que el exceso de células ZnT3positivas en los animales KO para NOSn pertenece a la subpoblación neuroquímica de células CR-positivas. Es decir, existe un aumento en el número de células PGs de tipo II que expresan el transportador ZnT3. Esto nos indica que en estos animales, se produce bien un cambio en la expresión de ZnT3 en algunas células yuxtaglomerulares, o bien, una mayor incorporación de células PGs de nueva generación que se diferencian al fenotipo CR-positivo y que expresan ZnT3. Consideremos, en primer lugar que se trata de un cambio plástico de células PGs que incrementan su expresión de ZnT3, manteniéndose el número total de PGs constante entre animales control y KO para NOSn. Puesto que la población de células PGs NOSn-positivas prácticamente desaparece en los animales KO para NOSn, pensamos que pueden ser las células PGs NOSn-positivas y ZnT3-CR-negativas en el animal control, las que, en los KO, en lugar de NOSn expresan ZnT3 y CR. De este modo una población de células presente en ambos tipos de animales expresaría diferentes marcadores en función de la presencia o ausencia de la isoenzima NOSn. Aunque en la rata se ha descrito que toda la población de células NOSn es GAD67 positiva (Crespo y cols., 2003), en el caso del ratón existen células PGs que expresan NOSn y que no son GAD67 positivas (Kosaka y Kosaka, 2007). Por lo tanto, tanto si las células PGs que cambian su expresión fuesen NOSn-GAD67-positivas, como NOSnpositivas GAD67-negativas, nuestros resultados de densidad de células GAD67 se ajustarían a la hipótesis, ya que observamos un aumento de las células GAD67positivas pero que no es estadísticamente significativo. De confirmarse esta hipótesis el siguiente paso sería conocer el motivo por el que estas células expresan ZnT3 en los animales NOS, puesto que no hemos observado ningún precedente en la bibliografía en la que ocurra este cambio plástico. Sin embargo, en lo que se refiere al incremento en la expresión de la proteína CR en estos animales, sabemos que la expresión de dicha proteína ligante de calcio está regulada positivamente por zinc (Billing-Marczak y cols., 2004). Esto podría explicar la expresión de CR en las células PGs que expresan ZnT3 en los animales KO como un hecho secundario, consecuencia del incremento de zinc en estas células. 
Consideremos, en segundo lugar, que la aparición de esta población se corresponde con células PGs de nueva generación. En el SNC persisten durante la vida adulta dos regiones neurogénicas activas: la región subgranular del giro dentado del hipocampo y la zona subventricular de los ventrículos laterales (Altman, 1969). En relación a esta última, las células proliferativas que se encuentran en las paredes de los ventrículos laterales migran desde la zona subventricular (ZSV) a lo largo de la corriente migratoria rostral hasta alcanzar el BO (Lois y Álvarez Buylla, 1993). Una vez allí se distribuyen principalmente por la CGr y la CG, donde se diferencian respectivamente a granos y células PGs (Lois y Álvarez-Buylla, 1993, 1994; Álvarez-Buylla y Lois, 1995; Whitman y Greer, 2009). Hoy conocemos que el ON está directamente relacionado con la regulación de la neurogénesis adulta, tanto en el giro dentado del hipocampo como en la zona subventricular (Gibbs, 2003; Packer y cols., 2003). Su efecto se ha comprobado mediante inhibidores del ON así como empleando animales KO para la NOSn (Packer y cols., 2003). En ambos casos, la consecuencia es siempre un incremento significativo de la neurogénesis. Este hecho apoya la hipótesis de que el incremento de células ZnT3-CR-positivas en la CG de los KO para NOSn se debe a un aumento en las nuevas células que se incorporan a dicha capa. Además, en condiciones normales, los fenotipos más frecuentes adoptados por las células de nueva generación son GAD67, CR y TH (Whitman y Greer, 2007). Algo más del 70\% del total de las PGs de nueva generación son GAD67-positivas y alrededor del $40 \%$ y $20 \%$ son $\mathrm{CR}$ y $\mathrm{TH}$-positivas, respectivamente (Whitman y Greer, 2007). Nuestros resultados muestran un incremento en la densidad de células GAD67-positivas, CR-positivas y TH-positivas (aunque solo las CR-positivas aumentan de manera significativa), coincidiendo con la distribución mayoritaria por fenotipos de las células PG de nueva generación (Whitman y Greer, 2007). Todos estos datos indican que el incremento en el porcentaje de células PGs ZnT3-CR-positivas pueden ser el resultado del aumento en la neurogénesis que sufren estos animales (Packer y cols., 2003).

Sintetizando lo planteado en este apartado podemos decir que la ausencia de NOSn supone variaciones importantes en la proteína ZnT3, tanto en su cantidad total (disminuye), como en su distribución (hay más células ZnT3-positivas). Aunque los resultados observados para el marcaje $\mathrm{ZnSe}^{\mathrm{AMG}}$ en la $\mathrm{CG}$ de animales $\mathrm{KO}$ y control son equivalentes, hechos que nos llevan una vez más a la divergencia entre los iones zinc y el transportador ZnT3, la implicación obsevada de las neuronas nitrérgicas de 
la $\mathrm{CG}$ en la homeostasis de la proteína ZnT3 nos acerca un paso más en el conocimiento de lo que ocurre en esta capa. Es más, confirma la regulación zincérgica particular que ocurre en la CG en comparación con la inervación zincérgica que llega a la CGr del BO.

\section{Animales mutantes pcd: papel de las células mitrales en la inervación zincérgica}

Nuestros estudios previos de la inervación zincérgica en el sistema olfatorio demuestran que estas proyecciones poseen una gran capacidad plástica (Airado, 2005; Airado y cols., 2008). En los animales mutantes pcd, tras la pérdida de las células mitrales ocurre la desaparición de las proyecciones zincérgicas contralaterales del NOA al BO. Además, existe un incremento significativo en la densidad de somas ZEN positivos en el NOA que proyecta al BO ipsilateral (Airado y cols., 2008). En el trabajo actual hemos analizado cómo y en qúe medida afecta la pérdida progresiva de las células mitrales a la proteína ZnT3 en la CG, haciendo especial hincapié en el comportamiento de las células yuxtaglomerulares ZnT3-positivas que hasta el momento se desconocían.

Los animales control y los mutantes pcd no presentan diferencias en la cantidad de terminales ZEN (ni en la CGr, ni en la CG; Airado, 2005; Airado y cols., 2008). Los resultados obtenidos en el presente trabajo confirman este hecho, pues el análisis cuantitativo de la cantidad de proteína ZnT3 en cada glomérulo no presentó diferencias entre ambos grupos experimentales. Sabemos que la mayoría de los terminales de la CG proceden del NO (según nuestros resultados, como media el $71 \%$ de la proteína ZnT3 se encuentra en las NROs), por lo que parece que los terminales ZEN que pertenecen a NROs no cambian ni en número ni en distribución en el animal mutante pcd. Esto corrobora descripciones previas del animal pcd en las que la pérdida de las células mitrales no provoca cambios ni en el NO ni en el epitelio olfatorio (Greer y Shepherd, 1982). Los cambios en la inervación zincérgica centrífuga que llega al $\mathrm{BO}$ de los animales mutantes pcd (el incremento en las proyecciones ipsilaterales y la desaparición de las contralaterales), parecen compensar la cantidad de terminales centrífugos que llega finalmente a la CG. Así, ni con el método ZnSeAMG (Airado y cols., 2008), ni con la inmunohistoquímica para 
ZnT3 (como hemos visto en los resultados del presente trabajo) existen cambios en la cantidad de marcaje detectado en la CG.

Los resultados obtenidos en este trabajo de Tesis Doctoral incorporan dos importantes novedades en el modelo animal ped: la existencia de células ZnT3 positivas en la CG y el hecho de que su número sea significativamente superior al de la misma población existente en animales control. Tras los análisis realizados en los animales control y en los KO para NOSn, la aparición de células ZnT3-positivas también en los animales ped demuestra la relevancia del mantenimiento de la homeostasis de zinc en el BO de esta especie. Esto no resulta extraño teniendo en cuenta que los iones zinc están directamente implicados en el funcionamiento del SNC, participando en procesos como la neurogénesis, la apoptosis o la transmisión sináptica (Hosie y cols., 2003; Takeda y cols., 2003, 2004; Ruiz y cols., 2004, Sensi y Jeng, 2004; Corniola y cols., 2008; Suh y cols., 2009).

El incremento en el número de células ZnT3-positivas en la CG de los mutantes pcd puede deberse, al igual que comentamos en el caso del NOS, bien a un cambio plástico en la expresión de algunas células yuxtaglomerulares, o bien a un incremento en el número de células de nueva generación que se incorporan al BO de estos animales. El único estudio realizado hasta la fecha en el que se analiza la neurogénesis en los animales pcd no detecta cambios en el número final de células de nueva generación que alcanzan la CG en comparación con lo que ocurre en los animales control (Valero y cols., 2007). Por ello, pensamos que las diferencias observadas en el número de células yuxtaglomerulares ZnT3-positivas no son debidas a cambios en la incorporación de nuevas células procedentes de la ZSV, sino, probablemente, a cambios de expresión de ZnT3 en las células yuxtaglomerulares. De este modo, la pérdida de células mitrales provocaría que algunas células yuxtaglomerulares comenzaran a expresar Zn T3.

Al comprobar los porcentajes de colocalización de ZnT3 con cada uno de los marcadores, así como el número de células PGs que expresan cada marcador en los animales pcd no vimos ninguna diferencia con respecto a los animales control. Sin embargo, los resultados del recuento de células empenachadas ZnT3-positivas en la CG de los mutantes pcd mostraron un incremento significativo en esta población. Debido a esto, pensamos que el incremento en los somas ZnT3-positivos en la CG del BO de los animales pcd es consecuencia del aumento en la cantidad de células empenachadas, y no PGs, que expresan ZnT3. La población de células 
empenachadas externas no sufre cambios en el número de sus componentes en los mutantes pcd, aunque sí se han observado modificaciones plásticas en sus conexiones (Greer y Halàsz, 1987; Baker y Greer, 1990) que podrían involucrar los cambios de expresión en la proteína ZnT3 observados en la presente Tesis Doctoral.

Para averiguar el significado de la expresión de ZnT3 en las células empenachadas externas de la CG de animales pcd tenemos que conocer primero el papel que desarrolla este tipo celular en el procesamiento de la información olfatoria. Las células empenachadas externas poseen entre una y tres dendritas apicales que se ramifican dentro de uno o más glomérulos, así como varias dendritas laterales que se extienden por la CPE en la región adyacente a la CG (Shipley y Ennis, 1996). En un principio, se ha considerado que las proyecciones de las células empenachadas externas no salen fuera de esta estructura: algunas de ellas extienden sus axones a glomérulos vecinos, mientras que la mayoría dirigen sus axones hacia la CPI, donde viajan hasta la misma capa en el lado opuesto del mismo BO (Schoenfeld y cols., 1985). Estas colaterales intrabulbares, al llegar al lado bulbar opuesto, establecen contacto sináptico con las dendritas de los granos que allí se encuentran y conforman lo que se denomina el Sistema de Asociación Intrabulbar (SAI, Shoenfeld y cols., 1985; Liu y Shipley, 1994).

Supongamos que las células empenachadas ZnT3-positivas que observamos en los animales pcd pertenecen al SAI. Sabemos que las neuronas que forman el SAI son positivas para el marcaje del neuropéptido colecistoquinina. La liberación de colecistoquinina en la sinapsis provoca la despolarización de los granos con los que contactan en el lado opuesto del BO (Liu y Shipley, 1994; Kosaka y Kosaka, 2007). Esta despolarización implica un incremento en la inhibición que ejercen los granos sobre las células de proyección. Es decir, el SAI supone un modo de autorregulación de la información que recibe el BO contralateral antes de que ésta sea enviada a centros superiores. El incremento en células empenachadas ZnT3-positivas podría suponer una manera de regular el sistema inhibitorio de los granos del lado opuesto del BO en respuesta a la pérdida de células mitrales. Este hecho, se sumaría así a la demostración de las variaciones que se suceden tras cambios en la actividad olfatoria, en otros sistemas reguladores de los granos como el noradrenérgico, el serotonérgico o incluso el propio sistema zincérgico procedente del NOA (Gómez y cols., 2006, 2007; Airado y cols., 2008). 
Las células empenachadas externas son una población neuroquímica y electrofisiológicamente heterogénea (Shipley y Ennis, 1996; Crespo y cols., 1997a, b; Antal y cols., 2006; Kosaka y Kosaka, 2007). De hecho, no todas las células empenachadas externas forman parte del SAI, sino que hoy sabemos que también son una población heterogénea en la trayectoria de sus proyecciones. Así, recientemente se ha descrito que algunas células empenachadas externas proyectan también a regiones extrabulbares como el tubérculo olfatorio, la corteza insular y el núcleo endopiriforme dorsal (Puche y cols., 2005; Kosaka y Kosaka, 2007). Teniendo en cuenta este hecho, la pérdida de las células mitrales, principales neuronas de proyección, en los mutantes $p c d$, podría ser compensada en estos animales con la modificación de estas células empenachadas externas que también proyectan fuera del BO; no solo en la reorganización de sus conexiones sino también en la expresión de proteínas como ZnT3.

Recopilando lo expuesto en esta discusión podemos decir que el sistema zincérgico en el $\mathrm{BO}$ tiene un papel más importante de lo que hasta la fecha se pensaba. Nuestros resultados abren nuevas vías de estudio acerca del funcionamiento de la proteína ZnT3, la importancia del zinc en la modulación de la información olfatoria o la implicación de la glía en el mantenimiento de la homeostasis de zinc en el BO. Además, muestran al BO como una estructura con una inervación zincérgica autónoma. Posee un posible sistema astroglial de eliminación de zinc, equivalente al que existe en el hipocampo y además, presenta interneuronas ZnT3-positivas inhibitorias, al igual que ocurre en el cerebelo. Por último, la plasticidad observada frente a la pérdida de las células mitrales y de la enzima NOSn, en contraposición a la constancia en el marcaje presentada ante cambios de actividad, muestran la regulación tan fina que el sistema zincérgico realiza sobre el sistema olfatorio, necesitándose un sistema intacto para que se mantenga un equilibrio zincérgico preciso. Una revisión futura de los métodos de marcaje de zinc y el estudio del BO a partir de biosensores fluorescentes nos permitirán conocer mejor la localización de estos iones en cada momento y su implicación en la transmisión de la información olfatoria en roedores. 

Conclusiones 



\section{Conclusiones}

De acuerdo con los objetivos planteados en este trabajo de Tesis Doctoral y como consecuencia de los resultados obtenidos y la discusión llevada a cabo, hemos llegado a las siguientes conclusiones:

1. La astroglía del bulbo olfatorio participa en la homeostasis zincérgica especial de la capa glomerular. La presencia de zinc en el interior de estas células, junto con la expresión de metalotioneínas sugiere la posible colaboración de estos astrocitos en la reducción de zinc extracelular.

2. En la capa glomerular del bulbo olfatorio existe una subpoblación de células yuxtaglomerulares caracterizada por la presencia de transportador ZnT3 y/o zinc vesicular en su soma. La implicación de este subtipo celular en la modulación olfatoria supone la existencia de un sistema zincérgico intrínseco al bulbo olfatorio. Existen además glomérulos específicos enriquecidos en marcaje zincérgico.

3. El óxido nítrico proveniente de la NOSn influye en la cantidad de proteína ZnT3 disponible en la capa glomerular del bulbo olfatorio. La falta de actividad de la enzima NOSn resulta en una disminución del volumen que ocupa el transportador ZnT3 en la capa glomerular y en un incremento en la población de células yuxtaglomerulares, probablemente de nueva generación, positivas a ZnT3 y a calretinina.

4. El sistema zincérgico de la capa glomerular del bulbo olfatorio posee capacidad plástica frente a la pérdida de las principales neuronas de proyección del bulbo olfatorio, pues, tras la neurodegeneración de las células mitrales en el ratón pcd, advertimos un cambio significativo en la expresión de ZnT3 en las células empenachadas externas de estos animales.

5. La inervación zincérgica en la capa de los granos del bulbo olfatorio es diferente a la observada en la capa glomerular. Así, a diferencia del marcaje heterogéneo de los glomérulos, la distribución del transportador de zinc ZnT3 es uniforme en la capa de los granos. Sin embargo, este estrato no presenta modificaciones en el marcaje tras la ausencia de actividad NOSn o tras la pérdida de 
las células mitrales. Sí observamos variaciones en el marcaje zincérgico tras modificar experimentalmente la cantidad de zinc disponible en el tejido.

6. El bulbo olfatorio es una estructura que presenta una gran carga zincérgica, de forma especial en la capa glomerular. El descubrimiento de células yuxtaglomerulares con transportador ZnT3, la influencia de las células mitrales en la expresión de ZnT3, la aparición de astrocitos con zinc en su interior, la presencia de glomérulos ZEN, la implicación del óxido nítrico, y el desfase de marcaje entre técnicas demuestran una gran relevancia de la homeostasis de zinc en esta zona de relevo y modulación de la información sensorial. 


\section{BIBLIOGRAFÍA}





\section{Bibliografía}

Ache B.W. (1987). Chemoreception in invertebrates. En: Neurobiology of taste and smell (Finger, T. y Silver, W., eds.) pp. 39-64. John Wiley and Sons. Nueva York.

Adlard P.A., Cherny R.A., Finkelstein D.I., Gautier E., Robb E., Cortes M., Volitakis I., Liu X., Smith J.P., Perez K., Laughton K., Li Q.X., Charman S.A., Nicolazzo J.A., Wilkins S., Deleva K., Lynch T., Kok G., Ritchie C.W., Tanzi R.E., Cappai R., Masters C.L., Barnham K.J. y Bush A.I. (2008). Rapid restoration of cognition in Alzheimer's transgenic mice with 8-hydroxy quinoline analogs is associated with decreased interstitial $\beta$-Amiloyd. Neuron, 59 (1): 43-55.

Aguilar-Alonso P., Martínez-Fong D., Pazos-Salazar N.G., Brambila E., GonzálezBarrios J.A., Mejorada A., Flores G., Millán-Perezpena L., Rubio H. y LeónChávez B.A. (2008). The increase in zinc levels and upregulation of zinc transporters are mediated by nitric oxide in the cerebral cortex after transient ischemia in the rat. Brain Res, 1200: 89-98.

Airado C. (2005). Proyecciones zincérgicas al bulbo olfatorio desde el núcleo olfatorio anterior: caracterización, distribución y comparación entre el ratón mutante pcd y control. En: Trabajo de Grado. Universidad de Salamanca.

Airado C., Gómez C., Recio J.S., Baltanás F.C., Weruaga E. y Alonso J.R. (2008). Zincergic innervation from the anterior olfactory nucleus to the olfactory bulb displays plastic responses after mitral cell loss. J Chem Neuroanat, 36 (3-4): 197-208.

Alberts I.L., Nadassy K. y Wodak S.J. (1998) Analysis of zinc binding sites in protein crystal structures. Protein Sci, 7 (8): 1700-1716.

Allison A.C. y Warwick R.T. (1949). Quantitative observations on the olfactory system of the rabbit. Brain, 72 (2): 186-197. 
Allison A.C. (1953). The morphology of the olfactory system in the vertebrates. Biol Rev Cambridge Phil Soc, 28: 195-244.

Alonso J.R., Arévalo R., Porteros A., Briñón J.G., Lara J. y Aijón J. (1993) Calbindin D-28K and NADPH-diaphorase activity are localized in different populations of periglomerular cells in the rat olfactory bulb. $J$ Chem Neuroanat, 6 (1): 1-6.

Alonso J.R., Arévalo R., García-Ojeda E., Porteros A., Briñón J.G. y Aijón J. (1995). NADPH-diaphorase active and calbindin D-28k-immunoreactive neurons and fibers in the olfactory bulb of the hedgehog (Erinaceus europaeus). J Comp Neurol, 351 (2): 307-327.

Alpers D.H. (1994). Zinc and deficiencies of taste and smell. JAMA, 272 (16): 12331234.

Altman J. (1969). Autoradiographic and histological studies of postnatal neurogenesis. IV. Cell proliferation and migration in the anterior forebrain, with special reference to persisting neurogenesis in the olfactory bulb. $J$ Comp Neurol, 137 (4): 433-457.

Álvarez-Buylla A. y Lois C. (1995). Neuronal stem cells in the brain of adult vertebrates. Stem Cells, 13(3):263-72.

Andreini C., Banci L., Bertini I. y Rosato A. (2006a) Counting the zinc-proteins encoded in the human genome. J Proteome Res, 5 (1): 196-201.

Andreini C., Banci L., Bertini I. y Rosato A. (2006b). Zinc through the three domains of life. J Proteome Res, 5 (11): 3173-3178.

Andres K.H. (1970). Anatomy and ultrastructure of the olfactory bulb in fish, amphibia, reptiles, birds, and mammals. En: Ciba Foundation Symposium of Taste and Smell in Vertebrates (Wolstenholme, G. y Knight, J., eds.) pp. 177196. Churchill. Londres.

Andrews J.C., Nolan J.P., Hammerstedt R.H. y Bavister B.D. (1994). Role of zinc during hamster sperm capacitation. Biol Reprod, 51 (6): 1238-1247. 
Antal M., Eyre M., Finklea B. y Nusser Z. (2006). External tufted cells in the main olfactory bulb form two distinct subpopulations. Eur J Neurosci, 24(4):112436.

Aras M.A., Hara H., Hartnett K.A., Kandler K. y Aizenman E. (2009). Protein kinase $\mathrm{C}$ regulation of neuronal zinc signaling mediates survival during preconditioning. J Neurochem. 110 (1): 106-17.

Aravindakumar C.T., Ceulemans J. y de Ley M. (1999). Nitric oxide induces $\mathrm{Zn}^{2+}$ release from metallothionein by destroying zinc-sulphur clusters without concomitant formation of S-nitrosothiol. Biochem J, 344 (1): 253-258.

Assaf S.Y. y Chung S.H. (1984). Release of endogenous $\mathrm{Zn}^{2+}$ from brain-tissue during activity. Nature, 308 (5961): 734-736.

Auld D.S. (2001). Zinc coordination sphere in biochemical zinc sites. Biometals, 14 (3-4): 271-313.

Baba A., Etoh S. e Iwata H. (1991) Inhibition of NMDA-induced protein kinase C translocation by a $\mathrm{Zn}^{2+}$ chelator: implication of intracellular $\mathrm{Zn}^{2+}$. Brain Res, 557 (1-2): 103-108.

Bailey M.S. y Shipley M.T. (1993). Astrocyte subtypes in the rat olfactory bulb: morphological heterogeneity and differential laminar distribution. J Comp Neurol, 328 (4): 501-526.

Baker H. (1986). Species differences in the distribution of substance P and tyrosine hydroxylase immunoreactivity in the olfactory bulb. J Comp Neurol, 252 (2): 206-226.

Baker H. y Greer C.A. (1990). Region specific consequences of PCD gene expression in the olfactory system. J Comp Neurol, 293 (1): 125-133.

Baker H. (1990). Unilateral, neonatal olfactory deprivation alters tyrosine hydroxylase expression but not aromatic amino acid decarboxylase or GABA immunoreactivity. Neuroscience, 36 (3): 761-771. 
Balu R., Pressler R.T. y Strowbridge B.W. (2007). Multiple modes of synaptic excitation of olfactory bulb granule cells. J Neurosci, 27 (21): 5621-5632.

Barnham K.J. y Bush A.I. (2008). Metals in Alzheimer's and Parkinson's diseases. Curr Opin Chem Biol, 12 (2): 222-228.

Bartolomei J.C. y Greer C.A. (1998) The organization of piriform cortex and the lateral olfactory tract following the loss of mitral cells in pcd mice. Exp Neurol, 154 (2): 537-550.

Berkowicz D.A., Trombley P.Q. y Shepherd G.M. (1994). Evidence for glutamate as the olfactory receptor cell neurotransmitter. J Neurophysiol, 71 (6): 25572561.

Besser L., Chorin E., Sekler I., Silverman W.F., Atkin S., Russell J.T. y Hershfinkel M. (2009). Synaptically released zinc triggers metabotropic signaling via a zinc-sensing receptor in the hippocampus. J Neurosci, 29 (9): 2890-2901.

Best A.R. y Wilson D.A. (2003). A postnatal sensitive period for plasticity of cortical afferents but not cortical association fibers in rat piriform cortex. Brain Res, 961 (1): 81-87.

Billing-Marczak K., Zieminska E., Lesniak W., Lazarewicz J.W., Kuznicki J. (2004). Calretinin gene promoter activity is differently regulated in neurons and cancer cells. Role of AP2-like cis element and zinc ions. Biochim Biophys Acta, 1678(1): 14-21.

Blanes T. (1898) Sobre algunos puntos dudosos de la estructura del bulbo olfatorio. Rev Trim Micrograf, 3: 99-127.

Bonino M., Cantino D. y Sassoe-Pognetto M. (1999). Cellular and subcellular localizacion of gamma-aminobutyric acid B receptors in the rat olfactory bulb. Neurosci Lett, 274 (3): 195-198.

Bossy-Wetzel E., Talantova M.V., Lee W.D., Scholzke M.N., Harrop A., Mathews E., Gotz T., Han J., Ellisman M.H., Perkins G.A. y Lipton S.A. (2004). Crosstalk between nitric oxide and zinc pathways to neuronal cell death 
involving mitochondrial dysfunction and p38-activated $\mathrm{K}^{+}$channels. Neuron, 41 (3): 351-365.

Briñón J.G., Alonso J.R., García-Ojeda E., Crespo C., Arévalo R. y Aijón J. (1997). Calretinin- and parvalbumin-immunoreactive neurons in the rat main olfactory bulb do not express NADPH-diaphorase activity. $J$ Chem Neuroanat, 13 (4): 253-264.

Briñón J.G., Crespo C., Weruaga E., Martínez-Guijarro F.J., Aijón J. y Alonso J.R. (2001). Bilateral olfactory deprivation reveals a selective noradrenergic regulatory input to the olfactory bulb. Neuroscience, 102 (1): 1-10.

Brown C.E. y Dyck R.H. (2002). Rapid, experience-dependent changes in levels of synaptic zinc in primary somatosensory cortex of the adult mouse. $J$ Neurosci, 22 (7): 2617-2625.

Brown C.E. y Dyck R.H. (2003) Experience-dependent regulation of synaptic zinc is impaired in the cortex of aged mice. Neuroscience, 119 (3): 795-801.

Brown C.E. y Dyck R.H. (2004). Distribution of zincergic neurons in the mouse forebrain. J Comp Neurol, 479 (2): 156-167.

Bruckdorfer R. (2005). The basics about nitric oxide. Mol Aspects Med, 26 (1-2): 331.

Brunert D., Kurtenbach S., Isik S., Benecke H., Gisselmann G., Schuhmann W., Hatt H. y Wetzel C.H. (2009). Odorant-dependent generation of nitric oxide in mammalian olfactory sensory neurons. PLoS One, 4 (5): e5499.

Brunetti M., Miscena A., Salviati A. y Gaiti A. (1987). Effect of aging on the rate of axonal transport of choline-phosphoglycerides. Neurochem Res, 12 (1): 6165 .

Brunjes P.C., Smith-Crafts L.K. y McCarty R. (1985). Unilateral odor deprivation: effects on the development of olfactory bulb catecholamines and behavior. Brain Res, 354 (1): 1-6. 
Brunjes P.C. y Frazier L.L. (1986). Maturation and plasticity in the olfactory system of vertebrates. Brain Res, 396 (1): 1-45.

Brunjes P.C. (1988). Precocity and plasticity: odor deprivation and brain development in the precocial mouse Acomys cahirinus. Neuroscience, 24 (2): 579-582.

Brunjes P.C. (1994). Unilateral naris closure and olfactory system development. Brain Res, 19 (1): 146-160.

Brunjes P.C., Illig K.R. y Meyer E.A. (2005). A field guide to the anterior olfactory nucleus (cortex). Brain Res, 50 (2): 305-335.

Buck L. (1996). Information coding in the vertebrate olfactory system. Annu Rev Neurosci, 19: 517-544.

Bush A.I., Pettingell W.H., Paradis M.D. y Tanzi R.E. (1994). The role of zinc in A$\beta$-amyloidosis. Neurobiol Aging, 15: 50.

Bush A.I. (2002). Metal complexing agents as therapies for Alzheimer's disease. Neurobiol Aging, 23 (6): 1031-1038.

Bush A.I. (2003a). Copper, zinc, and the metallobiology of Alzheimer's disease. Alzheimer Dis Assoc Disord, 17 (3): 147-150.

Bush A.I. (2003b). The metallobiology of Alzheimer's disease. Trends Neurosci, 26 (4): 207-214.

Cancedda L., Putignano E., Sale A., Viegi A., Berardi N. y Maffei L. (2004). Acceleration of visual system development by environmental enrichment. $J$ Neurosci, 24 (20): 4840-4848.

Canzoniero L.M., Sensi S.L. y Choi D.W. (1997). Measurement of intracellular free zinc in living neurons. Neurobiol Dis, 4 (3-4): 275-279.

Cao J., Bobo J.A., Liuzzi J.P. y Cousins R.J. (2001). Effects of intracellular zinc depletion on metallothionein and ZIP2 transporter expression and apoptosis. $J$ Leukoc Biol, 70 (4): 559-566. 
Carnes K.M., Fuller T.A. y Price J.L. (1990). Sources of presumptive glutamatergic/aspartatergic afferents to the magnocellular basal forebrain in the rat. J Comp Neurol, 302 (4): 824-852.

Carson K.A. (1984). Quantitative localization of neurons projecting to the mouse main olfactory bulb. Brain Res Bull, 12 (6): 629-634.

Casanovas-Aguilar C., Reblet C., Pérez-Clausell J. y Bueno-López J.L. (1998). Zincrich afferents to the rat neocortex: projections to the visual cortex traced with intracerebral selenite injections. J Chem Neuroanat, 15 (2): 97-109.

Caviness V.S. y Sidman R.L. (1972). Olfactory structures of the forebrain in the reeler mutant mouse. J Comp Neurol, 145 (1): 85-104.

Caviness V.S. y Rakic P. (1978). Mechanisms of cortical development: a view from mutations in mice. Annu Rev Neurosci, 1: 297-326.

Chen J., Tu Y., Moon C., Matarazzo V., Palmer A.M. y Ronnett G.V. (2004). The localization of neuronal nitric oxide synthase may influence its role in neuronal precursor proliferation and synaptic maintenance. Dev Biol, 269 (1): 165-182.

Chen N.S., Moshaver A. y Raymond L.A. (1997). Differential sensitivity of recombinant N-methyl-D-aspartate receptor subtypes to zinc inhibition. Mol Pharmacol, 51 (6): 1015-1023.

Cheng C.L. y Reynolds I.J. (1998). Calcium-sensitive fluorescent dyes can report increases in intracellular free zinc concentration in cultured forebrain neurons. J Neurochem, 71 (6): 2401-2410.

Cherny R.A., Atwood C.S., Xilinas M.E., Gray D.N., Jones W.D., McLean C.A., Barnham K.J., Volitakis I., Fraser F.W., Kim Y., Huang X., Goldstein L.E., Moir R.D., Lim J.T., Beyreuther K., Zheng H., Tanzi R.E., Masters C.L. y Bush A.I. (2001). Treatment with a copper-zinc chelator markedly and rapidly inhibits $\beta$-amyloid accumulation in Alzheimer's disease transgenic mice. Neuron, 30 (3): 665-676. 
Chi Z.H., Wang X., Cai J.Q., Stoltenberg M., Danscher G. y Wang Z.Y. (2008). Zinc transporter 3 immunohistochemical tracing of sprouting mossy fibres. Neurochem Int, 52 (7): 1305-1309.

Cho J.Y., Min N., Franzen L. y Baker H. (1996). Rapid down-regulation of tyrosine hydroxylase expression in the olfactory bulb of naris-occluded adult rats. $J$ Comp Neurol, 369 (2): 264-276.

Choi D.W., Yokoyama M. y Koh J. (1988). Zinc neurotoxicity in cortical cell culture. Neuroscience, 24 (1): 67-79.

Chowanadisai W., Kelleher S.L. y Lonnerdal B. (2005). Zinc deficiency is associated with increased brain zinc import and LIV-1 expression and decreased ZnT-1 expression in neonatal rats. $J$ Nutr, 135 (5): 1002-1007.

Christensen M.K. y Frederickson C.J. (1998). Zinc-containing afferent projections to the rat corticomedial amygdaloid complex: A retrograde tracing study. $J$ Comp Neurol, 400 (3): 375-390.

Clark W.L. y Warwick R.T. (1946). The pattern of olfactory innervation. J Neurol Neurosurg Ps, 9 (3): 101-111.

Clark W.L. (1951). The projection of the olfactory epithelium on the olfactory bulb in the rabbit. J Neurol Neurosur Ps, 14 (1): 1-10.

Clark W.L. (1957). The Ferrier lecture: Inquiries into the anatomical basis of olfactory discrimination. Proc R Soc Lond Ser B-Biol Sci, 146 (924): 299318.

Cleland T.A. y Linster C. (2003). Central olfactory structures. En: Handbook of Olfaction and Gustation (Doty R.L. Ed.) pp. 165-180. Marcel Dekker. Filadelfia.

Cole T.B., Wenzel H.J., Kafer K.E., Schwartzkroin P.A. y Palmiter R.D. (1999) Elimination of zinc from synaptic vesicles in the intact mouse brain by disruption of the ZnT3 gene. Proc Natl Acad Sci U S A, 96 (4): 1716-1721. 
Coleman J.E. (1992). Zinc proteins - enzymes, storage proteins, transcription factors, and replication proteins. Annu Rev Biochem, 61: 897-946.

Colvin R.A., Davis N., Nipper R.W. y Carter P.A. (2000). Zinc transport in the brain: routes of zinc influx and efflux in neurons. $J$ Nutr, 130(5S Suppl): 14841487.

Colvin R.A. (2002). pH dependence and compartmentalization of zinc transported across plasma membrane of rat cortical neurons. Am J Physiol-Cell Physiol, 282 (2): 317-329.

Colvin R.A., Fontaine C.P., Laskowski M. y Thomas D. (2003). $\mathrm{Zn}^{2+}$ transporters and $\mathrm{Zn}^{2+}$ homeostasis in neurons. Eur J Pharmacol, 479 (1-3): 171-185.

Corniola R.S., Tassabehji N.M., Hare J., Sharma G. y Levenson C.W. (2008). Zinc deficiency impairs neuronal precursor cell proliferation and induces apoptosis via p53-mediated mechanisms. Brain Res, 1237: 52-61.

Cortese-Krott M.M., Suschek C.V., Wetzel W., Kroncke K.D. y Kolb-Bachofen V. (2009). Nitric oxide-mediated protection of endothelial cells from hydrogen peroxide is mediated by intracellular zinc and glutathione. Am J Physiol Cell Physiol, 296 (4): 811-820.

Costello L.C., Liu Y., Zou J. y Franklin R.B. (1999). Evidence for a zinc uptake transporter in human prostate cancer cells which is regulated by prolactin and testosterone. J Biol Chem, 274 (25): 17499-17504.

Crespo C., Porteros A., Arévalo R., Briñón J.G., Aijón J. y Alonso J.R. (1996). Segregated distribution of nitric oxide synthase-positive cells in the periglomerular region of typical and atypical olfactory glomeruli. Neurosci Lett, 205 (3): 149-152.

Crespo C., Alonso J.R., Briñón J.G., Weruaga E., Porteros A., Arévalo R. y Aijón J. (1997a). Calcium-binding proteins in the periglomerular region of typical and typical olfactory glomeruli. Brain Res, 745 (1-2): 293-302. 
Crespo C., Jorge R.J., Alonso J.R., Briñón J.G., Arévalo R. y Aijon J. (1997b). Segregated distribution of $\mathrm{TH}-\mathrm{imm}$ unoreactivity in olfactory glomeruli. Neuroreport, 8 (9-10): 2311-2316.

Crespo C., Cracia-Llanes F.J., Blasco-Ibáñez J.M., Gutièrrez-Mecinas M. y Marqués-Marí A.I. (2003). Nitric oxide synthase containing periglomerular cells are GABAergic in the rat olfactory bulb. Neurosci Lett, 349(3): 151-4.

Cuajungco M.P. y Lees G.J. (1998). Diverse effects of metal chelating agents on the neuronal cytotoxicity of zinc in the hippocampus. Brain Res, 799 (1): 97-107.

Cummings D.M. y Brunjes P.C. (1994). Changes in cell proliferation in the developing olfactory epithelium following neonatal unilateral naris occlusion. Exp Neurol, 128 (1): 124-128.

Czupryn A. y Skangiel-Kramska J. (2001). Differential response of synaptic zinc levels to sensory deprivation in the barrel cortex of young and adult mice. Exp Brain Res, 141 (4): 567-572.

Czupryn A. y Skangiel-Kramska J. (2003). Switch time-point for rapid experiencedependent changes in zinc-containing circuits in the mouse barrel cortex. Brain Res Bull, 61 (4): 385-391.

Dalton T.P., He L., Wang B., Miller M.L., Jin L., Stringer K.F., Chang X., Baxter C.S. y Nebert D.W. (2005). Identification of mouse SLC39A8 as the transporter responsible for cadmium-induced toxicity in the testis. Proc Natl Acad Sci U S A, 102 (9): 3401-3406.

Danscher G. (1981). Histochemical demonstration of heavy metals. A revised version of the sulphide silver method suitable for both light and electronmicroscopy. Histochemistry, 71 (1): 1-16.

Danscher G. (1982). Exogenous selenium in the brain. A histochemical technique for light and electron microscopical localization of catalytic selenium bonds. Histochemistry, 76 (3): 281-293. 
Danscher G., Stoltenberg M. y Juhl S. (1994). How to detect gold, silver and mercury in human brain and other tissues by autometallographic silver amplification. Neuropathol Appl Neurobiol, 20 (5): 454-467.

Danscher G. (1996). The autometallographic zinc-sulphide method. A new approach involving in vivo creation of nanometer-sized zinc sulphide crystal lattices in zinc-enriched synaptic and secretory vesicles. Histochem J, 28 (5): 361-373.

Danscher G., Jo S.M., Varea E., Wang Z., Cole T.B. y Schroeder H.D. (2001). Inhibitory zinc-enriched terminals in mouse spinal cord. Neuroscience, 105 (4): $941-947$.

Danscher G., Stoltenberg M., Bruhn M., Sondergaard C. y Jensen D. (2004). Immersion autometallography: histochemical in situ capturing of zinc ions in catalytic zinc-sulfur nanocrystals. J Histochem Cytochem, 52 (12): 16191625.

Danscher G. y Stoltenberg M. (2005). Zinc-specific autometallographic in vivo selenium methods: tracing of zinc-enriched (ZEN) terminals, ZEN pathways, and pools of zinc ions in a multitude of other ZEN cells. $J$ Histochem Cytochem, 53 (2): 141-153.

Davenport D. (1955). Specificity and behavior in symbioses. Q Rev Biol, 30: 29-46.

Davis B.J. y Macrides F. (1981). The organization of centrifugal projections from the anterior olfactory nucleus, ventral hippocampal rudiment and piriform cortex to main olfactory bulb in the hamster. An autoradiographic study. J Comp Neurol, 203: 475-493.

Davis B.J. (1991). NADPH-diaphorase activity in the olfactory system of the hamster and rat. J Comp Neurol, 314 (3): 493-511.

de Biasi S. y Bendotti C. (1998). A simplified procedure for the physical development of the sulphide silver method to reveal synaptic zinc in combination with immunocytochemistry at light and electron microscopy. $J$ Neurosci Methods, 79 (1): 87-96. 
de Blas A.L., Vitorica J. y Friedrich P. (1988). Localization of the GABA-A receptor in the rat brain with a monoclonal antibody to the $57,000 \mathrm{Mr}$ peptide of the GABA-A receptor/benzodiazepine receptor/ $\mathrm{Cl}^{-}$channel complex. J Neurosci, 8 (2): 602-614.

de Olmos J., Hardy H. y Heimer L. (1978). The afferent connections of the main and the accessory olfactory bulb formations in the rat: an experimental HRPstudy. J Comp Neurol, 181 (2): 213-244.

Delgado N.M., Magdaleno V.M., Merchant H., Rosado A. y Reyes R. (1984). Heparin-induced release of DNA template restrictions in human sperm zincdepleted nuclei. Arch Androl, 12 (2-3): 211-216.

Dennis B.J. y Kerr D.I. (1968). An evoked potential study of centripetal and centrifugal connections of the olfactory bulb in the cat. Brain Res, 11 (2): 373-396.

Descarries L., Watkins K.C., García S. y Beaudet A. (1982). The serotonin neurons in nucleus raphe dorsalis of adult rat: a light and electron microscope radioautographic study. J Comp Neurol, 207 (3): 239-254.

Devergnas S., Chimienti F., Naud N., Pennequin A., Coquerel Y., Chantegrel J., Favier A. y Seve M. (2004). Differential regulation of zinc efflux transporters ZnT-1, ZnT-5 and ZnT-7 gene expression by zinc levels: a real-time RT-PCR study. Biochem Pharmacol, 68 (4): 699-709.

Dineley K.E., Scanlon J.M., Kress G.J., Stout A.K. y Reynolds I.J. (2000) Astrocytes are more resistant than neurons to the cytotoxic effects of increased $\left[\mathrm{Zn}^{2+}\right] \mathrm{i}$. Neurobiol Dis, 7 (4): 310-320.

Dinsdale D. (1984). Ultrastructural-localization of zinc and calcium within the granules of rat Paneth cells. J Histochem Cytochem, 32 (2): 139-145.

Dyck R.H., Chaudhuri A. y Cynader M. (2003). Experience-dependent regulation of the zincergic innervation of visual cortex in adult monkeys. Cereb Cortex, 13 (10): 1094-1109. 
Eisthen H.L. (1997). Evolution of vertebrate olfactory systems. Brain Behav Evol, 50 (4): 222-233.

Emsley J. (2001). Nature's building blocks. An A-Z guide to the elements. Oxford University Press. Oxford.

Engineer N.D., Percaccio C.R., Pandya P.K., Moucha R., Rathbun D.L. y Kilgard M.P. (2004). Environmental enrichment improves response strength, threshold, selectivity, and latency of auditory cortex neurons. J Neurophysiol, 92 (1): 73-82.

Ennis M., Zimmer L.A. y Shipley M.T. (1996). Olfactory nerve stimulation activates rat mitral cells via NMDA and non-NMDA receptors in vitro. Neuroreport, 7 (5): 989-992.

Fernández-González A., La Spada A.R., Treadaway J., Higdon J.C., Harris B.S., Sidman R.L., Morgan J.I. y Zuo J. (2002). Purkinje Cell Degeneration (pcd) phenotypes caused by mutations in the axotomy-induced gene, Nna1. Science, 295 (5561): 1904-1906.

Finger E.T. y Silver L.W. (1987). Neurobiology of taste and smell. (Finger E.T. y Silver L.W. Eds.) John Wiley \& sons. Nueva York.

Franklin K.B. y Paxinos G. (1997). The mouse brain in stereotaxic coordinates. Academic Press. San Diego.

Franklin P.A., Pullen R.G. y Hall G.H. (1992). Blood-brain exchange routes and distribution of ${ }^{65} \mathrm{Zn}$ in rat-brain. Neurochem Res, 17 (8): 767-771.

Frederickson C.J. (1989). Neurobiology of zinc and zinc-containing neurons. Int Rev Neurobiol, 31: 145-238.

Frederickson C.J., Klitenick M.A., Manton W.I. y Kirkpatrick J.B. (1983). Cytoarchitectonic distribution of zinc in the hippocampus of man and the rat. Brain Res, 273 (2): 335-339. 
Frederickson C.J., Kasarskis E.J., Ringo D. y Frederickson R.E. (1987). A quinoline fluorescence method for visualizing and assaying the histochemically reactive zinc (bouton zinc) in the brain. J Neurosci Methods, 20 (2): 91-103.

Frederickson C.J. y Danscher G. (1990). Zinc-containing neurons in hippocampus and related CNS structures. Progr Brain Res, 83: 71-84.

Frederickson C.J. y Moncrieff D.W. (1994). Zinc-containing neurons. Biol Signals, 3 (3): 127-139.

Frederickson C.J., Suh S.W., Silva D., Frederickson C.J. y Thompson R.B. (2000). Importance of zinc in the central nervous system: The zinc-containing neuron. J Nutr, 130 (5): 1471-1483.

Frederickson C.J. y Bush A.I. (2001). Synaptically released zinc: physiological functions and pathological effects. Biometals, 14 (3-4): 353-366.

Frederickson C.J., Cuajungco M.P., LaBuda C.J. y Suh S.W. (2002). Nitric oxide causes apparent release of zinc from presynaptic boutons. Neuroscience, 115 (2): 471-474.

Friedlich A.L., Lee J.Y., van Groen T., Cherny R.A., Volitakis I., Cole T.B., Palmiter R.D., Koh J.Y. y Bush A.I. (2004). Neuronal zinc exchange with the blood vessel wall promotes cerebral amyloid angiopathy in an animal model of Alzheimer's disease. J Neurosci, 24 (13): 3453-3459.

Friedman B. y Price J.L. (1984). Fiber systems in the olfactory bulb and cortex: a study in adult and developing rats, using the Timm method with the light and electron microscope. J Comp Neurol, 223 (1): 88-109.

Fuller T.A. y Price J.L. (1988). Putative glutamatergic and/or aspartatergic cells in the main and accessory olfactory bulbs of the rat. J Comp Neurol, 276 (2): 209-218.

Gaither L.A. y Eide D.J. (2001). The human ZIP1 transporter mediates zinc uptake in human K562 erythroleukemia cells. J Biol Chem, 276 (25): 22258-22264. 
Gao H.L., Feng W.Y., Li X.L., Xu H., Huang L. y Wang Z.Y. (2009). Golgi apparatus localization of ZnT7 in the mouse cerebellum. Histol Histopathol, 24 (5): 567-572.

Gelhaye M., Trabalon M., Martrette J.M. y Legrand-Frossi C. (2006). Effects of early olfactory deprivation on novelty-seeking behavior and primary and secondary lymphoid organs in young rats. Psychoneuroendocrino, 31 (8): 997-1008.

Getchell T.V. (1986). Functional properties of vertebrate olfactory receptor neurons. Physiol Rev, 66 (3): 772-818.

Gibbs. S.M. (2003). Regulation of neuronal proliferation and differentiation by nitric oxide. Mol Neurobiol, 27(2):107-20.

Golgi C. (1875). Sulla fina struttura degli bulbi olfactorii. Reggio-Emilia, Roma.

Gómez C., Briñón J.G., Barbado M.V., Weruaga E., Valero J. y Alonso J.R. (2005). Heterogeneous targeting of centrifugal inputs to the glomerular layer of the main olfactory bulb. J Chem Neuroanat, 29 (4): 238-254.

Gómez C., Briñón J.G., Colado M.I., Orio L., Vidal M., Barbado M.V. y Alonso J.R. (2006). Differential effects of unilateral olfactory deprivation on noradrenergic and cholinergic systems in the main olfactory bulb of the rat. Neuroscience, 141 (4): 2117-2128.

Gómez C., Briñón J.G., Orio L., Colado M.I., Lawrence A.J., Zhou F.C., Vidal M., Barbado M.V. y Alonso J.R. (2007). Changes in the serotonergic system in the main olfactory bulb of rats unilaterally deprived from birth to adulthood. $J$ Neurochem, 100 (4): 924-938.

Graziadei P.P.C. y Graziadei G.A. (1979). Neurogenesis and neuron regeneration in the olfactory system of mammals. I. Morphological aspects of differentiation and structural organization of the olfactory sensory neurons. J Neurocytol, 8 (1): $1-18$. 
Greer C.A. y Shepherd G.M. (1982). Mitral cell degeneration and sensory function in the neurological mutant mouse Purkinje Cell Degeneration ( $p c d)$. Brain Res, 235 (1): 156-161.

Greer C.A., Stewart W.B., Teicher M.H. y Shepherd G.M. (1982). Functional development of the olfactory bulb and a unique glomerular complex in the neonatal rat. J Neurosci, 2 (12): 1744-1759.

Greer C.A. y Halász N. (1987). Plasticity of dendrodendritic microcircuits following mitral cell loss in the olfactory bulb of the murine mutant Purkinje Cell Degeneration. J Comp Neurol, 256 (2): 284-298.

Guix F.X., Uribesalgo I., Coma M. y Muñoz F.J. (2005). The physiology and pathophysiology of nitric oxide in the brain. Prog Neurobiol, 76 (2): 126-152.

Guthrie K.M. y Gall C.M. (1995). Odors increase Fos in olfactory bulb neurons including dopaminergic cells. Neuroreport, 6 (16): 2145-2149.

Haase H. y Beyersmann D. (2002). Intracellular zinc distribution and transport in C6 rat glioma cells. Biochem Biophys Res Commun, 296 (4): 923-928.

Haberly L.B. y Price J.L. (1978). Association and commissural fiber systems of the olfactory cortex of the rat. II. Systems originating in the olfactory peduncle. $J$ Comp Neurol, 181 (4): 781-807.

Haberly L.B. (2001). Parallel-distributed processing in olfactory cortex: new insights from morphological and physiological analysis of neuronal circuitry. Chem Senses, 26 (5): 551-576.

Halàsz N. (1990). The vertebrate olfactory system. Chemical neuroanatomy, function, and development. Akadémiai Kiadó. Budapest.

Halàsz N. y Greer C.A. (1993). Terminal arborizations of olfactory nerve fibers in the glomeruli of the olfactory bulb. J Comp Neurol, 337 (2): 307-316.

Hambidge M. (2000). Human zinc deficiency. J Nutr, 130: 1344-1349. 
Harris J.A., West A.K. y Chuah M.I. (2009). Olfactory ensheathing cells: Nitric oxide production and innate immunity. Glia, 57(16):1848-57.

Harris W.R. y Keen C. (1989). Calculations of the distribution of zinc in a computer model of human serum. J Nutr, 119 (11): 1677-1682.

Hasan M. (1977). Method for demonstrating zinc content of brain using 2-carboxy2'-hydroxy-5'-sulfoformazylbenzene perfusion-staining. Experientia, 33 (4): $552-553$.

Hasumi M., Suzuki K., Matsui H., Koike H., Ito K. y Yamanaka H. (2003). Regulation of metallothionein and zinc transporter expression in human prostate cancer cells and tissues. Cancer Lett, 200 (2): 187-195.

Hershfinkel M., Kandler K., Knoch M.E., Dagan-Rabin M., Aras M.A., Abramovitch-Dahan C., Sekler I. y Aizenman E. (2009). Intracellular zinc inhibits KCC2 transporter activity. Nat Neurosci, 12 (6): 725-727.

Hesse G.W. (1979). Chronic zinc-deficiency alters neuronal function of hippocampal mossy fibers. Science, 205 (4410): 1005-1007.

Heuchel R., Radtke F., Georgiev O., Stark G., Aguet M. y Schaffner W. (1994). The transcription factor MTF-1 is essential for basal and heavy metal-induced metallothionein gene expression. EMBO J, 13 (12): 2870-2875.

Hidalgo J., Aschner M., Zatta P. y Vasak M. (2001). Roles of the metallothionein family of proteins in the central nervous system. Brain Res Bull, 55 (2): 133145.

Hoffman W.H. y Haberly L.B. (1993). Role of synaptic excitation in the generation of bursting-induced epileptiform potentials in the endopiriform nucleus and piriform cortex. J Neurophysiol, 70 (6): 2550-2561.

Holm I.E. (1989). Electron microscopic analysis of glial cells in the rat telencephalon stained with the Neo-Timm and selenium methods. Histochemistry, 92 (4): 301-306. 
Holst B., Egerod K.L., Schild E., Vickers S.P., Cheetham S., Gerlach L.O., Storjohann L., Stidsen C.E., Jones R., Beck-Sickinger A.G. y Schwartz T.W. (2007). GPR39 signaling is stimulated by zinc ions but not by obestatin. Endocrinology, 148 (1): 13-20.

Hsiao B., Dweck D. y Luetje C.W. (2001). Subunit-dependent modulation of neuronal nicotinic receptors by zinc. J Neurosci, 15; 21(6): 1848-56.

Hosie A.M., Dunne E.L., Harvey R.J. y Smart T.G. (2003). Zinc-mediated inhibition of GABA-A receptors: discrete binding sites underlie subtype specificity. Nature Neurosci, 6 (4): 362-369.

Howell G.A., Welch M.G. y Frederickson C.J. (1984). Stimulation-induced uptake and release of zinc in hippocampal slices. Nature, 308 (5961): 736-738.

Huang L. y Gitschier J. (1997). A novel gene involved in zinc transport is deficient in the lethal milk mouse. Nat Genet, 17 (3): 292-297.

Huang L., Kirschke C.P. y Gitschier J. (2002). Functional characterization of a novel mammalian zinc transporter, ZnT6. J Biol Chem, 277 (29): 26389-26395.

Huang L., Kirschke C.P., Zhang Y. y Yu Y.Y. (2005). The ZIP7 gene (Slc39a7) encodes a zinc transporter involved in zinc homeostasis of the Golgi apparatus. J Biol Chem, 280 (15): 15456-15463.

Huang P.L., Dawson T.M., Bredt D.S., Snyder S.H. y Fishman M.C. (1993). Targeted disruption of the neuronal nitric oxide synthase gene. Cell, 75 (7): 1273-1286.

Huang P.L. (1999). Neuronal and endothelial nitric oxide synthase gene knockout mice Braz J Med Biol Res, 32 (11): 1353-1359.

Hubbard P.C. y Lummis S.C. (2000). $\mathrm{Zn}^{2+}$ enhancement of the recombinant 5-HT(3) receptor is modulated by divalent cations, 14;394(2-3):189-97.

Iguchi K., Usui S., Inoue T., Sugimura Y., Tatematsu M. y Hirano K. (2002). Highlevel expression of zinc transporter-2 in the rat lateral and dorsal prostate. $J$ Androl, 23 (6): 819-824. 
Jackowski A., Parnavelas J.G. y Lieberman A.R. (1978). The reciprocal synapse in the external plexiform layer of the mammalian olfactory bulb. Brain Res, 159 (1): $17-28$.

Jackson K.A., Helston R.M., McKay J.A., O'Neill E.D., Mathers J.C. y Ford D. (2007). Splice variants of the human zinc transporter ZnT5 (SLC30A5) are differentially localized and regulated by zinc through transcription and mRNA stability. J Biol Chem, 282 (14): 10423-10431.

Jackson K.A., Valentine R.A., Coneyworth L.J., Mathers J.C. y Ford D. (2008). Mechanisms of mammalian zinc-regulated gene expression. Biochem Soc Trans, 36: 1262-1266.

Jackson V.R., Nothacker H.P. y Civelli O. (2006). GPR39 receptor expression in the mouse brain. Neuroreport, 17 (8): 813-816.

Jacobson M. (1990). Developmental Neurobiology. p. 776. Plenum Press. Nueva York.

Jia Y., Jeng J.M., Sensi S.L. y Weiss J.H. (2002). $\mathrm{Zn}^{2+}$ currents are mediated by calcium-permeable AMPA/kainate channels in cultured murine hippocampal neurones. J Physiol, 543: 35-48.

Jo S.M., Won M.H., Cole T.B., Jensen M.S., Palmiter R.D. y Danscher G. (2000). Zinc-enriched (ZEN) terminals in mouse olfactory bulb. Brain Res, 865 (2): 227-236.

Jo S.M., Kim Y.K., Wang Z. y Danscher G. (2002). Retrograde tracing of zincenriched (ZEN) neuronal somata projecting to the olfactory bulb. Brain Res, 956: $230-235$.

Jo S.M., Danscher G., Schroder H.D. y Suh S.W. (2008). Depletion of vesicular zinc in dorsal horn of spinal cord causes increased neuropathic pain in mice. Biometals, 21 (2): 151-158.

Johnson B.A., Woo C.C. y Leon M. (1998). Spatial coding of odorant features in the glomerular layer of the rat olfactory bulb. J Comp Neurol, 393 (4): 457-471. 
Johnson B.A., Woo C.C., Hingco E.E., Pham K.L. y Leon M. (1999). Multidimensional chemotopic responses to n-aliphatic acid odorants in the rat olfactory bulb. J Comp Neurol, 409 (4): 529-548.

Johnson B.A., Xu Z., Ali S.S. y Leon M. (2009). Spatial representations of odorants in olfactory bulbs of rats and mice: similarities and differences in chemotopic organization. J Comp Neurol, 514 (6): 658-673.

Jüch M., Smalla K.H., Kähne T., Lubec G., Tischmeyer W., Gundelfinger E.D. y Engelmann M. (2009). Congenital lack of nNOS impairs long-term social recognition memory and alters the olfactory bulb proteome. Neurobiol Learn Mem, 92(4): 469-84.

Jung M.W., Larson J. y Lynch G. (1990). Role of NMDA and non-NMDA receptors in synaptic transmission in rat piriform cortex. Exp Brain Res, 82 (2): 451455.

Kaisman-Elbaz T., Sekler I., Fishman D., Karol N., Forberg M., Kahn N., Hershfinkel M. y Silverman W.F. (2009). Cell death induced by zinc and cadmium is mediated by clusterin in cultured mouse seminiferous tubules. $J$ Cell Physiol, 220 (1): 222-229.

Kambe T., Narita H., Yamaguchi-Iwai Y., Hirose J., Amano T., Sugiura N., Sasaki R., Mori K., Iwanaga T. y Nagao M. (2002). Cloning and characterization of a novel mammalian zinc transporter, zinc transporter 5, abundantly expressed in pancreatic beta cells. J Biol Chem, 277 (21): 19049-19055.

Kantheti P., Díaz M.E., Peden A.E., Seong E.E., Dolan D.F., Robinson M.S., Noebels J.L. y Burmeister M.L. (2003). Genetic and phenotypic analysis of the mouse mutant mh2J, an Ap3d allele caused by IAP element insertion. Mamm Genome, 14 (3): 157-167.

Kasarskis E.J. (1984). Zinc-metabolism in normal and zinc-deficient rat brain. Exp Neurol, 85 (1): 114-127. 
Kashiwadani H., Sasaki Y.F., Uchida N. y Mori K. (1999). Synchronized oscillatory discharges of mitral/tufted cells with different molecular receptive ranges in the rabbit olfactory bulb. J Neurophysiol, 82 (4): 1786-1792.

Kasowski H.J., Kim H. y Greer C.A. (1999). Compartmental organization of the olfactory bulb glomerulus. J Comp Neurol, 407 (2): 261-274.

Kelleher S.L. y Lönnerdal B. (2002). Zinc transporters in the rat mammary gland respond to marginal zinc and vitamin A intakes during lactation. J Nutr, 132 (11): 3280-3285.

Keller A., Yagodin S., Aroniadou-Anderjaska V., Zimmer L.A., Ennis M., Sheppard N.F., Jr. y Shipley M.T. (1998). Functional organization of rat olfactory bulb glomeruli revealed by optical imaging. J Neurosci, 18 (7): 2602-2612.

Kida E. y Matyja E. (1990). Prevention of quinolinic acid neurotoxicity in rat hippocampus in vitro by zinc. Ultrastructural observations. Neuroscience, 37 (2): 347-352.

Kirschke C.P. y Huang L. (2003). ZnT7, a novel mammalian zinc transporter, accumulates zinc in the Golgi apparatus. J Biol Chem, 278 (6): 4096-4102.

Kishi K. (1987). Golgi studies on the development of granule cells of the rat olfactory bulb with reference to migration in the subependymal layer. J Comp Neurol, 258 (1): 112-124.

Klenoff J.R. y Greer C.A. (1998). Postnatal development of olfactory receptor cell axonal arbors. J Comp Neurol, 390 (2): 256-267.

Koh J.Y. y Choi D.W. (1994). Zinc toxicity on cultured cortical neurons: involvement of N-Methyl-D-Aspartate receptors. Neuroscience, 60 (4): 10491057.

Koh J.Y., Suh S.W., Gwag B.J., He Y.Y., Hsu C.Y. y Choi D.W. (1996). The role of zinc in selective neuronal death after transient global cerebral ischemia. Science, 272 (5264): 1013-1016. 
Köhler C., Eriksson L.G., Flood P.R., Hardie J.A., Okuno E. y Schwarcz R. (1988). Quinolinic acid metabolism in the rat brain. Immunohistochemical identification of 3-hydroxyanthranilic acid oxygenase and quinolinic acid phosphoribosyltransferase in the hippocampal region. $J$ Neurosci, 8 (3): 975987.

Korichneva I., Hoyos B., Chua R., Levi E. y Hammerling U. (2002). Zinc release from protein kinase $\mathrm{C}$ as the common event during activation by lipid second messenger or reactive oxygen. J Biol Chem, 277 (46): 44327-44331.

Korol D.L. y Brunjes P.C. (1990). Rapid changes in 2-deoxyglucose uptake and amino acid incorporation following unilateral odor deprivation: a laminar analysis. Brain Res, 52: 75-84.

Kosaka K., Heizmann C.W. y Kosaka T. (1994). Calcium-binding protein parvalbumin-immunoreactive neurons in the rat olfactory bulb. 1 . Distribution and structural features in adult rat. Exp Brain Res, 99 (2): 191204.

Kosaka K., Aika Y., Toida K., Heizmann C.W., Hunziker W., Jacobowitz D.M., Nagatsu I., Streit P., Visser T.J. y Kosaka T. (1995). Chemically defined neuron groups and their subpopulations in the glomerular layer of the rat main olfactory bulb. Neurosci Res, 23 (1): 73-88.

Kosaka K., Toida K., Margolis F.L. y Kosaka T. (1997). Chemically defined neuron groups and their subpopulations in the glomerular layer of the rat main olfactory bulb. II Prominent differences in the intraglomerular dendritic arborization and their relationship to olfactory nerve terminals. Neuroscience, 76 (3): $775-786$.

Kosaka K., Toida K., Aika Y. y Kosaka T. (1998) How simple is the organization of the olfactory glomerulus?: the heterogeneity of so-called periglomerular cells. Neurosci Res, 30 (2): 101-110.

Kosaka T., Kosaka K., Hama K., Wu J.Y. y Nagatsu I. (1987). Differential effect of functional olfactory deprivation on the GABAergic and catecholaminergic traits in the rat main olfactory bulb. Brain Res, 413 (1): 197-203. 
Kosaka T. y Kosaka K. (2004). Neuronal gap junctions between intraglomerular mitral/tufted cell dendrites in the mouse main olfactory bulb. Neurosci Res, 49 (4): 373-378.

Kosaka T. y Kosaka K. (2007). Heterogeneity of nitric oxide synthase-containing neurons in the mouse main olfactory bulb. Neurosci Res, 57 (2): 165-178.

Kratskin I. y Gershuni, G.V. (1987). Centrifugal innervation of the main olfactory bulb in vertebrates. pp: 101-120. Nauka. Leningrado.

Kratskin I. y Belluzzi O. (2003) Anatomy and neurochemistry of the olfactory bulb. En: Handbook of Olfation and Gustation (Doty, R. L. Ed.) pp: 139-164. Marcel Dekker, Filadelfia.

Kratskin I., Kenigfest N., Rio J.P., Djediat C. y Reperant J. (2006). Immunocytochemical localization of the GABA-B2 receptor subunit in the glomeruli of the mouse main olfactory bulb. Neurosci Lett, 402 (1-2): 121125.

Labarca P. y Bacigalupo J. (1988). Ion channels from chemosensory olfactory neurons. J Bioenerg Biomembr, 20 (5): 551-569.

Lancaster J.R., Jr. (1994). Simulation of the diffusion and reaction of endogenously produced nitric oxide. Proc Natl Acad Sci U S A, 91 (17): 8137-8141.

Land P.W. y Akhtar N.D. (1999). Experience-dependent alteration of synaptic zinc in rat somatosensory barrel cortex. Somatosens Mot Res, 16 (2): 139-150.

Land P.W. y Shamalla-Hannah L. (2002). Experience-dependent plasticity of zinccontaining cortical circuits during a critical period of postnatal development. J Comp Neurol, 447 (1): 43-56.

Landis S.C. y Mullen R.J. (1978). The development and degeneration of Purkinje cells in pcd mutant mice. J Comp Neurol, 177 (1): 125-143.

Langmade S.J., Ravindra R., Daniels P.J. y Andrews G.K. (2000). The transcription factor MTF-1 mediates metal regulation of the mouse ZnT1 gene. J Biol Chem, 275 (44): 34803-34809. 
Lannfelt L., Blennow K., Zetterberg H., Batsman S., Ames D., Harrison J., Masters C.L., Targum S., Bush A.I., Murdoch R., Wilson J. y Ritchie C.W. (2008). Safety, efficacy, and biomarker findings of PBT2 in targeting A $\beta$ as a modifying therapy for Alzheimer's disease: a phase IIa, double-blind, randomised, placebo-controlled trial. Lancet Neurol, 7 (9): 779-786.

Lee J.Y., Cole T.B., Palmiter R.D., Suh S.W. y Koh J.Y. (2002). Contribution by synaptic zinc to the gender-disparate plaque formation in human Swedish mutant APP transgenic mice. Proc Natl Acad Sci U S A, 99 (11): 7705-7710.

Lee J.Y., Kim J.H., Hong S.H., Lee J.Y., Cherny R.A., Bush A.I., Palmiter R.D. y Koh J.Y. (2004). Estrogen decreases zinc transporter 3 expression and synaptic vesicle zinc levels in mouse brain. J Biol Chem, 279 (10): 86028607.

Lee W., Cheng T.W. y Gong Q. (2008). Olfactory sensory neuron-specific and sexually dimorphic expression of protocadherin 20. J Comp Neurol, 507 (1): 1076-1086.

Lengyel I., Fieuw-Makaroff S., Hall A.L., Sim A.T., Rostas J.A. y Dunkley P.R. (2000). Modulation of the phosphorylation and activity of calcium/calmodulin-dependent protein kinase II by zinc. J Neurochem, 75 (2): 594-605.

Li Y., Hough C.J., Suh S.W., Sarvey J.M. y Frederickson C.J. (2001a). Rapid translocation of $\mathrm{Zn}^{2+}$ from presynaptic terminals into postsynaptic hippocampal neurons after physiological stimulation. J Neurophysiol, 86 (5): 2597-2604.

Li Y., Hough C.J., Frederickson C.J. y Sarvey J.M. (2001b). Induction of mossy fiber $\mathrm{Ca} 3$ long-term potentiation requires translocation of synaptically released $\mathrm{Zn}^{2+}$. J Neurosci, 21 (20): 8015-8025.

Lichten L.A. y Cousins R.J. (2009). Mammalian zinc transporters: Nutritional and physiologic regulation. Annu Rev Nutr, 29: 153-76 
Liesegang R.E. (1911). Die Kolloidchemie der histologischen Silberfärbungen. Kolloid Beihefte, 3: 1-46.

Liguz-Lecznar M., Nowicka D., Czupryn A. y Skangiel-Kramska J. (2005). Dissociation of synaptic zinc level and zinc transporter 3 expression during postnatal development and after sensory deprivation in the barrel cortex of mice. Brain Res Bull, 66 (2): 106-113.

Lin B., Ginsberg M.D., Busto R. y Dietrich W.D. (1998). Sequential analysis of subacute and chronic neuronal, astrocytic and microglial alterations after transient global ischemia in rats. Acta Neuropathol, 95 (5): 511-523.

Liu W.L. y Shipley M.T. (1994). Intrabulbar associational system in the rat olfactory bulb comprises cholecystokinin-containing tufted cells that synapse onto the dendrites of GABAergic granule cells. J Comp Neurol, 346(4):541-58.

Liuzzi J.P., Blanchard R.K. y Cousins R.J. (2001). Differential regulation of zinc transporter 1, 2, and 4 mRNA expression by dietary zinc in rats. $J$ Nutr, 131 (1): 46-52.

Lois C., García-Verdugo J.M. y Álvarez-Buylla A. (1996). Chain migration of neuronal precursors. Science, 271(5251): 978-981.

Lois C. y Álvarez-Buylla A. (1993). Proliferating subventricular zone cells in the adult mammalian forebrain can differentiate into neurons and glia. Proc Natl Acad Sci U S A, 90(5):2074-7.

Lois C. y Álvarez-Buylla A. (1994). Long-distance neuronal migration in the adult mammalian brain. Science, 264(5162):1145-8.

López-García C., Molowny A. y Pérez-Clausell J. (1983). Volumetric and densitometric study in the cerebral cortex and septum of a lizard (Lacerta galloti) using the Timm method. Neurosci Lett, 40 (1): 13-18.

López-García C. y Martínez-Guijarro F.J. (1988). Neurons in the medial cortex give rise to Timm-positive boutons in the cerebral cortex of lizards. Brain Res, 463 (2): 205-217. 
López-García C., Varea E., Palop J.J., Nacher J., Ramírez C., Ponsoda X. y Molowny A. (2002). Cytochemical techniques for zinc and heavy metals localization in nerve cells. Microsc Res Techn, 56 (5): 318-331.

Loranca A. y Salas M. (2001). Social play development in pre-weaning olfactory deprived or stimulated rats. Brain Res, 921 (1-2): 150-159.

Lowe G. y Gold G.H. (1993). Nonlinear amplification by calcium-dependent chloride channels in olfactory receptor cells. Nature, 366 (6452): 283-286.

Luskin M.B. (1993). Restricted proliferation and migration of postnatally generated neurons derived from the forebrain subventricular zone. Neuron, 11 (1): 173189.

Luskin M.B. (1998). Neuroblasts of the postnatal mammalian forebrain: their phenotype and fate. J Neurobiol, 36 (2): 221-233.

Mackay-Sim A. y Dreosti I.E. (1989). Olfactory function in zinc-deficient adult mice. Exp Brain Res, 76 (1): 207-212.

Macrides F. y Davis B.J. (1983). The olfactory bulb. En: Chemical neuroanatomy (Emson, P.C. Ed.) pp. 391-426. Raven Press. Nueva York.

Malaiyandi L.M., Dineley K.E. y Reynolds I.J. (2004). Divergent consequences arise from metallothionein overexpression in astrocytes: zinc buffering and oxidant-induced zinc release. Glia, 45 (4): 346-353.

Maret W. (2009). Molecular aspects of human cellular zinc homeostasis: redox control of zinc potentials and zinc signals. Biometals, 22 (1): 149-157.

Margeta-Mitrovic M., Mitrovic I., Riley R.C., Jan L.Y. y Basbaum A.I. (1999). Immunohistochemical localization of $\mathrm{GABA}(\mathrm{B})$ receptors in the rat central nervous system. J Comp Neurol, 405 (3): 299-321.

Martínez-Guijarro F.J., Molowny A. y López-García C. (1987). Timm-staining intensity is correlated with the density of Timm-positive presynaptic structures in the cerebral cortex of lizards. Histochemistry, 86 (3): 315-319. 
Maske H. (1955). Über den topochemischen Nachweis von Zink im Ammonshorn verschiedener Säugestiere. Naturwissenschaften, 42: 424.

Mateo A.O. y de Artiñano A.A. (2000). Nitric oxide reactivity and mechanisms involved in its biological effects. Pharmacol Res, 42 (5): 421-427.

Matsutani S. y Yamamoto N. (2008). Centrifugal innervation of the mammalian olfactory bulb. Anat Sci Int, 83 (4): 218-227.

McKee K.K., Tan C.P., Palyha O.C., Liu J., Feighner S.D., Hreniuk D.L., Smith R.G., Howard A.D. y Van der Ploeg L.H. (1997). Cloning and characterization of two human G protein-coupled receptor genes (GPR38 and GPR39) related to the growth hormone secretagogue and neurotensin receptors. Genomics, 46 (3): 426-434.

McLean J.H. y Shipley M.T. (1987a). Serotonergic afferents to the rat olfactory bulb: I. Origins and laminar specificity of serotonergic inputs in the adult rat. $J$ Neurosci, 7 (10): 3016-3028.

McLean J.H. y Shipley M.T. (1987b) Serotonergic afferents to the rat olfactory bulb: II. Changes in fiber distribution during development. J Neurosci, 7 (10): 3029-3039.

McLean J.H. y Shipley M.T. (1991). Postnatal development of the noradrenergic projection from locus coeruleus to the olfactory bulb in the rat. J Comp Neurol, 304 (3): 467-477.

McLean J.H., Shipley M.T., Nickell W.T., Aston-Jones G. y Reyher C.K. (1989). Chemoanatomical organization of the noradrenergic input from locus coeruleus to the olfactory bulb of the adult rat. J Comp Neurol, 285:339-349.

McMahon R.J. y Cousins R.J. (1998). Regulation of the zinc transporter ZnT-1 by dietary zinc. Proc Natl Acad Sci U S A, 95 (9): 4841-4846.

Meisami E. y Safari L. (1981). A quantitative study of the effects of early unilateral olfactory deprivation on the number and distribution of mitral and tufted cells and of glomeruli in the rat olfactory bulb. Brain Res, 221 (1): 81-107. 
Mengual E., Casanovas-Aguilar C., Pérez-Clausell J., y Giménez-Amaya J.M. (2001). Thalamic distribution of zinc-rich terminal fields and neurons of origin in the rat. Neuroscience, 102 (4): 863-884.

Miller L.M., Wang Q., Telivala T.P., Smith R.J., Lanzirotti A., y Miklossy J. (2006). Synchrotron-based infrared and X-ray imaging shows focalized accumulation of $\mathrm{Cu}$ and $\mathrm{Zn}$ co-localized with beta-amyloid deposits in Alzheimer's disease. J Struct Biol, 155 (1): 30-37.

Miller P.S., Da Silva H.M. y Smart T.G. (2005). Molecular basis for zinc potentiation at strychnine-sensitive glycine receptors. J Biol Chem, 280 (45): 37877-84.

Mocchegiani E., Bertoni-Freddari C., Marcellini F. y Malavolta M. (2005) Brain, aging and neurodegeneration: role of zinc ion availability. Prog Neurobiol, 75 (6): $367-390$.

Moreno-López B. y González-Forero D. (2006). Nitric oxide and synaptic dynamics in the adult brain: physiopathological aspects. Rev Neurosci, 17 (3): 309-357.

Mori K., Kishi K., y Ojima H. (1983). Distribution of dendrites of mitral, displaced mitral, tufted, and granule cells in the rabbit olfactory bulb. J Comp Neurol, 219 (3): 339-355.

Mugnaini E., Wouterlood F.G., Dahl A.L. y Oertel W.H. (1984). Immunocytochemical identification of GABA-ergic neurons in the main olfactory bulb of the rat. Arch Ital Biol, 122(2): 83-113.

Mullen R.J., Eicher E.M. y Sidman R.L. (1976). Purkinje Cell Degeneration, a new neurological mutation in the mouse. Proc Natl Acad Sci USA, 73 (1): 208212.

Mullis K., Faloona F., Scharf S., Saiki R., Horn G. y Erlich H. (1986). Specific enzymatic amplification of DNA in vitro: the polymerase chain reaction. Cold Spring Harb Symp Quant Biol, 51: 263-273. 
Murphy G.J., Glickfeld L.L., Balsen Z. y Isaacson J.S. (2004). Sensory neuron signaling to the brain: properties of transmitter release from olfactory nerve terminals. J Neurosci, 24 (12): 3023-3030.

Nagao H., Yoshihara Y., Mitsui S., Fujisawa H. y Mori K. (2000). Two mirror-image sensory maps with domain organization in the mouse main olfactory bulb. Neuroreport, 11 (13): 3023-3027.

Nakashima A.S. y Dyck R.H. (2009). Zinc and cortical plasticity. Brain Res, 59 (2): $347-373$.

Ni H., Jiang Y.W., Tao L.Y., Jin M.F. y Wu X.R. (2009). ZnT-1, ZnT-3, CaMK II, PRG-1 expressions in hippocampus following neonatal seizure-induced cognitive deficit in rats. Toxicol Lett, 184 (3): 145-150.

Nolan E.M., Jaworski J., Okamoto K., Hayashi Y., Sheng M. y Lippard S.J. (2005). QZ1 and QZ2: rapid, reversible quinoline-derivatized fluoresceins for sensing biological Zn(II). J Am Chem Soc, 127 (48): 16812-16823.

Ohana E., Sekler I., Kaisman T., Kahn N., Cove J., Silverman W.F., Amsterdam A. y Hershfinkel M. (2006). Silencing of ZnT-1 expression enhances heavy metal influx and toxicity. J Mol Med, 84 (9): 753-763.

Okamoto K. y Hashimoto M. (1944). The histochemical test-methd of zinc. Jpn J Constit Med, 18: 33.

Ordy J.M., Wengenack T.M., Bialobok P., Coleman P.D., Rodier P., Baggs R.B., Dunlap W.P. y Kates B. (1993). Selective vulnerability and early progression of hippocampal CA1 pyramidal cell degeneration and GFAP-positive astrocyte reactivity in the rat four-vessel occlusion model of transient global ischemia. Exp Neurol, 119 (1): 128-139.

Packer M.A., Stasiv Y., Benraiss A., Chmielnicki E., Grinberg A., Westphal H., Goldman S.A. y Enikolopov G. (2003). Nitric oxide negatively regulates mammalian adult neurogenesis. Proc Natl Acad Sci U S A, 100(16):9566-71. 
Palmiter R.D. y Findley S.D. (1995) Cloning and functional characterization of a mammalian zinc transporter that confers resistance to zinc. EMBO J, 14 (4): 639-649.

Palmiter R.D., Cole T.B., Quaife C.J. y Findley S.D. (1996a). ZnT-3, a putative transporter of zinc into synaptic vesicles. Proc Natl Acad Sci U S A, 93 (25): 14934-14939.

Palmiter R.D., Cole T.B. y Findley S.D. (1996b). ZnT-2, a mammalian protein that confers resistance to zinc by facilitating vesicular sequestration. EMBO J, 15 (8): 1784-1791.

Palmiter R.D. (1998). The elusive function of metallothioneins. Proc Natl Acad Sci U S A, 95 (15): 8428-8430.

Panzanelli P., Perazzini A.Z., Fritschy J.M. y Sassoe-Pognetto M. (2005). Heterogeneity of gamma-aminobutyric type A receptors in mitral and tufted cells of the rat main olfactory bulb. J Comp Neurol, 484 (1): 121-131.

Paoletti P., Ascher P. y Neyton J. (1997). High-affinity zinc inhibition of NMDA NR1-NR2A receptors. J Neurosci, 17 (20): U8.

Pekcec A., Loscher W. y Potschka H. (2006). Neurogenesis in the adult rat piriform cortex. Neuroreport, 17 (6): 571-574.

Penkowa M., Nielsen H., Hidalgo J., Bernth N. y Moos T. (1999). Distribution of metallothionein I + II and vesicular zinc in the developing central nervous system: correlative study in the rat. J Comp Neurol, 412 (2): 303-318.

Pérez-Clausell J. y Danscher G. (1985). Intravesicular localization of zinc in rat telencephalic boutons. A histochemical study. Brain Res, 337 (1): 91-98.

Pérez-Clausell J., Frederickson C.J. y Danscher G. (1989). Amygdaloid efferents through the stria terminalis in the rat give origin to zinc-containing boutons. $J$ Comp Neurol, 290 (2): 201-212.

Peters A. y Feldman M. (1973). The cortical plate and molecular layer of the late rat fetus. Z Anat Entwicklungsgesch, 141 (1): 3-37. 
Peters S., Koh J. y Choi D.W. (1987). Zinc selectively blocks the action of NMethyl-D-Aspartate on cortical neurons. Science, 236 (4801): 589-593.

Pfaffl M.W. y Windisch W. (2003). Influence of zinc deficiency on the mRNA expression of zinc transporters in adult rats. J Trace Elem Med Biol, 17 (2): 97-106.

Pinching A.J. y Powell T.P.S. (1971a). The neuron types of the glomerular layer of the olfactory bulb. J Cell Sci, 9 (2): 305-345.

Pinching A.J. y Powell T.P.S. (1971b). The neuropil of the glomeruli of the olfactory bulb. J Cell Sci, 9 (2): 347-377.

Polley D.B., Kvasnak E. y Frostig R.D. (2004). Naturalistic experience transforms sensory maps in the adult cortex of caged animals. Nature, 429 (6987): 67-71.

Poston M.R., Bailey M.S., Schwarcz R. y Shipley M.T. (1991). Differential complementary localization of metabolic enzymes for quinolinic acid in olfactory bulb astrocytes. J Comp Neurol, 311 (3): 367-374.

Powell T.P.S., Cowan W.M. y Raisman G. (1965). The central olfactory connexions. J Anat, 99 (4): 791-813.

Prasad A.S., Schulert A.R., Miale A. Jr., Faid Z., y Sandstead H.H. (1963). Zinc and iron deficiencies in male subjects with dwarfism and hypogonadism but without ancylostomiasis, schistosomiasis or severe anemia. Am J Clin Nutr, 12: 437-444.

Price J.L. y Powell T.P.S. (1970a). The morphology of the granule cells of the olfactory bulb. J Cell Sci, 7 (1): 91-123.

Price J.L. y Powell T.P.S. (1970b) The mitral and short axon cells in of the olfactory bulb. J Cell Sci, 7: 631-651.

Price J.L. y Powell T.P.S. (1971). Certain observations on the olfactory pathway. $J$ Anat, 110 (1): 105-126. 
Price J.L. (1973). Autoradiographic study of complementary laminar patterns of termination of afferent fibers to olfactory cortex. J Comp Neurol, 150 (1): 87108.

Price J.L. (1987). The central olfactory and accessory olfactory system. En: Neurobiology of taste and smell (Finger T. y Silver W., eds.) pp. 179-204. John Wiley and Sons. Nueva York.

Puche A.C., Parrish-Aungst S., Valentino K. Y Shiplwy M.T. (2005). External tufted cells: instant messaging to cortex? Abstract Viewer/Itinerary Planner. Washington DC: Society of Neuroscience No. 740.14

Pullen R.G., Franklin P., Hall G.H. (1990). ${ }^{65} \mathrm{Zn}$ uptake from blood into brain and other tissues in the rat. Neurochem Res, 15 (10): 1003-1008.

Puopolo M. y Belluzzi O. (1998). Functional heterogeneity of periglomerular cells in the rat olfactory bulb. Eur J Neurosci, 10 (3): 1073-1083.

Qian H., Malchow R.P., Chappell R.L. y Ripps H. (1996). Zinc enhances ionic currents induced in skate Müller (glial) cells by the inhibitory neurotransmitter GABA. Proc Biol Sci, 263 (1371): 791-796.

Qian J. y Noebels J.L. (2005). Visualization of transmitter release with zinc fluorescence detection at the mouse hippocampal mossy fibre synapse. $J$ Physiol, 566: 747-758.

Qin H., Shen H., Wang F. y Guo J. (2004). Expression of metallothioneins on zinc exposure in rat hippocampal neurons. Wei Sheng Yan Jiu, 33 (5): 562-564.

Quaye V.L., Shamalla-Hannah L. y Land P.W. (1999). Experience-dependent alteration of zinc-containing circuits in somatosensory cortex of the mouse. Brain Res, 114 (2): 283-287.

Rachline J., Perin-Dureau F., Le Goff A., Neyton J. y Paoletti P. (2005). The micromolar zinc-binding domain on the NMDA receptor subunit NR2B. $J$ Neurosci, 25 (2): 308-317. 
Ramón y Cajal S. (1911). Histologie du système nerveux de l'homme et des vértebrés. Maloine. París.

Ray J.P., Russchen F.T., Fuller T.A. y Price J.L. (1992). Sources of presumptive glutamatergic/aspartatergic afferents to the mediodorsal nucleus of the thalamus in the rat. J Comp Neurol, 320 (4): 435-456.

Recio J.S., Weruaga E., Gómez C., Valero J., Briñón J.G. y Alonso J.R. (2007). Changes in the connections of the main olfactory bulb after mitral cell selective neurodegeneration. J Neurosci Res, 85 (11): 2407-2421.

Redenti S. y Chappell R.L. (2004). Localization of zinc transporter-3 (ZnT-3) in mouse retina. Vision Res, 44 (28): 3317-3321.

Reyher C.K., Lubke J., Larsen W.J., Hendrix G.M., Shipley M.T. y Baumgarten H.G. (1991). Olfactory bulb granule cell aggregates: morphological evidence for interperikaryal electrotonic coupling via gap junctions. J Neurosci, 11 (6): 1485-1495.

Reynolds E.S. (1963). The use of lead citrate at high $\mathrm{pH}$ as an electron-opaque stain in electron microscopy. J Cell Biol, 17: 208-212.

Reynolds I.J. y Miller R.J. (1988). Tricyclic antidepressants block N-Methyl-DAspartate receptors. Similarities to the Action of Zinc. Brit J Pharmacol, 95 (1): 95-102.

Ribak C.E., Vaughn J.E., Saito K, Barber R. y Roberts E. (1977). Glutamate descarboxylase localization in neurons of the olfactory bulb. Brain Res, 126: $1-18$.

Ritchie C.W., Bush A.I., Mackinnon A., Macfarlane S., Mastwyk M., MacGregor L., Kiers L., Cherny R., Li Q.X., Tammer A., Carrington D., Mavros C., Volitakis I., Xilinas M., Ames D., Davis S., Beyreuther K., Tanzi R.E. y Masters C.L. (2003). Metal-protein attenuation with iodochlorhydroxyquin (clioquinol) targeting $A \beta$ - amyloid deposition and toxicity in Alzheimer disease: a pilot phase 2 clinical trial. Arch Neurol, 60 (12): 1685-1691. 
Rochefort C., Gheusi G., Vincent J.D. y Lledó P.M. (2002). Enriched odor exposure increases the number of newborn neurons in the adult olfactory bulb and improves odor memory. J Neurosci, 22 (7): 2679-2689.

Romero-Grimaldi C., Gheusi G., Lledó P.M. y Estrada C. (2006). Chronic inhibition of nitric oxide synthesis enhances both subventricular zone neurogenesis and olfactory learning in adult mice. Eur J Neurosci, 24 (9): 2461-2470.

Rosselli-Austin L. y Williams J. (1990). Enriched neonatal odor exposure leads to increased numbers of olfactory bulb mitral and granule cells. Brain Res, 51 (1): 135-137.

Royet J.P., Souchier C., Jourdan F. y Ploye H. (1988). Morphometric study of the glomerular population in the mouse olfactory bulb: numerical density and size distribution along the rostrocaudal axis. J Comp Neurol, 270 (4): 559568.

Rubin B.D. y Katz L.C. (2001). Spatial coding of enantiomers in the rat olfactory bulb. Nat Neurosci, 4 (4): 355-356.

Ruiz A., Walker M.C., Fabian-Fine R. y Kullmann D.M. (2004). Endogenous zinc inhibits GABA-A receptors in a hippocampal pathway. J Neurophysiol, 91 (2): 1091-1096.

Salazar G., Love R., Styers M.L., Werner E., Peden A., Rodríguez S., Gearing M., Wainer B.H. y Faundez V. (2004). AP-3-dependent mechanisms control the targeting of a chloride channel (ClC-3) in neuronal and non-neuronal cells. $J$ Biol Chem, 279 (24): 25430-25439.

Salazar G., Falcon-Pérez J.M., Harrison R. y Faundez V. (2009). Slc30a3 (ZnT3) oligomerization by dityrosine bonds regulates its subcellular localization and metal transport capacity. PLoS One, 4 (6): e5896 .

Sandeman R. y Sandeman D. (2000). "Impoverished" and "enriched" living conditions influence the proliferation and survival of neurons in crayfish brain. J Neurobiol, 45 (4): 215-226. 
Sandstead H.H. (2000). Zinc: Growth, development, and function. J Trace Elem Exp Med, 13 (1): 41-49.

Sandstead H.H., Frederickson C.J. y Penland J.G. (2000). History of zinc as related to brain function. $J$ Nutr, 130 (2): 496S-502S.

Schetz J.A., Chu A. y Sibley D.R. (1999). Zinc modulates antagonist interactions with D2-like dopamine receptors through distinct molecular mechanisms. $J$ Pharmacol Exp Ther, 289 (2): 956-964.

Schneider S.P. y Macrides F. (1978). Laminar distributions of interneurons in the main olfactory bulb of the adult hamster. Brain Res Bull, 3: 73-82.

Schoenfeld T.A., Marchand J.E. y Macrides F. (1985). Topographic organization of tufted cell axonal projections in the hamster main olfactory bulb: an intrabulbar associational system. J Comp Neurol, 235 (4): 503-518.

Scott J.W., McBride R.L. y Schneider S.P. (1980). The organization of projections from the olfactory bulb to the piriform cortex and olfactory tubercle in the rat. J Comp Neurol, 194 (3): 519-534.

Scotto L.S., Strambi C., Strambi A., Charpin P., Augier R., Aouane A. y Cayre M. (2000) Influence of environmental stimulation on neurogenesis in the adult insect brain. J Neurobiol, 45 (3): 162-171.

Seki T. y Arai Y. (1991). Expression of highly polysialylated NCAM in the neocortex and piriform cortex of the developing and the adult rat. Anat Embryol, 184 (4): 395-401.

Sensi S.L., Yin H.Z., Carriedo S.G., Rao S.S. y Weiss J.H. (1999). Preferential Zn ${ }^{2+}$ influx through $\mathrm{Ca}^{2+}$-permeable AMPA/kainate channels triggers prolonged mitochondrial superoxide production. Proc Natl Acad Sci U S A, 96 (5): 2414-2419.

Sensi S.L. y Jeng J.M. (2004). Rethinking the excitotoxic ionic milieu: the emerging role of $\mathrm{Zn}^{2+}$ in ischemic neuronal injury. Curr Mol Med, 4 (2): 87-111. 
Seong E., Wainer B.H., Hughes E.D., Saunders T.L., Burmeister M. y Faundez V. (2005). Genetic analysis of the neuronal and ubiquitous AP-3 adaptor complexes reveals divergent functions in brain. Mol Biol Cell, 16 (1): 128140.

Shankar A.H. y Prasad A.S. (1998). Zinc and immune function: the biological basis of altered resistance to infection. Am J Clin Nutr, 68 (2): 447-463.

Shapiro L.A., Ng K.L., Zhou Q.Y. y Ribak C.E. (2007). Olfactory enrichment enhances the survival of newly born cortical neurons in adult mice. Neuroreport, 18 (10): 981-985.

Sheline C.T., Ying H.S., Ling C.S., Canzoniero L.M. y Choi D.W. (2002). Depolarization-induced ${ }^{65} \mathrm{Zn}$ influx into cultured cortical neurons. Neurobiol Dis, 10 (1): 41-53.

Sheline C.T., Takata T., Ying H., Canzoniero L.M., Yang A., Yu S.P. y Choi D.W. (2004). Potassium attenuates zinc-induced death of cultured cortical astrocytes. Glia, 46 (1): 18-27.

Shepherd G.M. (1972). Synaptic organization of the mammalian olfactory bulb. Physiol Rev, 52 (4): 864-917.

Shimada H., Yasutake A., Hirashima T., Takamure Y., Kitano T., Waalkes M.P. y Imamura Y. (2008) Strain difference of cadmium accumulation by liver slices of inbred Wistar-Imamichi and Fischer 344 rats. Toxicol In Vitro, 22 (2): 338343.

Shinoda K., Shiotani Y. y Osawa Y. (1989). "Necklace olfactory glomeruli" form unique components of the rat primary olfactory system. J Comp Neurol, 284 (3): $362-373$.

Shinoda K., Yagi H., Osawa Y. y Shiotani Y. (1990). Involvement of specific placental antigen X-P2 in rat olfaction: an immunohistochemical study in the olfactory bulb. J Comp Neurol, 294 (3): 340-344. 
Shipley M.T. y Adamek G.D. (1984). The connections of the mouse olfactory bulb: A study using orthograde and retrograde transport of wheat germ agglutinin conjugated to horseradish-peroxidase. Brain Res Bull, 12 (6): 669-688.

Shipley M.T., McLean J.H. y Ennis M. (1995). Olfactory system. En: The rat nervous system. (Paxinos G. Ed.) pp. 899-926. Academic Press. Nueva York.

Shipley M.T. y Ennis M. (1996). Functional organization of olfactory system. $J$ Neurobiol, 30 (1): 123-176.

Simons T.J. (1993). Measurement of free $\mathrm{Zn}^{2+}$ ion concentration with the fluorescent-probe mag-fura-2 (Furaptra). J Biochem Bioph Meth, 27 (1): 2537.

Slomianka L., Danscher G. y Frederickson C.J. (1990). Labeling of the neurons of origin of zinc-containing pathways by intraperitoneal injections of sodium selenite. Neuroscience, 38 (3): 843-854.

Slomianka L. (1992). Neurons of origin of zinc-containing pathways and the distribution of zinc-containing boutons in the hippocampal region of the rat. Neuroscience, 48 (2): 325-352.

Smart T.G., Hosie A.M. y Miller P.S. (2004). $\mathrm{Zn}^{2+}$ ions: Modulators of excitatory and inhibitory synaptic activity. Neuroscientist, 10 (5): 432-442.

Smidt K., Jessen N., Petersen A.B., Larsen A., Magnusson N., Jeppesen J.B., Stoltenberg M., Culvenor J.G., Tsatsanis A., Brock B., Schmitz O., Wogensen L., Bush A.I. y Rungby J. (2009). Slc30a3 responds to glucoseand zinc variations in beta-cells and is critical for insulin production and in vivo glucose-metabolism during beta-cell stress. PLoS One, 4 (5): e5684.

Smith T.C. y Jahr C.E. (2002). Self-inhibition of olfactory bulb neurons. Nat Neurosci, 5 (8): 760-766.

Spahl D.U., Berendji-Grun D., Suschek C.V., Kolb-Bachofen V. y Kroncke K.D. (2003). Regulation of zinc homeostasis by inducible NO synthase-derived 
NO: nuclear metallothionein translocation and intranuclear $\mathrm{Zn}^{2+}$ release. Proc Natl Acad Sci U S A, 100 (24): 13952-13957.

Speciale C., Okuno E. y Schwarcz R. (1987). Increased quinolinic acid metabolism following neuronal degeneration in the rat hippocampus. Brain Res, 436 (1): $18-24$.

Squitti R., Gorgone G., Binetti G., Ghidoni R., Pasqualetti P., Draicchio F., Albini E., Benedetti L., Lucchini R. y Rossini P.M. (2007). Metals and oxidative stress in Parkinson's disease from industrial areas with exposition to environmental toxins or metal pollution. G Ital Med Lav Ergon, 29: 294-296.

St John J.A. y Key B. (2001). Chemically and morphologically identificable glomeruli in the rat olfactory bulb. J Comp Neurol, 436(4): 497-507.

Stoltenberg M., Nejsum L.N., Larsen A. y Danscher G. (2004). Abundance of zinc ions in synaptic terminals of mocha mutant mice: zinc transporter 3 immunohistochemistry and zinc sulphide autometallography. J Mol Histol, 35 (2): 141-145.

Stoltenberg M., Bruhn M., Sondergaard C., Doering P., West M.J., Larsen A., Troncoso J.C. y Danscher G. (2005). Immersion autometallographic tracing of zinc ions in Alzheimer $\beta$-amyloid plaques. Histochem Cell Biol, 123 (6): 605-611.

Stone D.M., Grillo M., Margolis F.L., Joh T.H. y Baker H. (1991). Differential effect of functional olfactory bulb deafferentation on tyrosine hydroxylase and glutamic acid decarboxylase messenger RNA levels in rodent juxtaglomerular neurons. J Comp Neurol, 311 (2): 223-233.

Styers M.L., Salazar G., Love R., Peden A.A., Kowalczyk A.P. y Faundez V. (2004). The endo-lysosomal sorting machinery interacts with the intermediate filament cytoskeleton. Mol Biol Cell, 15 (12): 5369-5382.

Suh S.W., Thompson R.B. y Frederickson C.J. (2001). Loss of vesicular zinc and appearance of perikaryal zinc after seizures induced by pilocarpine. Neuroreport, 12 (7): 1523-1525. 
Suh S.W., Jo S.M., Vajda Z. y Danscher G. (2005). Adrenalectomy-induced ZnT3 downregulation in mouse hippocampus is followed by vesicular zinc depletion. Neurosci Lett, 377 (3): 164-169.

Suh S.W. (2009). Detection of zinc translocation into apical dendrite of CA1 pyramidal neuron after electrical stimulation. J Neurosci Methods, 177 (1): 113.

Suh S.W., Won S.J., Hamby A.M., Yoo B.H., Fan Y., Sheline C.T., Tamano H., Takeda A. y Liu J. (2009). Decreased brain zinc availability reduces hippocampal neurogenesis in mice and rats. J Cereb Blood Flow Metab, 29(9):1579-1588.

Takeda A., Ohnuma M., Sawashita J. y Okada S. (1997). Zinc transport in the rat olfactory system. Neurosci Lett, 225 (1): 69-71.

Takeda A. (2000). Movement of zinc and its functional significance in the brain. Brain Res, 34 (3): 137-148.

Takeda A., Tamano H., Enomoto S. y Oku N. (2001). Zinc-65 imaging of rat brain tumors. Cancer Res, 61 (13): 5065-5069.

Takeda A., Hirate M., Tamano H. y Oku N. (2003). Release of glutamate and GABA in the hippocampus under zinc deficiency. J Neurosci Res, 72 (4): 537-542.

Takeda A., Minami A., Seki Y. y Oku N. (2004). Differential effects of Zinc on Glutamatergic and GABAergic neurotransmitter systems in the hippocampus. J Neurosci Res, 75 (2): 225-229.

Tanda K., Nishi A., Matsuo N., Nakanishi K., Yamasaki N., Sugimoto T., Toyama K., Takao K. y Miyakawa T. (2009). Abnormal social behavior, hyperactivity, impaired remote spatial memory, and increased D1-mediated dopaminergic signaling in neuronal nitric oxide synthase knockout mice. Mol Brain, 2 (1): 19.

Teicher M.H., Stewart W.B., Kauer J.S. y Shepherd G.M. (1980). Suckling pheromone stimulation of a modified glomerular region in the developing rat 
olfactory bulb revealed by the 2-deoxyglucose method. Brain Res, 194 (2): $530-535$.

Tennyson V.M. (1970). The fine structure of the axon and growth cone of the dorsal root neuroblast of the rabbit embryo. J Cell Biol, 44 (1): 62-79.

Thompson R.B., Peterson D., Mahoney W., Cramer M., Maliwal B.P., Suh S.W., Frederickson C., Fierke C. y Herman P. (2002). Fluorescent zinc indicators for neurobiology. J Neurosci Meth, 118 (1): 63-75.

Tiedge H. y Brosius J. (1996). Translational machinery in dendrites of hippocampal neurons in culture. $J$ Neurosci, 16 (22): 7171-7181.

Timm F. (1958). Zur Histochemie der Schwemetalle das Sulfid Silber verfahren. Dtsch Z Ges Gerchtl Med, 46: 706-711.

Valente T. y Auladell C. (2002). Developmental expression of ZnT3 in mouse brain: correlation between the vesicular zinc transporter protein and chelatable vesicular zinc (CVZ) cells. Glial and neuronal CVZ cells interact. Mol Cell Neurosci, 21 (2): 189-204.

Valero J., Berciano M.T., Weruaga E., Lafarga M. y Alonso J.R. (2006). Preneurodegeneration of mitral cells in the pcd mutant mouse is associated with DNA damage, transcriptional repression, and reorganization of nuclear speckles and Cajal bodies. Mol Cell Neurosci, 33 (3): 283-295.

Valero J., Weruaga E., Murias A.R., Recio J.S., Curto G.G., Gómez C. y Alonso J.R. (2007). Changes in cell migration and survival in the olfactory bulb of the pcd/pcd mouse. Dev Neurobiol, 67 (7): 839-859.

Varea E., Alonso-Llosa G., Molowny A., López-García C. y Ponsoda X. (2006). Capture of extracellular zinc ions by astrocytes. Glia, 54 (4): 304-315.

Verma P., Chierzi S., Codd A.M., Campbell D.S., Meyer R.L., Holt C.E. y Fawcett J.W. (2005). Axonal protein synthesis and degradation are necessary for efficient growth cone regeneration. J Neurosci, 25 (2): 331-342. 
Viancour T.A. y Kreiter N.A. (1993). Vesicular fast axonal transport rates in young and old rat axons. Brain Res, 628: 209-217.

Vizuete M.L., Venero J.L., Vargas C., Revuelta M., Machado A. y Cano J. (2001) Potential role of endogenous brain-derived neurotrophic factor in long-term neuronal reorganization of the superior colliculus after bilateral visual deprivation. Neurobiol Dis, 8 (5): 866-880.

Vogelaar C.F., Gervasi N.M., Gumy L.F., Story D.J., Raha-Chowdhury R., Leung K.M., Holt C.E. y Fawcett J.W. (2009). Axonal mRNAs: characterisation and role in the growth and regeneration of dorsal root ganglion axons and growth cones. Mol Cell Neurosci, 42 (2): 102-115.

Waguespack A.M., Reems M.R., Butman M.L., Cherry J.A. y Coppola D.M. (2005). Naris occlusion alters olfactory marker protein immunoreactivity in olfactory epithelium. Brain Res, 1044 (1): 1-7.

Wang Z., Li J.Y., Dahlstrom A. y Danscher G. (2001). Zinc-enriched GABAergic terminals in mouse spinal cord. Brain Res, 921: 165-172.

Wang Z., Danscher G., Kim Y.K., Dahlstrom A. y Mook J.S. (2002a). Inhibitory zinc-enriched terminals in the mouse cerebellum: doubleimmunohistochemistry for zinc transporter 3 and glutamate decarboxylase. Neurosci Lett, 321: 37-40.

Wang Z., Li J.Y., Danscher G. y Dahlstrom A. (2002b). Localization of zincenriched neurons in the mouse peripheral sympathetic system. Brain Res, 928: $165-174$.

Wang Z., Danscher G., Dahlstrom A. y Li J.Y. (2003). Zinc transporter 3 and zinc ions in the rodent superior cervical ganglion neurons. Neuroscience, 120: 605-616.

Wang Z., Stoltenberg M., Huang L., Danscher G., Dahlstrom A., Shi Y. y Li J.Y. (2005). Abundant expression of zinc transporters in Bergman glia of mouse cerebellum. Brain Res Bull, 64 (5): 441-448. 
Wang Z. y Dahlstrom A. (2008). Axonal transport of zinc transporter 3 and zinc containing organelles in the rodent adrenergic system. Neurochem Res, 33 (12): 2472-2479.

Weaver B.P., Dufner-Beattie J., Kambe T. y Andrews G.K. (2007). Novel zincresponsive post-transcriptional mechanisms reciprocally regulate expression of the mouse Slc39a4 and Slc39a5 zinc transporters (Zip4 and Zip5). Biol Chem, 388 (12): 1301-1312.

Weiss J.H., Hartley D.M., Koh J.Y. y Choi D.W. (1993). AMPA receptor activation potentiates zinc neurotoxicity. Neuron, 10 (1): 43-49.

Weiss J.H. y Sensi S.L. (2000). $\mathrm{Ca}^{2+}-\mathrm{Zn}^{2+}$ permeable AMPA or kainate receptors: possible key factors in selective neurodegeneration. Trends Neurosci, 23 (8): $365-371$.

Weiss J.H., Sensi S.L. y Koh J.Y. (2000) $\mathrm{Zn}^{2+}$ : a novel ionic mediator of neural injury in brain disease. Trends Pharmacol Sci, 21 (10): 395-401.

Weitzdoerfer R., Hoeger H., Engidawork E., Engelmann M., Singewald N., Lubec G. y Lubec B. (2004). Neuronal nitric oxide synthase knock-out mice show impaired cognitive performance. Nitric Oxide-Biol Ch, 10 (3): 130-140.

Wensink J., Molenaar A.J., Woroniecka U.D. y Vandenhamer C.J.A. (1988). Zinc uptake into synaptosomes. J Neurochem, 50 (3): 782-789.

Wenzel H.J., Cole T.B., Born D.E., Schwartzkroin P.A. y Palmiter R.D. (1997). Ultrastructural localization of zinc transporter-3 (ZnT-3) to synaptic vesicle membranes within mossy fiber boutons in the hippocampus of mouse and monkey. Proc Nat Acad Sci U S A, 94 (23): 12676-12681.

Weruaga E., Crespo C., Porteros A., Briñón J.G., Arévalo R., Aijón J. y Alonso J.R. (1998). NADPH-diaphorase histochemistry reveals heterogeneity in the distribution of nitric oxide synthase-expressing interneurons between olfactory glomeruli in two mouse strains. J Neurosci Res, 53 (2): 239-250. 
Weruaga E., Briñón J.G., Porteros A., Arévalo R., Aijón J. y Alonso J.R. (2000). Expression of neuronal nitric oxide synthase/NADPH-diaphorase during olfactory deafferentation and regeneration. Eur J Neurosci, 12 (4): 11771193.

Westbrook G.L. y Mayer M.L. (1987). Micromolar concentrations of $\mathrm{Zn}^{2+}$ antagonize NMDA and GABA responses of hippocampal neurons. Nature, 328 (6131): 640-643.

Whitman M.C. y Greer C.A. (2007). Synaptic integration of adult-generated olfactory bulb granule cells: basal axodendritic centrifugal input precedes apical dendrodendritic local circuits. J Neurosci, 27(37):9951-61.

Whitman M.C. y Greer C.A. (2009). Adult neurogenesis and the olfactory system. Prog Neurobiol, 89(2):162-75.

Williams K. (1996). Separating dual effects of zinc at recombinant N-methyl-Daspartate receptors. Neurosci Lett, 215 (1): 9-12.

Wilson D.A., Best A.R. y Brunjes P.C. (2000). Trans-neuronal modification of anterior piriform cortical circuitry in the rat. Brain Res, 853 (2): 317-322.

Wimmer U., Wang Y., Georgiev O. y Schaffner W. (2005). Two major branches of anti-cadmium defense in the mouse: MTF-1/metallothioneins and glutathione. Nucleic Acids Res, 33 (18): 5715-5727.

Woo C.C. y Leon M. (1995). Early olfactory enrichment and deprivation both decrease beta-adrenergic receptor density in the main olfactory bulb of the rat. J Comp Neurol, 360 (4): 634-642.

Woo C.C., Wilson D.A., Sullivan R.M. y Leon M. (1996). Early locus coeruleus lesions increase the density of beta-adrenergic receptors in the main olfactory bulb of rats. Int J Dev Neurosci, 14: 913-919.

Woo C.C., Hingco E.E., Taylor G.E. y Leon M. (2006). Exposure to a broad range of odorants decreases cell mortality in the olfactory bulb. Neuroreport, 17 (8): 817-821. 
Xie X.M. y Smart T.G. (1991). A physiological role for endogenous zinc in rat hippocampal synaptic neurotransmission. Nature, 349 (6309): 521-524.

Xie X.S., Crider B.P. y Stone D.K. (1989). Isolation and reconstitution of the chloride transporter of clathrin-coated vesicles. J Biol Chem, 264(32): 188703.

Yasuda S., Miyazaki T., Munechika K., Yamashita M., Ikeda Y. y Kamizono A. (2007). Isolation of $\mathrm{Zn}^{2+}$ as an endogenous agonist of GPR39 from fetal bovine serum. J Recept Signal Transduct Res, 27 (4): 235-246.

Yun H.-Y., Dawson V.L., y Dawson T.M. (1996). Neurobiology of nitric oxide. Crit Rev Neurobiol, 10 (3-4): 291-316.

Zaborszky L., Carlsen J., Brashear H.R. y Heimer L. (1986). Cholinergic and GABAergic afferents to the olfactory bulb in the rat with special emphasis on the projection neurons in the nucleus of the horizontal limb of the diagonal band. J Comp Neurol, 243 (4): 488-509.

Zangger K., Oz G., Haslinger E., Kunert O. y Armitage I.M. (2001). Nitric oxide selectively releases metals from the amino-terminal domain of metallothioneins: potential role at inflammatory sites. FASEB J, 15 (7): 13031305.

Zheng L.M., Ravel N. y Jourdan F. (1987). Topography of centrifugal acetylcholinesterase-positive fibres in the olfactory bulb of the rat: evidence for original projections in atypical glomeruli. Neuroscience, 23 (3): 10831093.

Zheng L.M. y Jourdan F. (1988). Atypical olfactory glomeruli contain original olfactory axon terminals: an ultrastructural horseradish peroxidase study in the rat. Neuroscience, 26 (2): 367-378.

Zilles K. (1992). Neuronal plasticity as an adaptive property of the central nervous system. Ann Anat, 174 (5): 383-391. 